\title{
Who's who in Magelona: Phylogenetic hypotheses under Magelonidae Cunningham \& Ramage, 1888 (Annelida: Polychaeta)
}

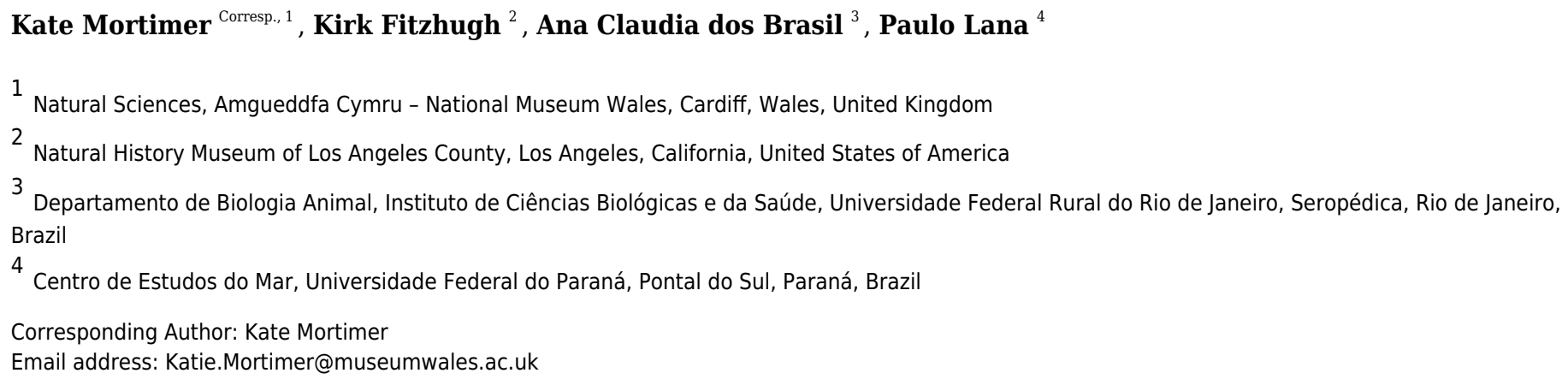

Known as shovel head worms, members of Magelonidae comprise a group of polychaetes readily recognised by the uniquely shaped, dorso-ventrally flattened prostomium and paired ventro-laterally inserted papillated palps. The present study is the first published account of inferences of phylogenetic hypotheses within Magelonidae. Members of 72 species of Magelona and two species of Octomagelona were included, with outgroups including members of one species of Chaetopteridae and four of Spionidae. The phylogenetic inferences were performed to causally account for 176 characters distributed among 79 subjects, and produced 2,417,600 cladograms, each with 404 steps. A formal definition of Magelonidae is provided, represented by a composite phylogenetic hypothesis explaining seven synapomorphies: shovel-shaped prostomium, prostomial ridges, absence of nuchal organs, ventral insertion of palps and their papillation, presence of a burrowing organ, and unique body regionation. Octomagelona is synonymised with Magelona due to the latter being paraphyletic relative to the former. The consequence is that Magelonidae is monotypic, such that Magelona cannot be formally defined as associated with any phylogenetic hypotheses. As such, the latter name is an empirically empty placeholder, but because of the binomial name requirement mandated by the International Code of Zoological Nomenclature, the definition is identical to that of Magelonidae. Several key features for future descriptions are suggested: prostomial dimensions, presence/absence of prostomial horns, morphology of anterior lamellae, presence/absence of specialised chaetae, and lateral abdominal pouches. Additionally, great care must be taken to fully describe and illustrate all thoracic chaetigers in descriptions. 


\section{Who's who in Magelona: Phylogenetic hypotheses under \\ 2 Magelonidae Cunningham \& Ramage, 1888 (Annelida: \\ 3 Polychaeta)}

4

6 Kate Mortimer $^{1}$, Kirk Fitzhugh ${ }^{2}$, Ana Claudia dos Brasil ${ }^{3}$ and Paulo Lana ${ }^{4}$

$8{ }^{1}$ Amgueddfa Cymru - National Museum Wales, Cardiff, CF10 3NP, Wales, United Kingdom

$9 \quad 2$ Natural History Museum of Los Angeles County, Los Angeles, California, United States of

10 America

$11{ }^{3}$ Departamento de Biologia Animal, Instituto de Ciências Biológicas e da Saúde, Universidade

12 Federal Rural do Rio de Janeiro, 23890-000 Seropédica, RJ, Brazil

$13{ }^{4}$ Centro de Estudos do Mar, Universidade Federal do Paraná, 83255-000 Pontal do Sul, Paraná, 14 Brazil

15

16 Corresponding author:

17 Kate Mortimer ${ }^{1}$

Amgueddfa Cymru - National Museum Wales, Cardiff, CF10 3NP, Wales, United Kingdom

Email address: Katie.Mortimer@museumwales.ac.uk 


\section{ABSTRACT}

22 Known as shovel head worms, members of Magelonidae comprise a group of polychaetes readily

23

24 recognised by the uniquely shaped, dorso-ventrally flattened prostomium and paired ventrolaterally inserted papillated palps. The present study is the first published account of inferences of phylogenetic hypotheses within Magelonidae. Members of 72 species of Magelona and two species of Octomagelona were included, with outgroups including members of one species of Chaetopteridae and four of Spionidae. The phylogenetic inferences were performed to causally account for 176 characters distributed among 79 subjects, and produced 2,417,600 cladograms, each with 404 steps. A formal definition of Magelonidae is provided, represented by a composite phylogenetic hypothesis explaining seven synapomorphies: shovel-shaped prostomium, prostomial ridges, absence of nuchal organs, ventral insertion of palps and their papillation, presence of a burrowing organ, and unique body regionation. Octomagelona is synonymised with Magelona due to the latter being paraphyletic relative to the former. The consequence is that Magelonidae is monotypic, such that Magelona cannot be formally defined as associated with any phylogenetic hypotheses. As such, the latter name is an empirically empty placeholder, but because of the binomial name requirement mandated by the International Code of Zoological Nomenclature, the definition is identical to that of Magelonidae. Several key features for future descriptions are suggested: prostomial dimensions, presence/absence of prostomial horns, morphology of anterior lamellae, presence/absence of specialised chaetae, and lateral abdominal pouches. Additionally, great care must be taken to fully describe and illustrate all thoracic chaetigers in descriptions. 


\section{INTRODUCTION}

45

46

47

48

49

50

51

52

Felix qui potuit rerum cognoscere causas - Virgil, Georgics, Vol. 1, Books I-II

The Magelonidae, known commonly as the shovel head worms, gain their name from their uniquely flattened, spade-shaped prostomia used in burrowing through soft sediments. They comprise a relatively small family of marine annelids, with members distributed among 77 species, although many more individuals to which new species hypotheses will refer are likely. Magelonids are generally found at depths of less than $100 \mathrm{~m}$, although members of deeper water species at depths of 1000-4000 m have been recorded (Hartman, 1971; Aguirrezabalaga, Ceberio \& Fiege, 2001). They predominately burrow through sands and muds, although members of several tubicolous species are known (Mills \& Mortimer, 2019; Mortimer, 2019). Individuals feed using two slender palps (Mortimer \& Mackie, 2014), which are unique amongst polychaetes in being papillated and ventrally inserted.

The unusual morphology of magelonids has often led to difficulties in relating them to other annelid groups. Johnston (1865), puzzled by their peculiar external form, placed them at the end of his catalogue, under the family Maeadae, based on the new genus and species Maea mirabilis. Later, McIntosh (1877) included magelonids within the Spionidae, after synonymising Maea Johnston, 1865 with Magelona Müller, 1858. Whilst Cunningham \& Ramage (1888) erected the family Magelonidae stating "We have formed a special family for it, as it cannot be admitted into the Spionidae, with which it is most nearly allied, or into any other family." McIntosh, who published extensively on magelonid morphology (McIntosh, 1877, 1878, 1879, 1911), suggested similarities with spioniforms such as members of Prionospio Malmgren, 1867, and Heterospio Ehlers, 1874, but also with the chaetopterid Spiochaetopterus Sars, 1853. He additionally noted that the way the "proboscis" (cf. Character descriptions below regarding 
67 terminology) operated and the structure of the "snout and circulatory organs" are features sui

68

69 generis. However, the placement of magelonids with spioniform polychaetes has continued until semi-recently. The latest studies have proposed placement alongside the Chaetopteridae, Sipuncula, and Oweniidae (Struck et al., 2015; Weigert et al., 2014; Helm et al., 2018), or as sister taxon of all other annelids along with the Oweniidae (Palaeoannelida) (Weigert et al., 2016). These phylogenetic considerations will be discussed more fully later in this paper. Whilst the systematic position of the family may have received some attention, phylogenetic relationships within have received far less. Perhaps the relatively uniform bodies of magelonids have been a contributing factor. Currently the family contains two genera: the type genus Magelona F. Müller, 1858, and the monotypic Octomagelona Aguirrezabalaga, Ceberio \& Fiege, 2001, differentiated by the number of thoracic chaetigers. All previously introduced generic names for the group have been synonymised (Maea Johnston, 1865, Rhynophylla Carrington, 1865, Meredithia Hernández-Alcántara \& Solís-Weiss, 2000). Brasil (2003) inferred phylogenetic hypotheses among members of the family based on external morphological characters, confirming the monophyletic status of the group. Her analysis concluded that both Octomagelona and Meredithia were paraphyletic, but no further conclusions could be made. The present study aims to expand the unpublished analysis performed by Brasil (2003) to include additional taxa and characters.

\section{MATERIAL AND METHODS}

\section{Methodological considerations}

What is and is not contained in the present study is based on several interrelated principles that initially might not appear consistent with some of today's thinking regarding biological 
90

91

92

93

94

95

96

97

systematics. These principles are not of our making, but rather are firmly established perspectives within philosophy of science, and familiar to many fields of science beyond systematics. The last several decades have witnessed systematics engaging in a growing tendency toward developing insular views that are at odds with basic tenets of logic, reasoning, and scientific inquiry. For these reasons, we regard it as imperative to present justifications for what is and is not included in this study from a methodological perspective. The disinterested reader can ignore this section without damage, but the information provided does offer a useful summary for those more inclined toward a much-needed critical thinking in systematics.

\section{The goal of scientific inquiry}

As systematics is a field of science and subfield of evolutionary biology, it should cohere with the acknowledged goal of scientific inquiry. That goal is to not only describe phenomena but also pursue causal understanding of what is encountered (Hanson, 1958; Hempel, 1965; Rescher, 1970; Popper, 1983, 1992; Salmon, 1984b; Van Fraassen, 1990; Strahler, 1992; Mahner \& Bunge, 1997; Hausman, 1998; Thagard, 2004; Nola \& Sankey, 2007; de Regt, Leonelli \& Eiger, 2009; Hoyningen-Huene, 2013; Potochnik, 2017, 2020; Anjum \& Mumford, 2018; Currie, 2018). In the context of systematics that pursuit includes describing the characteristics of organisms, in the form of differentially shared characters, as well as exploring possible past causal events that account for those characters, either as matters of proximate and/or ultimate causes sensu Mayr (1961, 1993; Fitzhugh, 2012, 2016a). As aptly expressed by Uller \& Laland (2019: 1), "Scientific inference typically relies on establishing causation. This is also the case in evolutionary biology, a discipline charged with providing historical accounts of the properties of living things, as well as an understanding of the processes that explain the origin of those properties."

Peer] reviewing PDF | (2021:05:61394:1:1:NEW 20 Jul 2021) 
114 something of a misnomer. Inferring phylogenetic hypotheses from a set of observed character

115 data only achieves the objective of explaining those data, with implicit acknowledgement that no

116 phylogenetic inference can exhaustively account for all potentially observable characters of

117 organisms. Phrases of the form "the phylogeny of $X$ " incorrectly connote that a final solution is

118 being offered, when in fact such would be impossible. Emphasising the term phylogeny has the

119 undesirable consequence of suggesting that this is the objective of systematics, thus

120 overshadowing the pursuit of causes, which is the real aim of scientific inquiry. The same

121 critique applies to the commonly used phrase "molecular phylogeny." There can be no

122 "phylogeny" of molecules, just as there can be no separate phylogenies for any arbitrary

123 subdivisions of classes of characters that are in need of being explained.

124 The causal objective in systematics is the arena within which taxa are considered. Taxa are best

125 regarded not as either class constructs, mere groupings, things, entities, or ontological

126 individuals, but rather as the variety of explanatory hypotheses routinely and purposely inferred.

127 These hypotheses include species and phylogenetic hypotheses, albeit there are other classes of

128 explanatory hypotheses that in their own right deserve to be called taxa (Fig. 1; cf. Hennig, 1966:

129 fig. 6) given that they as well are inferred causal accounts (Fitzhugh, 2012, 2016a; see also

130 Fitzhugh, 2005b, 2006a, 2008a, 2009, 2013, 2015). Consider for instance the phylogenetic and

131 specific "relations" shown in Fig. 1. Each clearly illustrates that individuals along the top of the

132 diagram are what exist in the present, and lines connecting to lower individuals indicate past

133 tokogenetic events. This diagram also implies past, albeit quite vague, causes such as novel

134 character origin and fixation events among individuals in populations, as well as population

135 splitting events. To say Fig. 1 shows several "lineages" is just an imprecise way of referring to 
136 the totality of past causal events that account for what are observed of the organisms in the

137 present. A further consequence is that taxa are neither described, discovered, nor delimited; they

138 are inferred as reactions to what we observe of the properties of organisms. What are described

139 are individuals at specific moments in their life history (Fitzhugh, 2012, 2016a, see also

140 Fitzhugh, 2008a, 2009, 2013, 2015; operational examples include Fitzhugh, 2010b; Nogueira,

141 Fitzhugh \& Rossi, 2010; Nogueira, Fitzhugh \& Hutchings, 2013; Nogueira et al., 2017, 2018;

142 Fitzhugh et al., 2015); what Hennig (1966) termed semaphoronts (Fig. 1; cf. Hennig, 1966: fig.

143 6). The interplay between the descriptive and the explanatory will become apparent later (cf.

144 Phylogenetic inference $=$ abduction $)$.

The present study seeks to infer taxa in the form of phylogenetic hypotheses, which are

146 subsumed under the more inclusive (composite) phylogenetic hypothesis formally called

147 Magelonidae. We acknowledge that species hypotheses have been previously and separately

148 inferred and are not the focus of this paper. Whilst this distinction between phylogenetic and

149 specific hypotheses has been the typical and inferentially appropriate approach in systematics,

150 exceptions can be found among some publications (e.g., Nygren et al., 2018; Shimabukuro et al.,

151 2019; Radashevsky et al., 2020), in which species hypotheses are simultaneously inferred with

152 phylogenetic hypotheses that only causally account for sequence data, after which morphological

153 characters are incorrectly introduced in a post hoc manner. Notwithstanding the fact that the

154 requirement of total evidence (RTE; Fitzhugh, 2006b; see Sequence data and explanatory

155 hypotheses, below) is violated, such inferences have questionable merits for the fact that

156 explaining shared nucleotides or amino acids requires, at a minimum, discriminating between

157 causes such as genetic drift, and selection via downward causation (see Sequence data and

158 explanatory hypotheses, below). The nature of phylogenetics algorithms is such that they are 
159 agnostic as to detailed causal parameters, requiring that one must give specific consideration to

160 drift or selection, which can determine whether or not sequence data can be directly explained

161 via phylogenetic inferences. This is an issue that has been largely ignored in discussions of

162 phylogenetic inference (Fitzhugh, 2016b). Once again, the objective of inferring these different

163 classes of hypotheses is to pursue causal understanding of the properties of organisms.

\section{Characters and observation statements}

165 Scientific inquiry is in reaction to the objects and events we perceive in the universe.

166 Conceptualising and then communicating our perceptions require accurate conveyance of

167 observation statements. Systematics has had a long tradition of speaking of organismal

168 observations in terms of characters and states (Sokal \& Sneath, 1963; Sneath \& Sokal, 1973).

169 Fitzhugh (2006c) remarked on the fact that the character/state distinction as well as other, similar

170 perspectives in systematics are not accurate representations of observation statements, especially

171 compared to the established views in epistemology, where observation statements are presented

172 as relations between subjects and predicates (Strawson, 1971; Alston, 1993; Audi, 1998).

173 Consider for instance, the statement, "These chaetae are bidentate." The terms chaetae and

174 bidentate do not refer to character and state, respectively. That one can observe objects they call

175 chaetae is because of the properties or characters of those objects. Instead of character and state,

176 the observation statement refers to the subject chaetae, and the predicate bidentate is applied to

177 that subject, reflecting a particular property or character perceived of the object as subject

178 (Hanson, 1958; Mahner \& Bunge, 1997; Strawson, 1971; Gracia, 1988; Armstrong, 1997).

179 Whilst observation statements of organisms are often of intrinsic properties, there also are 180 relational or extrinsic characters (Findlay, 1936; Sider, 1996; Armstrong, 1997; Francescotti,

181 2014; Allen, 2016). A common example in systematics involves sequence data, e.g., "Individuals 
182 to which species hypothesis $X$-us $x$-us refer have [subject] nucleotide $\mathrm{G}$ at [predicate] position

183 546." Being in a particular position is relative to other objects. The character/state distinction

184 ignores this relational aspect, leading to nonsensical characterisations, such as, “...if nucleotide

185 A is observed to occur at position 139 in a sequence, 'position 139' is the character [sic] and 'A'

186 is the state assigned to that character" (Swofford et al., 1996: 412). Obviously, a position cannot

187 be a character of an object since the position is dependent upon other objects.

188 The traditional emphasis on "character coding" leading to compilations of observations in

189 the form of the data matrix has treated columns as "characters" and each cell as a "state."

190 Fitzhugh (2006c: fig. 1) pointed out, however, that if observations are to be accurately implied

191 by entries in a matrix then each cell represents a complete observation statement of subject-

192 predicate relations, such that each column denotes each subject (Fig. 2A). This also

193 accommodates relational characters (Fitzhugh, 2016b). But with the emphasis on causal inquiry

194 in systematics, a data matrix is not only a codified representation of observation statements. The

195 matrix must also imply the why-questions that inquiry seeks to answer in the form of explanatory

196 hypotheses known as taxa. This necessitates knowing the formal structure of those questions and

197 how they, like observation statements, are implied by the matrix. This will be addressed next.

198 Basis for phylogenetic inference: why-questions

199 The inferences of explanatory hypotheses vis-à-vis taxa do not appear ex nihilo. As a significant

200 role of scientific inquiry is the pursuit of causal understanding, there is a vital conceptual link

201 between our observations and explanatory hypotheses. That link exists through the implicit or

202 explicit why-questions that are prompted by observations, such that the hypotheses we infer are

203 intended as answers to those questions. The formal structure of why-questions has relevance to 
204 systematics for the fact that those questions are implicitly present in a character data matrix

205 provided to a computer algorithm that infers phylogenetic hypotheses (Fitzhugh, 2006c, 2016b).

Whilst we tend to think of why-questions as having the form, "Why (is) $q$ (the case)?,"

207

208

209

210

211

212

213

214

215

216

217

218

219

220

221

222

223

224

225

226

such a structure is an incomplete representation. The form of why-questions is instead what is often referred to as contrastive, "Why (is) $q$ (the case) in contrast to $p$ ?" (Salmon, 1984b; Sober, 1984, 1986, 1994; Salmon, 1989; Van Fraassen, 1990; Lipton, 2004; Fitzhugh, 2006a, 2006b, 2006c; 2016b; Lavelle, Botterill \& Lock, 2013). A contrastive why-question contains observation statement $q$, the fact to be explained, and $p$, the foil, which is usually a condition ordinarily expected or previously explained. Asking a why-question often occurs because we are faced with a situation that is unexpected or surprising (the fact), and it is that element of surprise, against what is expected (the foil), that leads to the desire for an explanation. The fact/foil distinction associated with implied why-questions can be found in the data matrices used to infer phylogenetic hypotheses, when "outgroup" (=foil) and "ingroup" (=fact) taxa are designated (Fitzhugh, 2006c, 2016b) (Fig. 2B).

It is often acknowledged (Bromberger, 1966; Sober, 1986, 1988; Barnes, 1994; Marwick, 1999; Sintonen, 2004; Schurz, 2005) that why-questions include the presupposition that fact and foil statements must be true, otherwise there is no basis for asking such questions. This also follows from the common-sense notion that we assume the truth of our observation statements; otherwise, scientific inquiry would not be feasible. This assumption has special implications for explaining sequence data when rates of substitution are involved, which will be addressed later (see Sequence data and explanatory hypotheses). Explaining a fact entails also explaining the foil, and while those explanations are due to separate causal events, they should be due to the same type of cause (Sober, 1986; Barnes, 1994; see also Cleland, 2001, 2002, 2009, 2011, 2013; 
227 Tucker, 2004, 2011; Turner, 2007; Jeffares, 2008). Designations of outgroup and ingroup

228 accommodate this requirement (Fitzhugh, 2006c).

\section{Forms of reasoning}

230 In speaking of inferring phylogenetic hypotheses, or any other class of taxon for that matter, it is

231 necessary to acknowledge the type of reasoning used to produce those hypotheses as well as the

232 reasoning available for empirically testing them. This provides a clear basis for establishing

233 which, if any, of the currently available phylogenetic inference procedures are logically and

234 scientifically sound.

235 Three forms of reasoning are often recognised: abduction, deduction, and induction.

236 Among formal treatments of logic, abduction, if acknowledged at all, is typically subsumed

237 under induction (e.g., Kneale \& Kneale, 1964; Salmon, 1967, 1984a; Copi \& Cohen, 1998),

238 since the purview of logic is to identify and discriminate logically valid (deductive: true premises

239 give a true conclusion) from invalid or fallacious (inductive: true premises do not guarantee true

240 conclusions) arguments. For purposes of explicating the processes of scientific inquiry, however,

241 it is appropriate to regard abduction as distinct from induction. Operationally each form of

242 reasoning plays a respective role in different stages of inquiry, where those stages include at a

243 minimum the inferences of theories and hypotheses, and the subsequent empirical testing of

244 those propositions. The stage of inquiry most associated with systematics is abduction (Peirce,

245 1878, 1931, 1932, 1933a, 1933b, 1934, 1935, 1958a, 1958b; Hanson, 1958; Achinstein, 1970;

246 Fann, 1970; Reilly, 1970; Curd, 1980; Nickles, 1980; Thagard, 1988; Josephson \& Josephson,

247 1994; Baker, 1996; Hacking, 2001; Magnani, 2001, 2009, 2017; Psillos, 2002, 2007, 2011;

248 Godfrey-Smith, 2003; Norton, 2003; Walton, 2004; Gabbay \& Woods, 2005; Aliseda, 2006;

249 Schurz, 2008; Park, 2017), i.e., the inferences of hypotheses as the means of causally accounting 
250 for the various differentially shared characters observed among organisms (Fitzhugh, 2005a,

251 2005b, 2006a, 2006b, 2008a, 2008b, 2008c, 2009, 2010a, 2013, 2014, 2015, 2016a, 2016b,

252 2016c, 2016d, 2021). Subsequent empirical assessments of explanatory hypotheses rely on

253 deducing predictions of expected consequences - potential test evidence - if the causal claims in

254 hypotheses are true. The act of testing, which involves determining manifestations of test

255 evidence, is inductive. The operational relations between ab-, de-, and induction received

256 extensive attention in the 19th and early 20th centuries by the polymath, Charles Sanders Peirce

257 (1835-1914) (Peirce, 1931, 1932, 1933a, 1933b, 1934, 1935, 1958a, 1958b), but full

258 appreciation of Peirce's ideas did not become realised until the second half of the 20th century

259 (Hanson, 1958; Fann, 1970; Reilly, 1970; Thagard, 1988; Josephson \& Josephson, 1994;

260 Magnani, 2001, 2009, 2017; Psillos, 2002, 2011; Walton, 2004; Gabbay \& Woods, 2005;

261 Aliseda, 2006; Schurz, 2008; Park, 2017). As noted by Peirce (1932: 2.106),

262

263

264

265

266

267

268

269

270

271

Abduction[...] is merely preparatory. It is the first step of scientific reasoning, as induction is the concluding step[...] Abduction makes its start from the facts, without, at the outset, having any particular [hypothesis] in view, though it is motivated by the feeling that a [hypothesis] is needed to explain the surprising facts. Induction makes its start from a hypothesis which seems to recommend itself, without at the outset having any particular facts in view, though it feels the need of facts to support the [hypothesis]. Abduction seeks a [hypothesis]. Induction seeks for facts.

The "facts" Peirce refers to in relation to abduction are the various characteristics of organisms in need of explanation, whereas the "facts" associated with induction are test evidence.

Peer] reviewing PDF | (2021:05:61394:1:1:NEW 20 Jul 2021) 
272 Discussions of relations between these stages of inquiry in systematics can be found in Fitzhugh

273 (2005a, 2006a, 2006b, 2008b, 2010a, 2012, 2013, 2016a, 2016c, 2016d).

274 Whilst systematics in recent decades, especially beginning with the school of thought

275 called cladistics, has laid great emphasis on the testing of hypotheses, usually at the expense of

276 conflating testing with hypothesis inference (reviewed by Fitzhugh, 2016c, 2016d). Actual

277 testing by way of induction of the variety of hypotheses implied by cladograms is rarely

278 performed. Instead, the tendency is to merely replace results of previous abductions with new

279 abductions as new observed effects become available, which is neither an act of testing nor a

280 basis for claiming that previous hypotheses have been "defeated" or overturned. Associated with

281 confusing hypothesis inference with testing has been the misconception that character data used

282 to infer hypotheses also provide evidential support for those hypotheses, leading to false claims

283 that phylogenetic hypotheses are "robust" or "strongly supported" by the characters used to infer

284 those hypotheses. We will address this misunderstanding later (see Explanatory hypotheses and

285 the myth of evidential support).

286 In the context of phylogenetic hypotheses, examples of each of the stages of inquiry can

287 be represented by the following abbreviated forms, where the premises lie above the double

288 (non-deductive) or single (deductive) line, and the conclusion(s) allowed by those premises

289 below the line(s):

290 (1) Abduction - inferring hypotheses as answers to why-questions:

$291 \quad$ background knowledge, $b$

292

293

294

- theory(ies) $t$, such as "common ancestry"

- observed effects, as differentially shared characters, $e$

- explanatory hypotheses, e.g., cladograms, $h$ 
295 (2) Deduction - predictions of consequences given the truth of hypotheses:

$296 \quad$ background knowledge, $b$

297

298

299

300

301

302

303

304

305

306

307

308

309

310

311

312

313

314

315

316

- theory(ies) $t$ relevant to the observed effects

- specific causal conditions presented in explanatory hypothesis via (1)

- proposed conditions needed to perform test

- observed effects $e$, originally prompting $h$ [cf. (1)]

- predicted test evidence, i.e., effects related as closely as possible with the specific causal conditions of the hypothesis

\section{(3) Induction - hypothesis testing:}

- background knowledge, $b$

- theory(ies) relevant to observed effects, $t$

- test conditions performed

- confirming/disconfirming evidence, $e_{2}$ [observations of predicted test evidence in (2), or alternative observations]

- $h$ is confirmed/disconfirmed.

A useful way to think of these inferences is as reactions to particular questions. The form of each question determines what type of inference is used to produce a conclusion that serves as an answer. Respective questions and inferences are shown in Table 1.

Several points of logic need to be highlighted regarding the three types of reasoning, as they are relevant to inferences of phylogenetic hypotheses (in fact all taxa, for that matter). For any inference to be deemed factually correct, premises must be assumed to be true. A deduction is valid only if true premises guarantee a true conclusion, which is established by particular rules 
317 of logic that can be found in standard logic textbooks. Because of those rules, the content of a

318 deductive conclusion is already present in the premises, such that information in the conclusion

319 cannot go beyond what is already stated in the premises (Salmon, 1984a). Such reasoning is said

320 to be non-ampliative. By its very nature, deduction cannot introduce new ideas. All non-

321 deductive reasoning is ampliative, thus does not satisfy the criterion of logical validity. This

322 makes abduction a fundamentally important mode of reasoning in everyday life as well as all of

323 science. Abduction is the only type of reasoning from which new ideas are conceived. With true

324 premises, abductive and inductive reasoning do not guarantee true conclusions. The content of

325 those conclusions will extend beyond what is provided in the premises. Abductive conclusions

326 can be regarded as merely plausible: "By plausibility, I mean the degree to which a theory [or

327 hypothesis] ought to recommend itself to our belief independently of any kind of [test] evidence

328 other than our instinct urging us to regard it favorably" (Peirce, 1958b: 8.223). Inductive

329 conclusions, on the other hand, are probable given that they are determined by available test 330 evidence.

331

332

333

334

335

336

337

338

\section{Phylogenetic inference $=$ abduction}

Representing phylogenetic inference in a more complete form compared to what is shown in (1), the following example of abduction is somewhat closer to the actual abductive structure leading to phylogenetic hypotheses. The basis for this abduction would be to answer the why-question, "Why do semaphoronts to which specific hypotheses $x$-us and $y$-us refer have ventrolateral margins with appendages in contrast to smooth as seen among individuals to which other species hypotheses (a-us, b-us, etc.) refer?” (Fitzhugh, 2006c, 2012, 2013, 2015, 2016a, 2016b):

(4) - Background knowledge, $b$ 
- Phylogenetic theory: If character $x(0)$ exists among individuals of a reproductively isolated, gonochoristic or cross-fertilising hermaphroditic population and character $x(1)$ originates by mechanisms $a, b, c \ldots n$, and becomes fixed within the population by mechanisms $d, e, f \ldots n$ (= ancestral species hypothesis), followed by event(s) $g, h, i \ldots n$, - Observations (effects): Individuals to which specific hypotheses $x$-us and $y$-us refer have ventrolateral margins with appendages in contrast to smooth as seen among individuals to which other species hypotheses ( $a-u s, b$-us, etc.) refer.

- Causal conditions (phylogenetic hypothesis X-us): Ventrolateral margin appendages

Background knowledge b, as auxiliary theories and hypotheses, is generally not listed as a premise, but instead is established knowledge accepted as true that is needed for the other premises in an inference. Background knowledge is specified here for reference later when considering abduction in relation to sequence data. The major premise, Phylogenetic theory, is intentionally vague regarding causal specifics. This reflects the near-complete absence of causal explanatory content in phylogenetic hypotheses implied by cladograms (Fitzhugh, 2012, 2013, 
362 2016b). The theory as presented here is intentionally limited to gonochoristic or cross-fertilising

363 hermaphroditic organisms (Fitzhugh, 2013) since population-splitting events (“speciation”) are

364 not relevant to asexually reproducing, obligate parthenogenetic, or self-fertilising hermaphroditic

365 organisms. The theory states a common cause, which is consistent with the necessary

366 presupposition that observation statements are true, mentioned earlier; if we assume the truth of

367 our observations, then we should pursue explanations of those observations in a manner that

368 maximises the truth element as much as possible in those explanatory accounts. The minor

369 premise in this example, Observations (effects), presents only one set of observation statements,

370 as subject-predicate relations, i.e., ventrolateral body margins. This premise can be expanded to

371 include other relevant characters to be explained, as is typical of the standard character data

372 matrix. A data matrix implies both why-questions as well as the totality of observation

373 statements comprising this second premise (Fitzhugh, 2006c, 2016b). The conclusion, Causal

374 conditions, is the result of applying the Phylogenetic theory to Observations of effects. Such

375 conclusions, often represented by cladograms, serve as answers to the why-questions. The

376 limited causal details provided in the conclusion is a consequence of what little is offered in the

377 theory in terms of causal particulars. For this reason, cladograms are largely devoid of

378 explanatory information. As part of the ampliative nature of abduction, the premises can lead to a

379 single conclusion or multiple, mutually exclusive conclusions. Any valid deduction, on the other

380 hand, being non-ampliative, will only produce a single conclusion.

381 Whilst we often refer to a cladogram as a phylogenetic "hypothesis," they are in fact

382 composite constructs, implying a minimum of three classes of hypotheses: previously inferred

383 species hypotheses, hypotheses of character origin/fixation among members of ancestral 
384 populations, and population splitting events ("speciation") (Fig. 3). A fourth, ad hoc class of 385 hypothesis is typically invoked, called homoplasy (Lankester, 1870).

To manifest abductive inferences in a phylogenetics computer algorithm that emulate

387

388

what is presented in (4), the inferential form would be akin to the following (cf. Josephson \& Josephson, 1994),

(5) $\quad d$ is a collection of (presumed true) observation statements of differentiallyshared characters

- hypotheses, implied by cladograms $X_{1}, X_{2} \ldots X_{\mathrm{n}}$, are possible composite explanations of $d$

- select subset of cladograms with score $S_{\mathrm{n}}$ (minimal "tree length" = minimise ad hoc hypotheses of homoplasy)

- cladograms with score $S_{\mathrm{n}}$ are most plausible, mutually exclusive explanations of

$d$.

The algorithm functions in a manner that produces conclusions as if the common cause

Phylogenetic theory in (4) were operative. Notice as well that the first premise in (5) contains the assumption that observation statements regarding shared characters are true; the necessary presupposition of truth associated with implied why-questions in data matrices, if one accepts that the intent of these inferences is to explain observations. The phrase in the conclusion, "cladograms with score $S_{\mathrm{n}}$ are most plausible," is intentional. Plausibility indicates hypotheses are worthy of further consideration:

By Plausible, I mean a theory [or hypothesis] that has not yet been subjected to any test, although more or less surprising phenomena have occurred which it 
407

408

409

410

411

412

413

414

415

416

417

418

419

420

421

422

423

424

425

426

427

428

429

would explain if it were true, is in itself of such a character as to recommend it for further examination or, if it be highly plausible, justify us in seriously inclining toward belief in it, as long as the phenomena be inexplicable otherwise (Peirce, 1932: 2.662, emphasis original; Kapitan, 1997: 481).

Epistemically, a plausible hypothesis is far weaker than a hypothesis that has been successfully tested with the introduction of test evidence, i.e., (2), (3); a distinction that is too often ignored in the systematics literature because of the general misunderstanding of the meaning of evidential support (see Phylogenetic hypotheses and the myth of evidential support).

At first sight, the algorithmic representation of abduction in (5) might appear to be what has often been called "parsimony analysis." The difficulty with this perspective is that parsimony is not a form of reasoning that produces explanatory hypotheses. That responsibility resides with abduction. Parsimony is a comparative measure, where for instance of two hypotheses that predict the same results, the hypothesis that requires fewer assumptions is the simpler of the two. The third premise in (5) invokes this principle. That intended action of selection, based on minimising ad hoc hypotheses of homoplasy, is implemented for the sole purpose of serving as a surrogate for the application of the Phylogenetic theory in (4). This is not tantamount to a parsimony analysis or method. It is an instance of abductive reasoning.

It was noted earlier that abduction is the only type of reasoning that produces explanatory hypotheses; it is the only form of reasoning that introduces new ideas. The depiction of abduction in (4), or its algorithmic form in (5), is not only at odds with "parsimony" being an inference procedure but also contrary to claims in systematics that so-called "likelihood" or "Bayesian" methods can infer explanatory hypotheses. With his introduction of the likelihood principle, Fisher (1934; see also Hacking, 1965, 2001, Edwards, 1972) was clear that it is only 
430 relevant to considerations of test evidence subsequent to inferring hypotheses. Evidence $e$ in

431 representations of likelihood, e.g., $p(h \mid e)=l(h \mid e)$, refer to test evidence [cf. (2), (3)].

432 Probability $p$ quantifies anticipation of an outcome of testing, whereas likelihood $l$ quantifies

433 trust in the hypothesis as a consequence of testing. Characters used to abductively infer

434 phylogenetic hypotheses [cf. (1), (4), (5)] do not constitute test evidence, and likelihood does not

435 provide the means to infer explanatory hypotheses (contra e.g., Felsenstein, 1981, 2004;

436 Swofford et al., 1996; Huelsenbeck \& Crandall, 1997; Haber, 2011).

The intent of Bayes Theorem is to quantify changes in belief in hypotheses following the introduction of test evidence (Salmon, 1967; Howson \& Urbach, 1993; Hacking, 2001; contra

e.g., Huelsenbeck \& Ronquist, 2001; Huelsenbeck et al., 2001; Archibald, Mort \& Crawford, 2003; Felsenstein, 2004; Ronquist, van der Mark \& Huelsenbeck, 2009). Bayesianism is phylogenetic inference (e.g., Huelsenbeck et al., 2001: fig. 1) is represented as,

$$
p(\text { tree } \mid \text { characters })=p(\text { characters } \mid \text { tree }) \cdot p(\text { tree })
$$

445 This is not a meaningful implementation of the Theorem (Fitzhugh, 2010a, 2012, 2016a, 2016c, 2016d). The supposed prior probability, $p$ (tree), refers to all possible "tree topologies" for taxa considered. Such topologies are nothing but branching diagrams devoid of the empirical content typical of cladograms that imply the several classes of causal events discussed earlier (Fig. 2).

449 Tree diagrams disconnected from characters explained by those diagrams cannot be assigned 450 prior probabilities. More problematic is the use of differentially shared characters as "evidence"

451 to determine posterior probabilities. Character data cannot serve as test evidence for the

452 hypotheses intended to explain those data (see Phylogenetic hypotheses and the myth of 
453 evidential support). As with "parsimony" and "likelihood" methods, the "Bayesian" approach in 454 systematics fails to live up to its name.

In sum, neither "parsimony," "likelihood," nor "Bayesianism" are valid forms of

456 reasoning or methods for inferring explanatory hypotheses. Unfortunately, wider recognition of

457 the fundamental importance of abductive reasoning did not take hold among scientists until

458 Hanson (1958) pointed out its significance in his Patterns of Discovery, and later

459 acknowledgment of its importance in artificial intelligence (Thagard, 1988) and science in

460 general were embraced (Fann, 1970; Reilly, 1970; Thagard, 1988; Josephson \& Josephson, 1994;

461 Magnani, 2001, 2009, 2017; Psillos, 2002, 2011; Walton, 2004; Gabbay \& Woods, 2005;

462 Klienhans, Buskes \& de Regt, 2005; Aliseda, 2006; Schurz, 2008; Klienhans, Buskes \& de Regt,

463 2010; Park, 2017; Anjum \& Mumford, 2018). In the absence of awareness about abduction,

464 systematics since the 1960's was left with an inferential void that was filled with incorrect

465 applications under the false dichotomy of parsimony versus induction vis-à-vis statistics, where

466 the latter led to incorrectly applying likelihood and Bayesianism. What is actually being

467 performed in phylogenetic inference under these labels is abductive reasoning, albeit in a most

468 peculiar and not entirely philosophically or scientifically acceptable manner.

Regarding abductive inferences of phylogenetic hypotheses to explain sequence data,

470 there are two significant issues to consider. One issue will be discussed here, while the other will

471 be addressed later (see Sequence data and explanatory hypotheses). The treatment of sequence

472 data has often been seen as requiring the assumption of rates of substitution as part of the

473 inferences of phylogenetic hypotheses, along with "branch lengths" (i.e., number of substitutions

474 or character changes that have occurred "along" the branches of phylogenetic trees) (Swofford et

475 al., 1996; Felsenstein, 2004; Schmidt \& von Haeseler, 2009). Once we acknowledge that trees 
476 are only graphic devices for implying the various classes of explanatory hypotheses accounting

477 for observed characters (Fig. 2), it becomes apparent that those trees cannot have properties like

478 lengths of branches. The need to consider substitution rates has warranted the development of so-

479 called "model-based” approaches (Jukes \& Cantor, 1969; Felsenstein, 1978, 2004; Farris, 1983;

480 Swofford et al., 1996; Sullivan \& Joyce, 2005; Rindal \& Brower, 2011; Kapli, Yang \& Telford, 481 2020), under the guises of "likelihood" and "Bayesian," versus the "model-free" method of 482 "parsimony analysis." It should be apparent by now that this distinction, just like the methods, is 483 without merit. If we accept that phylogenetic inferences are abductive, then the inclusion of 484 substitution rates within abduction would have the following form (Fitzhugh, 2021):

485 (6) Background knowledge (partim): Observation statements assumed true, per alignments of 486 sequence data Theories: (a) Rates of sequence substitution, applied to sequence data;

(b) Common cause Phylogenetic theory of common ancestry, cf. (4), per Background knowledge Observation statements: Represented in data matrix as why-questions

Phylogenetic hypotheses: Diagrammatically implied by graphic devices called cladograms. sequence substitution is at odds with the Background knowledge of true observation statements of aligned sequences, and by extension also at odds with the implied why-questions one would ask for which the abduction seeks answers using a common-cause theory. Correcting for this contradiction would necessitate removing the theory of substitution rates as a premise in the 
499 abduction and placing it within the Background knowledge, such that originally aligned sequence

500 data would be modified to take substitution rates into consideration. By doing this, revised

501 observation statements could be presented, which re-establish assumptions that observation

502 statements are true. The Background knowledge in (6) would then have the following revised

503 form (Fitzhugh, 2021),

504 (7) Background knowledge, revised:

505

506

507

508

509

510

511

512

513

514

515

516

517

518

519

520

521 (a) observation statements of differentially shared characters, are initially assumed true, per alignments of sequence data;

(b) rates of sequence substitution taken into consideration;

(c) per (b), the assumption of truth of observation statements in (a) is not necessarily correct;

(d) per (b) and (c), observation statements are revised such that apparent shared nucleotides are renamed as different observation statements where applicable to re-establish true statements.

With the revised Background knowledge in (7), the ensuing abductive inference would then have the form shown in (4), which again provides answers to why-questions by way of common cause; there is no need to consider substitution rates within the inference. The inherent difficulty of accomplishing step (7)(d), however, will likely preclude even proceeding forward with causally accounting for those sequence data given that there are no empirical criteria for discerning identical nucleotides or amino acids as not being identical. This is a matter that has been overlooked in systematics. The alternative solution is to simply accept the truth of shared characters obtained through alignment, in which case abduction would again be as shown in (4) and neither substitution rates nor branch lengths would be considered. 
We have emphasised that cladograms or phylogenetic trees satisfy the goal of scientific

523

524

525

526

527

528

529

530

531

532

533

534

535

536

537

538

539

540

541

542

543

inquiry if they are interpreted as composite explanatory hypotheses (Fig. 3). Whilst the

explanatory nature of cladograms is sometimes explicitly acknowledged (e.g., Farris, 1983;

Swofford et al., 1996; Schmidt \& von Haeseler, 2009; Kapli, Yang \& Telford, 2020), often the

greater focus of phylogenetic studies is on just obtaining "trees," with little to no causal

considerations given (e.g., Felsenstein, 1981, 2004; Sullivan \& Joyce, 2005; Kapli, Yang \&

Telford, 2020). Consequences of this emphasis on trees as opposed to explanations includes an

erroneous method called character mapping (Fitzhugh, 2014). Mapping most often involves

obtaining phylogenetic trees using sequence data, then "optimising" other characters, usually

morphological, onto these diagrams, from which are determined vague evolutionary conclusions

regarding the mapped characters. This approach has become popular among polychaete

phylogenetic studies (e.g., Struck et al., 2011; Borda et al., 2012; Glasby, Schroeder \& Aguado,

2012; Goto et al., 2013; Weigert et al., 2014; Aguado et al., 2015; Andrade et al., 2015; Struck et al., 2015; Goto, 2016; Weigert \& Bleidorn, 2016; Kobayashi et al., 2018; Nygren et al., 2018;

Langeneck et al., 2019; Shimabukuro et al., 2019; Radashevsky et al., 2020; San Martín et al., 2020; Tilic et al., 2020; Gonzalez et al., 2021). Much credence has been given to mapping, albeit without foundation. For instance, Kapli, Yang \& Telford. (2020) state that,

Mapping heritable character states (phenotypic or genotypic) onto a tree is the basis of different evolutionary analyses: it allows us, for example, to make inferences [sic] about character homology and also to gain insights into character loss and convergent evolution[....] Whereas trees were initially based to a great extent on morphological characters, biological molecules - nucleic

Peer) reviewing PDF | (2021:05:61394:1:1:NEW 20 Jul 2021) 
acids and proteins - provide a far more powerful [sic] and plentiful source of information for reconstructing trees.

546 Mapping is flawed for a simple reason. That phylogenetic inference is abductive means inferring

547 hypotheses, implied by a cladogram, for one set of characters produces conclusions relevant only

548 to those characters. Any subsequent "mapping" of additional characters on that cladogram is not

549 a legitimate form of inference, abductive or otherwise. The premises of a "mapping inference"

550 make this apparent:

551 (8)

- tree topology, (a-us (b-us (c-us (d-us, e-us))))

552

- observed effects, as differentially shared characters, $e$

554 As a premise, a tree topology is an empirically empty statement since it would have been

555 previously inferred to account for characters other than those in the second premise. Attempting

556 to apply that first premise to the second is pointless since this cannot lead to any interpretable

557 conclusion - certainly not explanatory hypotheses. As such it is impossible to speak of

558 explanations of mapped characters. Like the past and present uncritical advocacy of phylogenetic

559 methods called "parsimony," "likelihood," and "Bayesian," the popularity of character mapping

560 is a further testament to the lack of consideration of formal reasoning in systematics.

\section{Phylogenetic hypotheses and the myth of evidential support}

562 The present study does not assess the veracity of either the Magelonidae or less inclusive

563 phylogenetic hypotheses in terms of evidential "support," nor are there attempts to use popular

564 methods such as the bootstrap or Bremer analysis to assert that hypotheses are either "strongly

565 supported" or "robust." Such perspectives have become all too common in systematics research, 
566 including those on annelids (e.g., Struck et al., 2011; Borda et al., 2012; Weigert et al., 2014;

567 Aguado et al., 2015; Andrade et al., 2015; Struck et al., 2015; Weigert et al., 2016; Gonzalez et

568 al., 2018; Nygren et al., 2018; Shimabukuro et al., 2019; San Martín et al., 2020; Stiller et al.,

569 2020; Tilic et al., 2020; Gonzalez et al., 2021). Reasons for not speaking of support in the present

570 study follow from the basics of reasoning described above. More detailed treatments of

571 misconceptions regarding evidence of, and support for phylogenetic hypotheses can be found in

572 Fitzhugh $(2012,2016 b, 2016 c)$.

573 First, to correctly speak of evidence means to refer to the premises that allow for a certain

574 conclusion (Longino, 1979; Salmon, 1984a; Achinstein, 2001). Whilst that evidence is said to

575 "support" a given conclusion, it is only inductive, i.e., test evidence or support (cf. [3]) that

576 matters in the pursuit of empirical evaluation, whether in matters of everyday life or during

577 scientific inquiry. An emphasis on test evidence certainly permeates all of evolutionary biology

578 and by extension it is understandable that it would be of concern in systematics. But this requires

579 being clear about (1) what is meant by the test evidence, (2) if that evidence is being used in the

580 proper context, and (3) whether or not bootstrap and Bremer "support" values are meaningfully

581 interpretable in relation to phylogenetic hypotheses.

582 Recall that the examples of ab-, de-, and induction in (1)-(3) draw clear distinctions

583 between premises and conclusions derived from those premises. Those premises constitute the

584 evidence for the respective conclusions [see also (4)-(6)]. Beyond basic matters of logic, we

585 need to be cognisant of the way evidence is interpreted in the separate stages of inquiry.

586 Evidence in relation to abduction is unremarkable in the sense that conclusions must be as they

587 are because of the premises [cf. (1), (4), (5)] (Fitzhugh, 2010a, 2012, 2016a, 2016c, 2016d). As

588 well, abductive conclusions cannot be changed or "defeated" with the introduction of additional 
589 effects to be explained. Adding those effects as premises only results in the inference of a new 590 set of hypotheses that have no relevance to previously inferred hypotheses. A related misconception is that statistical consistency applies to phylogenetic inference

592 (e.g., Felsenstein, 1978, 2004; Swofford et al., 1996; Heath, Hedtke \& Hillis, 2008; Assis, 2014; 593 Brower, 2018). When correctly interpreted, consistency is the view that as more and more test 594 evidence is introduced in support of a hypothesis, the closer one is supposedly getting to a true 595 proposition. The mistaken interpretation of consistency in systematics has led to the popular yet 596 erroneous view that sequence data are beneficial for discerning "phylogenies" because of the 597 vast increase in characters that are available (e.g., Goto, 2016; Tilic et al., 2020). For example, in 598 relation to phylogenetic inference, Felsenstein (2004: 107, 121, respectively) states, "An estimator is consistent if, as the amount of data gets larger and larger (approaching infinity), the estimator converges to the true value of the

Contrary to claims that consistency is relevant to phylogenetic inference, it has been 607 acknowledged since the early 20th century that continued additions of effects to abductive inferences provides no indication that a true, as opposed to plausible, set of explanatory 609 hypotheses has been attained (Peirce, 1902, 1932: 2.774-777; Rescher, 1978; Fitzhugh, 2012, 2016b). As new effects in need of explanation are sequentially added to abductive premises, each

611 subsequent conclusion will only offer a new set of hypotheses that have no relevance to 
612 previously inferred hypotheses. The emphasis on consistency in systematics is yet another

613 consequence of abduction not being recognised in lieu of a misplaced statistical (inductive)

614 mindset.

615 Deduction serves to conclude predictions of potential test evidence [cf. (2)] that might be

616 later sought during the process of testing. Much like premises-as-evidence in abduction, the

617 premises in deduction do not warrant any special attention in terms of "support." Where

618 evidence is of importance is during the act of testing, i.e., induction [cf. (3)]. For instance, a

619 conclusion that test evidence supports or confirms a hypothesis can be subsequently revised if

620 additional support through further testing is obtained, or additional test evidence might

621 eventually lead to a conclusion of disconfirmation. As noted by Lipton (2005), the process of

622 testing puts hypotheses at risk of being disconfirmed since there is no guarantee predicted test

623 evidence, via (2) and (3), will be found. Obtaining contrary evidence is always a possibility. It is

624 test evidence that matters when speaking of support. Abductive "support" lacks that

625 qualification, and character data are not test evidence.

626 Because an emphasis on causality has been largely wanting in recent decades in relation

627 to inferences of taxa-as-explanatory-hypotheses, references to support for phylogenetic

628 hypotheses has centered on support [sic] for "groups" or "clades" within cladograms (Fitzhugh,

629 2012). Such claims of support are misleading for two reasons. First, as mentioned above,

630 "support" for any abductive conclusion is trivial since the conclusion could not be otherwise

631 given the premises. In other words, unlike test evidence associated with induction, observations

632 of characters do not present any risk to the hypotheses explaining those characters. To assert, for

633 example, that characters "support" some phylogenetic hypothesis verges on circularity: the

634 conclusion(s) is/are determined by the premises and the premises support the conclusion(s). 
635 Second, our concern is not for groups, but rather various explanatory hypotheses. As all

636 phylogenetic hypotheses are composite (Fig. 3), an emphasis on groups is both artificial and

637 denies consideration of the variety of explanatory accounts implied by cladograms. Support in

638 relation to groups is epistemically meaningless.

639 There is a third difficulty, faced by the two popular "support" measures for phylogenetic

640 hypotheses [sic] (Efron, 1979; Efron \& Gong, 1983; Felsenstein, 1985, 2004; Bremer, 1988,

641 1994; Efron \& Tibshirani, 1993; Davis, 1995; Efron, Halloran \& Holmes, 1996; Holmes, 2003;

642 Soltis \& Soltis, 2003; Fitzhugh, 2006a, 2012, 2016c; Lemoine et al., 2018). Neither method

643 provides epistemically meaningful values regarding evidential support, contrary to the popularity

644 of their use, or claims that they provide a basis to say phylogenetic hypotheses are "robust." The

645 bootstrap was originally developed to test statistical hypotheses through a process of random

646 resampling from an original set of random samples taken from a population. The intent is to test

647 the hypothesis that a statistical parameter, inferred from the original samples, has the

648 hypothesised value, without having to perform additional sampling from the population. It is

649 important to note that the bootstrap approach is designed to test statistical, not explanatory

650 hypotheses. Phylogenetic hypotheses are not statistical constructs, as clearly shown in (4) and

651 (5). Like explanatory hypotheses, however, hypotheses of statistical estimates are inferred by

652 way of abduction. Such estimates are generalisations that account for observed instances as

653 representative of the population from which the sample was drawn. For example,

654 (8)

655

656
- Some balls in this bag are red

- $25 \%$ of balls in this random sample are red

- Hypothesis: $25 \%$ of all balls in this bag are red. 
657 Testing the hypothesis would proceed by predicting what should be observed if additional

658 random samples are taken. Such an inference could not be deductive, but rather what Peirce

659 (1932: 2.268) called a "statistical deduction,"

$660 \quad(9)$

- Hypothesis to be tested: $25 \%$ of all balls in this bag are red

661

- A random sample of balls will be taken from the bag

662

- Predicted test evidence: $25 \%$ of balls in the sample will be red.

663

664

665

666

667

668

669

670

671

672

673

674

675

676

677

678

679 used to originally infer the hypotheses, whereas testing explanatory hypotheses requires test

evidence that is different from the effects originally used to infer the hypotheses (Fitzhugh, 2016c, 2016d).

As suggested by Felsenstein $(1985,2004)$, the bootstrap method applied to phylogenetic hypotheses involves randomly sampling characters from an original character data matrix to create contrived data sets of the same size from which new cladograms are produced. Keep in mind that these cladograms, as "bootstrap replicates," are not explanatory hypotheses; they are merely branching diagrams derived from artificial data sets. Yet, it is claimed that the more often "clades" (actually only branching patterns) are obtained among these "replicates" that match the original groupings indicates higher "support" for those clades. This claim is, however, entirely incorrect. The "bootstrap replicates" have no epistemic relation to the original phylogenetic hypothesis(es) under consideration, such that any measure of "support" would be impossible to ascertain. Along with the statistical, i.e., inductive, mindset that was introduced into phylogenetic inference in the 1970's, the bootstrap method applied to phylogenetic hypotheses was largely an exercise in filling a perceived methodological void. Had the abductive nature of systematics been 
680 recognised early on, and character data not confused with test evidence, the state of the field 681 might have avoided so many scientifically questionable schemes. The only support relevant to 682 cladograms is valid test evidence produced in the process of testing the various classes of 683 hypotheses within a (composite) phylogenetic hypothesis [Fig. 3; cf. (2), (3)]. But as noted 684 earlier, such testing virtually never occurs, making the need for talk of support both gratuitous 685 and positively deceptive.

686 Just as the bootstrap provides results that cannot be interpreted as support for 687 phylogenetic hypotheses, the Bremer Index produces values that are equally impossible to 688 defend. Like the bootstrap, Bremer Index is claimed to determine support for groups, as opposed 689 to any particular hypotheses implied by cladograms. This support is based on the extent to which 690 groups or "clades" are present in cladograms of ever-increasing "length" beyond the original 691 minimum-length tree. The greater the tree length with a particular group still present is supposed 692 to represent greater "support" for or resiliency by that group. The problem is that trees of greater 693 length can only be interpreted as sets of explanatory hypotheses that have no epistemic relation 694 to the originally inferred hypotheses. The consequence is that values provided by the Bremer 695 Index offer no indication of support. Once again, in the absence of actually testing hypotheses, as 696 indicated in (2)-(3), no evidential test support is possible for hypotheses.

697 Finally, an oblique yet equally specious approach to garnering support comes from 698 comparisons of cladograms inferred from different sets of characters, sometimes referred to as 699 taxonomic congruence (Fitzhugh, 2014, 2016c). The idea is that if tree topologies are identical, 700 or nearly so, this justifies a sense of greater confidence or belief in those topologies (not the 701 implied explanatory hypotheses). Just as was noted earlier with regard to the error of character 702 mapping, comparisons of cladograms are an inferentially indefensible approach. Cladograms 
703 inferred to explain separate sets of characters are distinct compilations of explanatory constructs

704 that have no epistemic relevance to each other. A popular, somewhat related approach is to speak

705 of comparisons of past and present cladogram topologies inferred from updated compilations of

706 observations, remarking on the degree of similarities between groups in those topologies. The

707 same basic criticism against taxonomic congruence applies here. For example, previous

708 abductive inferences using data set $D_{1}$ give composite phylogenetic hypothesis $H_{1}$. With

709 subsequent characters added, $D_{1+2}$, a new composite phylogenetic hypothesis, $H_{2}$, is inferred. It

710 might seem reasonable to speak of topological similarities and differences between $H_{1}$ and $H_{2}$ but

711 this is a mistake. Again, $H_{1}$ and $H_{2}$ are distinct sets of explanatory hypotheses from different sets

712 of abductive premises. Just as there are no meaningful comparisons to be made between the

713 actual explanatory hypotheses implied by the different cladograms (cf. Fig. 2), there are no

714 relevant conclusions to be made regarding topological similarity or difference. In the absence of

715 recognising the nature of abduction or associated intent of those inferences, focusing on

716 phylogenetic tree comparisons offers no scientifically meaningful evaluation.

\section{Sequence data and explanatory hypotheses}

718 The pursuit of sequence data was not given consideration in this study. The reasoning behind this

719 decision will be outlined in this subsection. A more complete account is presented in Fitzhugh

720 (2016b; see also Nogueira et al., 2017: 683-684, Lovell \& Fitzhugh, 2020: 270, and Fitzhugh,

721 2021). Contrary to a claim made by a reviewer of an earlier draft of this paper, what is presented

722 in this section should not be interpreted as the assertion that we "do not believe in sequence

723 data." Rather, our intent is to point out inherent and significant difficulties that generally

724 preclude causally accounting for differentially shared nucleotides or amino acids via inferences

725 of phylogenetic hypotheses. 
727 systematics - follows from the fact that the goal of scientific inquiry is to continually acquire

728

729

730

731

732

733

734

735

736

737

738

739

740 causal understanding of phenomena, in the form of differentially shared characters of organisms, that we encounter as well as describe. The pursuit of that understanding begins with reactions to those effects, in the form of implicit or explicit why-questions, and subsequently inferring answers to those questions by way of abductive reasoning. As discussed earlier, abduction produces hypotheses that posit possible past causal events/conditions that account for observed effects, as shown in (1), (4), and (5). And, almost all actions in systematics are centered around abduction as opposed to testing hypotheses via induction (Fitzhugh, 2005a, 2006a, 2006b, 2008a, 2009, 2010a, 2012, 2013, 2014, 2015, 2016a, 2016b, 2016c, 2016d).

We pointed out earlier that composite phylogenetic hypotheses provide almost no causal specifics among the four classes of hypotheses implied by cladograms (Fig. 3). This is a consequence of the fact that phylogenetics computer algorithms emulate a vague form of abduction [e.g., (4), (5)]. Consider again what the Phylogenetic theory in (4) offers regarding character origin/fixation:

character $x(1)$ originates by [unstated] mechanisms $a, b, c \ldots n$, and becomes fixed within the population by [unstated] mechanisms $d, e, f \ldots n$ (= ancestral species hypothesis), followed by [unstated] event(s) $g, h, i \ldots n$, wherein the population is divided into two or more reproductively isolated populations.

The cause of character fixation in an ancestral population could at a minimum be assumed to be natural selection or genetic drift. In the absence of explicit causal specifics being presented in the Phylogenetic theory, it would have to be assumed that either selection or drift are reasonable causal alternatives. This equivalence is plausible for explaining phenotypic characters but cannot 
749 be applied to sequence data. For selection to operate, whether purifying or directional, variation

750 among heritable traits within a population must be identified that directly result in differential

751 fitness among individuals. Nucleotides and amino acids lack emergent properties that could

752 directly manifest fitness differences (for important nuances, cf. Linquist et al., 2020). Whilst

753 there are tests that can indicate whether selection has occurred in relation to sequence data, such

754 as the McDonald-Kreitman test (McDonald \& Kreitman, 1991; Sawyer, 1994; Hey, 1999; Hurst,

755 2002; Biswas \& Akey, 2006; Zhang \& Yu, 2006; Koonin, 2012; Petrov, 2014), these tests cannot

756 discriminate at what organisational level selection might have been directed. It is at higher

757 organisational levels that phenotypic characters can result in fitness variation. If selection is a

758 causal factor, it comes into play due to phenotypic effects at these higher levels. Alternatively,

759 since there is no direct selection for sequence data, phenotypic characters have the potential to

760 lead to differential fitness and intergenerational selection that can influence the occurrences of

761 those sequence data that produce the selected characters. The result is a form of indirect

762 selection, termed downward causation by Campbell (1974: 180),

763

"Where natural selection operates through life and death at a higher level of

764 organisation, the laws of the higher-level selective system determine in part the

765 distribution of lower-level events and substances."

766 Since the 1970's the importance of downward causation has become increasingly recognised 767 (e.g., Vrba \& Eldredge, 1984; Salthe, 1985; Lloyd, 1988; Auletta, Ellis \& Jaeger, 2008; Ellis, 768 2008, 2012, 2013; Ellis, Noble \& O’Connor, 2011; Jaeger \& Calkins, 2011; Laland et al., 2011;

769 Martínez \& Moya, 2011; Davies, 2012; Okasha, 2012; Walker, Cisneros \& Davies, 2012;

770 Griffiths \& Stotz, 2013; Martínez \& Esposito, 2014; Walker, 2014; Mundy, 2016; Callier, 2018; 
771 Pouyet et al., 2018; Salas, 2019; Yu et al., 2020), but its relevance to how sequence data are

772 explained via phylogenetic hypotheses has only recently been considered (Fitzhugh, 2016b).

If there can be no direct selection for sequence data, the issue then becomes one of

774

775

776

777

778

779

780

781

782

783

784

785

786

787

788

789

790

791

792

793

deciding to explain individual nucleotides or amino acids either directly via drift or indirectly

through downward causation. If the latter, it is first necessary to associate those sequence data

with the higher-level phenotypic characters to which selection is the hypothesised causal

condition. Those associated sequence data would then be excluded from phylogenetic inferences

since they would already be explained in conjunction with higher-level characters (Fitzhugh,

2016b). On the other hand, it might be argued that one could avoid the issue altogether by

assuming all sequence data should be explained by drift. This would be unrealistic as it

necessitates that selection at higher organisational levels never occurs. In the absence of being

able to discriminate between drift versus selection by downward causation, the only sensible

option is to forgo altogether attempts to causally account for shared nucleotides or amino acids

by way of phylogenetic inference. Otherwise, to explain shared nucleotides or amino acids with

phylogenetic hypotheses inferred under an entirely agnostic perspective [i.e., the Phylogenetic

theory in (4)] would be epistemically and scientifically unwarranted.

The inherent limitations for inferring explanatory hypotheses for sequence data have associated relevant consequences for mapping morphological characters on cladograms only inferred for sequence data. As discussed earlier (Phylogenetic inference = abduction; see also

(Fitzhugh, 2014), mapping is an epistemically unfounded approach to explaining characters. This

problem is compounded by the fact that not discriminating between genetic drift and natural

selection as possible causal factors when explaining sequence data yet again precludes rational

acceptance of phylogenetic hypotheses accounting for mapped characters. 

basis of downward causation or inability to distinguish drift from selection is at odds with the requirement of total evidence (RTE; cf. Fitzhugh, 2006b, for a discussion of the RTE in relation to systematics). Such is not the case. The RTE is a recognised maxim for all non-deductive reasoning (the requirement is automatically satisfied in deduction), wherein rational acceptance of a conclusion is based on considering all relevant evidence that can affect support (either negative or positive) for that conclusion (Carnap, 1950; Barker, 1957; Hempel, 1962, 1965, 1966, 2001; Salmon, 1967, 1984a, 1984b, 1989, 1998; Sober, 1975; Fetzer, 1993; Fetzer \& Almeder, 1993): “All that the requirement of total evidence says is that one's confidence in a hypothesis must be proportional to the support that that hypothesis receives from one's evidence..." (Neta, 2008: 91). Nearly all of the philosophical literature on the RTE has focused on test evidence in relation to induction [cf. (3)], which is understandable given that, for instance, to exclude known test evidence that could enhance or compromise acceptance of a theory or hypothesis would be less than rational. Whilst abductive reasoning has almost never figured into discussions of the RTE, the non-deductive nature of abduction necessitates its attention (Fitzhugh, 2006b). Consider the following example. For members of three species, $a-u s, b-u s$, and $c-u s$, there are characters

811 distributed among subjects 1-3 (cf. Fitzhugh, 2006c):

812

\begin{tabular}{lccc} 
Subjects: & 1 & 2 & 3 \\
\hline Outgroup & 0 & 0 & 0 \\
$a-u s$ & 0 & 1 & 1 \\
$b-u s$ & 1 & 0 & 1 \\
$c-u s$ & 1 & 1 & 0
\end{tabular}


817 If the characters among members of $a-u s, b-u s$, and $c-u s$ are explained separately, there would be

818 three sets of explanatory hypotheses (outgroup is excluded), represented here in parenthetical

819 form:

820

821

822

823

824

825

826

827

828

829

830

831

832

833

834

835

836

837

838

839

834

Subject 1: $\quad(a-u s(b-u s, c-u s))$

Subject 2: $\quad(b-u s(a-u s, c-u s))$

Subject 3: $\quad(c-u s(a-u s, b-u s))$.

The three sets of hypotheses are contradictory, and while each is supported by abductive evidence [cf. (1)], choosing among them based on the information provided would be problematic. This is the sort of situation the RTE is intended to address, as well as those instances that involve other degrees of data partitioning in relation to inferring phylogenetic hypotheses and character mapping. The nature of the abductive inferences involves explaining features of semaphoronts, such that the observed characters are part of the integrated network that makes up those individuals. The various phylogenetic theories applied to those characters [cf. (1)] assume that past causes operated on individuals, not distinct characters. Thus, explaining the characters under each subject would be relevant to explaining the other characters. The plausibility for any of the phylogenetic hypotheses would be based on an abductive inference where all the characters are treated as part of the premises.

Related to the topic highlighted in this subsection, it would not be a violation of the RTE to exclude from phylogenetic inferences those sequence data for which no empirical basis is available for discriminating drift from selection-via-downward-causation for sequence data. The difficulty faced is not a matter that falls under the purview of the RTE, but rather an inability to engage in abductive reasoning for a particular class of characters.

\section{Sequence data are not more objective than other classes of observations}


840 Consider the following statements,

841 "Molecular data are more objective and subject to considerably more rigor than

842

843

844

845

846

847

848

849

850

851

852

853

854

855

856

857

858

859

860

861

862 morphological data. DNA sequence contains four easily identified and mutually exclusive character states[....] Morphological and embryological character definitions and scoring of character states are far more subjective, and most characters have been repeatedly used without critical evaluation, calling into question the utility of morphological cladistic studies that span Metazoa[....]" (Halanych, 2004: 230).

"As we move forward with the deep-animal tree [sic], we should not employ morphology and developmental data to reconstruct the tree. There is too much historical baggage and subjectivity with these data. We should reconstruct the tree with molecular data and then use that tree to independently interpret the morphology and development in light of that tree[....]" (Halanych, 2016: 325).

"We present the view that rigorous and critical anatomical studies of fewer morphological characters, in the context of molecular phylogenies, is a more fruitful approach to integrating the strengths of morphological data with those of sequence data[....] We argue[...] that a main constraint of morphology-based phylogenetic inference concerns the limited number of unambiguous characters available for analysis in a transformational framework" (Scotland, Olmstead \& Bennett, 2003: 539).

Taken at face value, each statement appears damning of all or most observations of features of organisms other than sequence data in relation to inferring phylogenetic hypotheses. We have seen throughout this section, however, that the disconnect between principles of scientific

Peer] reviewing PDF | (2021:05:61394:1:1:NEW 20 Jul 2021) 
863 inquiry and recent views on phylogenetic inference have led to perspectives that cannot be

864 defended. This outcome extends to the notion that sequence data are somehow "more objective,"

865 "more fruitful," or more reliable than other observations. Asserting that one class of observations

866 is more effective than other classes presumes that the objective of phylogenetic inference is to

867 obtain "phylogenies" or "trees," which is at odds with pursuing explanations of all relevant

868 observations. If the objective of systematics is causal explanation, thus consistent with all of

869 scientific inquiry, then the pursuit of "phylogenies" or "trees" is not only contrary to that

870 objective but has led to erroneous inclinations in addition to the largely contrived

871 objective/subjective dichotomy. These erroneous pursuits include, but are not limited to (1)

872 inferring phylogenetic hypotheses for separate classes of characters, especially sequence data

873 versus morphology, and drawing comparisons between tree "topologies" (cf. Phylogenetic

874 hypotheses and the myth of evidential support), and (2) inferring phylogenetic hypotheses for

875 sequence data, then "mapping" morphological characters on the "tree" and making evolutionary

876 claims regarding the latter characters (cf. Phylogenetic inference $=$ abduction). To address the

877 claim that sequence data are more objective or less ambiguous requires that we first consider

878 what is meant by scientific objectivity. Then there are several additional issues in the above

879 quotes that need to be addressed.

880 As might be expected, objectivity has multiple meanings. Useful overviews can be found 881 in Daston \& Galison (2007), Gaukroger (2012), Reiss \& Sprenger (2017), and Wilson (2017).

882 Common interpretations of objectivity range from the view that judgements should be (a) free of 883 prejudice or bias, (b) free of assumptions, and/or (c) an accurate representation of, or 884 "faithfulness" to facts (Gaukroger, 2012). Each meaning can be applied to everyday life as well 885 as within fields of science. Regarding freedom from prejudice or bias, this is to speak of limiting 
886 levels of distortion beyond what is perceived. Freedom from assumptions would be impossible to

887 accomplish given the theory-laden nature of observation statements and other types of

888 propositions: "Every instance of scientific inquiry, every study, rests on a vast submerged set of

889 political, moral, and ultimately metaphysical assumptions" (Wilson, 2017). Scientific objectivity

890 has often been interpreted along the lines of "faithfulness to facts" (Daston \& Galison, 2007;

891 Reiss \& Sprenger, 2017), where we attempt to minimise arbitrary judgements; we want to

892 answer questions on the basis of the most appropriate evidence we have available. Objectivity

893 occurs in degrees - there is no absolute objectivity, which is why objectivity cannot be equated

894 with truth, which is absolute. Ultimately, "While we can strive for objectivity, inquiry is

895 inherently subjective" (Spencer, 2020).

896 Reiss \& Sprenger (2017) distinguish "product" and "process" objectivity. Product

897 objectivity regards the products of scientific inferences, such as theories, laws, and observation

898 statements, as accurate representations of the external world. Process objectivity refers to

899 processes and methods that are not dependent on social or ethical values, or the individual biases

900 of the scientist. It is product objectivity that is of concern when it comes to assessing the quotes

901 given above, claiming sequence data are in some way more objective or less ambiguous than

902 other classes of observations.

903 There is nothing in the conception of product objectivity that would support the claim

904 that observation statements of morphological features are less objective than sequence data,

905 much less that such a contrived distinction warrants the exclusion of an entire class of

906 observations from the goal of systematics. Indeed, that biologists hold different interpretations of

907 what they perceive of the properties of organisms is not tantamount to proffering less objective

908 observation statements. Those statements are themselves products of abductive reasoning 
909 (Peirce, 1935; Hoffman, 1995; Burton, 2000; Magnani, 2009; Anjum \& Mumford, 2018),

910 constrained by one's background knowledge, and like all hypotheses, are open to empirical

911 evaluation. If anything, it can be argued that sequence data are less than objective relative to

912 other classes of characters given the fact that attempted phylogenetic inferences explaining

913 differentially shared nucleotides or amino acids typically operate under the assumption that rates

914 of substitution must be imposed within abductive inferences (cf. Phylogenetic inference $=$

915 abduction). That assumption carries with it the implication that observation statements of shared

916 characters must be treated as potentially false, hence the need to interject substitution rates

917 within inferences, as indicated by the all-too-common emphasis on branch lengths. Considering

918 the rule for valid reasoning - that we should assume the truth of premises, discussed earlier - the

919 treatment of sequence data with "likelihood" and "Bayesian" methods pales against any criterion 920 of objectivity.

921 Rather than focusing on the false argument from objectivity as a basis to eliminate

922 observations of morphological characters in need of explanation, systematists should embrace as

923 much as possible all relevant observations per the goal of scientific inquiry discussed earlier and

924 the requirement of total evidence (Fitzhugh, 2006b). Two notable exceptions to considering

925 explaining differentially shared characters by way of phylogenetic hypotheses come from

926 conditions discussed earlier: (1) why-questions addressing some characters might not be

927 amenable to being answered by phylogenetic hypotheses, but instead one of the other classes of

928 explanatory hypotheses applied in systematics (Fig. 1); (2) epistemic limitations to explaining 929 sequence data because of an inability to discern explanations due to genetic drift versus selection 930 by way of downward causation (cf. Sequence data and explanatory hypotheses). Pursuing 
931 causality is the intent - not producing "trees" or "phylogenies," which are typically devoid of

932 causal considerations in relation to sequence data.

\section{Outgroup and ingroup taxa}

934 Outgroup and ingroup taxa considered in thus study include the following:

935

936

937

938

939

940

941

942

943

944

945

946

947

948

949

950

951

952

953 outgroups - Chaetopteridae: Phyllochaetopterus limicolus Hartman, 1960

Spionidae: $\quad$ Spio filicornis (Müller, 1776)

Prionospio ehlersi Fauvel, 1928

P. lighti Maciolek, 1985

Laonice cirrata (Sars, 1851)

ingroup - Magelona (72 species)

Octomagelona (2 species)

Descriptive details regarding members of the outgroups were obtained from the following literature sources:

P. limicolus - Blake (1996a)
S. filicornis - Meißner, Bick \& Bastrop (2011)
P. ehlersi - Blake (1996b)
P. lighti - Blake (1996b)
Laonice cirrata - Blake (1996b)

The choice of outgroups ideally would follow from more inclusive phylogenetic studies from which the immediate sister groups to Magelonidae have been ascertained. In this regard, the merits of recent phylogenetic hypotheses are questionable. In her review of the Magelonidae, Mortimer (2019) summarised past studies of phylogenetic relationships of magelonids to other groups within Polychaeta. As would be expected for a group as moderately disparate as 
954 magelonids, earlier conclusions were that they exhibit close relations with other spioniforms.

955 Recent phylogenetic studies based exclusively on morphological (Capa, Parapar \& Hutchings,

956 2012; Chen et al., 2020) or sequence characters (Weigert et al., 2014; Helm et al., 2018) have,

957 however, allied Magelonidae with Oweniidae, while Weigert et al.'s (2016) use of mitochondrial

958 sequences had Magelonidae and Chaetopteridae as sister taxa. Each approach has aspects that

959 call into question the respective conclusions. For instance, Capa, Parapar \& Hutchings (2012; see

960 also Capa, Parapar \& Hutchings, 2019) cautiously suggested a Magelonidae-Oweniidae clade

961 based on the absence of nuchal organs, fusion of pro- and peristomium, presence of a ventral

962 buccal organ, and monociliated cells. The absence of nuchal organs is not exclusive to

963 magelonids and oweniids (Purschke, 1997, 2005). Mortimer \& Mackie (2014) and Mortimer

964 (2019) have shown that pro- and peristomium are not entirely fused, and the magelonid

965 "burrowing organ" is not homologous to the oweniid buccal organ [Mortimer, 2019; see also

966 Character descriptions, Burrowing organ (subject 14), below]. Monociliated cells have only

967 been recorded from among members of Magelona mirabilis (Johnston, 1865) (Bartolomaeus,

968 1995, N.B. fig. 1A in this publication is not M. mirabilis; Patrick, Helm \& Bartolomaeus, 2019).

969 As part of their description of a fossil magelonid, Chen et al. (2020: fig. 8a; see also Parry et al.,

970 2016) presented phylogenetic hypotheses also suggesting Oweniidae and Magelonidae are

971 exclusive sister taxa, but their inferences are based on an overly broad taxon coverage and the

972 compilation of characters is inadequate to address phylogenetic relationships of magelonids to

973 other polychaetes. As discussed in the previous section (Methodological considerations -

974 Sequence data and explanatory hypotheses), the inherent problems associated with attempting

975 to explain shared nucleotides or amino acids undermine the plausibility of phylogenetic

976 hypotheses inferred from those premises. With the emphasis on an extensive treatment of 
977 magelonid morphological characters in this study, the greatest number of characters is shared

978 with members of Spionidae, making them an appropriate outgroup. Members of several genera

979 and species were included to accommodate variation within Spionidae. An additional spioniform

980 representative from the Chaetopteridae, Phyllochaetopterus limicolus, was also included.

981 Ideally, all currently recognised magelonid taxa would be included in inferences of the

982 phylogenetic hypotheses. This, however, relies on several factors. Initially, taxa were chosen

983 based on access to specimens, preferably type material, some of which had been observed

984 previously during descriptions and re-descriptions by the present authors. Specimens were

985 borrowed from the following institutions:

986 BMNH - Natural History Museum, London

987 MB - Museu Nacional de História Natural, Lisboa

988 MNCN - Museo Nacional de Ciencias Naturales, Madrid

989 MNHM - Muséum National d'Histoire Naturelle, Paris

990 NHMG - Gothenburg Museum of Natural History

991 NHMLAC - Natural History Museum of Los Angeles County

992 NMW - Amgueddfa Cymru - National Museum Wales

993 PMBC - Phuket Marine Biological Center

994 SMF - Senckenberg Research Institute and Natural History Museum, Frankfurt

995 USNM - Smithsonian National Museum of Natural History

996 ZMBN - University Museum of Bergen

997 ZMHB - Museum für Naturkunde der Humboldt-Universität zu Berlin

998 ZMUC - Zoological Museum, University of Copenhagen

999 ZUEC - Museu de Zoologia, Universidade de Campinas 
based on the level of information and detail in the original descriptions. It is only comparatively

1002

recently that the importance of illustrating and fully describing all thoracic chaetigers has been

1003

realised for the treatment of taxa for example, and further characters defined. Thus, many of the

1004

earliest descriptions lack much of the detail required for the current analysis. All ingroup taxa

1005

included in the analyses are listed in Table 2, including which specimens were observed and the

1006

institution from which they were borrowed. Table 2 also indicates whether observations were

1007

based solely on published material. Species not included within the analysis: Magelona agoensis

1008

Kitamori, 1967, M. americana Hartman, 1965, M. capax Hartman, 1965, M. capensis Day, 1961,

1009

M. japonica Okuda, 1937, M. kamala Nateewathana \& Hylleberg, 1991, M. koreana Okuda,

1010

1937, M. longicornis Johnston, 1901, M. methae Nateewathana \& Hylleberg, 1991, M.

1011

mickiminni Nateewathana \& Hylleberg, 1991, M. noppi Nateewathana \& Hylleberg, 1991, M.

1012

pectinata Nateewathana \& Hylleberg, 1991, M. petersenae Nateewathana \& Hylleberg, 1991, M.

1013

pettiboneae lanceolata Jones, 1963, M. rosea Moore, 1907 and M. sachalinenis Buzhinskaja,

$1014 \quad 1985$.

\section{Character descriptions}

A total of 176 characters distributed among 79 subjects (Table 3; Table S1) were used to infer phylogenetic hypotheses. Descriptions of characters are presented here.

\section{Characters of the anterior end: prostomium (subjects 1-9)}

1019 The form of the magelonid prostomium (subject 1) is considered a synapomorphy of the group, 1020 the name "shovel head worms" having been coined due to its peculiar shape. The dorso-ventrally 1021 flattened, shovel-shaped prostomium [character 1(1), Figs. 4 and 5] is a feature not observed 
1022 among members of the outgroups or any other polychaete group. Nuchal organs (subject 2) have

1023 not been recorded among adult members of any magelonid species [character 2(0)] but are

1024 present among all members of the outgroups [character 2(1)].

1025 The distal margin of the magelonid prostomium (subject 3) can vary from smooth

1026 [character 3(0), Figs. 4A and 4F], crenulate [character 3(1), Figs. 4B and 4C] or medially

1027 indented [character 3(2), Fig. 4D]. Uebelacker \& Jones (1984) stated that the presence of a

1028 crenulated prostomial margin is an excellent character for separation of species, although the

1029 degree of crenulation present shows great intraspecific variability. The crenulations may differ in

1030 number and form, for example, the distinct, triangular crenulations of Magelona sp. L of

1031 Uebelacker \& Jones (1984) or M. crenulifrons (Fig. 4B), in comparison to the numerous minute

1032 crenulations observed for M. longicornis or M. wilsoni (Fig. 4C). The crenulations among

1033 members of some species are difficult to discern and this is perhaps the reason they have been

1034 previously overlooked in some descriptions and erroneously reported as absent in others. The

1035 prostomial distal margin (subject 4) may additionally vary in shape, from triangular [character

1036 4(0), Fig. 4E], to rounded [character 4(1), Figs. 4A and 4F] or straight [character 4(2), Figs. 4G,

$10374 \mathrm{H}, 5 \mathrm{C}$ and 5E]. As subjects 3 and 4 relate directly to the shovel-shaped prostomium,

1038 characteristic of magelonids, it does not apply to any members of the outgroups.

1039 Horns are the distal projections of the prostomium (subject 5) that occur among members

1040 of some species of magelonids [character 5(1)], such as Magelona pacifica (Fig. 5A), or M.

1041 montera (Fig. 5B). Uebelacker \& Jones (1984) drew attention to this character for the initial

1042 separation of magelonid species. When present, horns can vary in size/shape (subject 6), from

1043 rudimentary [character 6(0), Figs. 4G, 4H, 5C and 5E], such as those observed among members

1044 of M. variolamellata and M. alleni (often described as a squared anterior margin), or 
1045 conspicuous structures as seen among members of species such as M. posterelongata [character

1046 6(1), Fig. 5D]. In the latter case, these are often very distinct from the distal prostomial margin.

1047 Prostomial horns do not occur in the outgroups, thus subjects 5 and 6 are not applicable.

1048 Several authors have identified dimensions of the prostomium (subject 7) as an important

1049 feature in the separation of magelonid species (Hartman, 1944; Wilson, 1958, 1959; Jones, 1963 ,

1050 1971, 1978; Uebelacker \& Jones, 1984; Bolívar \& Lana, 1986; Blake, 1996c; Mortimer, 2019).

1051 According to Uebelacker \& Jones (1984), the general shape and relative dimensions are fairly

1052 constant within each species, something which the current authors are in agreement.

1053 Consequently, the ratio of width to length was used to recognise three prostomial characters:

1054 prostomium longer than wide [character 7(0), Figs. 4A, 4F, 5B and 5D], as wide as long

1055 [character 7(1), Figs. 4B, 4D and 4G], and wider than long [character 7(2), Figs. 4C, 4H and 5E].

1056 Members of three species within the outgroups (Spio filicornis, Prionospio lighti and P. ehlersi)

1057 are considered to possess prostomia which are longer than wide [character 7(0)], whilst members

1058 of Phyllochaetopterus limicolus and Laonice cirrata have prostomia which are wider than long

1059 [character 7(2)].

1060 Magelonid prostomia carry paired “muscular”, dorsal longitudinal ridges (subject 8),

1061 which extend from the base of the prostomium towards the distal tip [character 8(1)]. Jones

1062 (1968) stated that their "inner surfaces, particularly dorsally and ventrally, are provided with

1063 longitudinal muscles," describing them as hollow, cylindroid structures, which he presumed were

1064 fluid filled. The number of prostomial ridges (subject 9) varies from one pair [character 9(0),

1065 Fig. 4H], such as members of Magelona equilamellae or two pairs [character 9(1), Figs. 4A-C,

1066 4E and 5B], as observed among members of M. pacifica (Fig. 5A). The ridges may vary in size

1067 and distinctiveness, the outer pair among members of some species being more difficult to 
1068 discern, e.g., M. alleni (Fig. 4G), to the distinct and transversely ridged structures seen in, for 1069 example, members of M. wilsoni (Fig. 4C). Prostomial ridges are not present among members of 1070 the outgroups [character 8(0)] and thus subject 9 is not applicable.

1071 Characters of the palps (subjects 10-13)

1072 Magelonids possess two long palps, considered to be peristomial, arising from the larval 1073 prototroch (Wilson, 1982). There has been much discussion about palp origin (subject 10), since 1074 they are ventrally inserted [character 10(1), Figs. 4F and 5G], rather than dorsally [character $107510(0)]$, the latter of which is seen among members of all other polychaete groups with palps, 1076 including the outgroups. In addition, the palps do not have the characteristic feeding groove seen 1077 among members of other taxa such as spionids and Myriowenia. However, an inconspicuous 1078 ventral line devoid of papillae is generally present. According to Orrhage (1966), palps among 1079 members of the Spionidae and Magelonidae are homologous because they are innervated by 1080 nerves from the same part of the brain. More recently Beckers, Helm \& Bartolomaeus (2019) 1081 stated that two nerves innervate the palps of members of the Magelonidae, Spionidae, 1082 Chaetopteridae and Oweniidae, indicating the purported plesiomorphic condition in Annelida. Magelonid palp surfaces (subject 11) are uniquely papillated, with ampulliform to digitiform papillae arranged in rows along the longitudinal axis [character 11(1), Figs. 4H, 5B and $5 \mathrm{~F}-\mathrm{H}]$. Members of the outgroups, along with all other polychaetes possess non-papillated 1086 palps [character 11(0)]. Although the number of rows of papillae varies among members of magelonid species, it is relatively stable among members of any particular species. As papillae are involved in obtaining food (Jones, 1968; Fauchald \& Jumars, 1979; Mortimer \& Mackie, 2014), variations in number of papillae may reflect different feeding strategies. In general, the number of rows of papillae are fewer distally in comparison to proximally (Jones, 1963, 1971, 
1091 1978). The number of rows of papillae in the proximal region of the palp (subject 12) were

1092 coded as three characters: two rows of papillae [character 12(0)], 4-8 rows [character 12(1)], and

1093 10-14 rows [character 12(2)]. The number of rows of papillae at the distal end (subject 13) were 1094 coded for 2 [character 13(0)], 4 [character 13(1)], or more than 4 rows [character 13(2)]. Where a 1095 range was observed among members of a species, the maximum number of rows was the value 1096 used. As with palps in other polychaete groups, those of magelonids are easily lost upon 1097 collection. Many descriptions do not include information about them, whilst others do not detail 1098 differences in number of papillae along the palp length. Many authors have undervalued the 1099 importance of palp characteristics in the descriptions of members of species. These two factors 1100 present the largest problem in coding these subjects. It should be noted that the number of rows 1101 of papillae may vary in animals with regenerating palps, particularly at the distal tips, thus 1102 affecting the ranges observed. Subjects 12 and 13 are not applicable to members of the outgroups 1103 since papillated palps are unique to magelonids.

1104

1105 1106 1107

\section{Burrowing organ (subject 14)}

Magelonids have long been described to possess a ventral eversible proboscis. A heartshaped sac (when fully everted; oval when only partially everted), carrying longitudinal ridges (Mortimer, 2019: fig. 4.2.4). However, recent studies show that this structure plays no part in feeding (and is not connected to the buccal region) but functions in burrowing only (Mortimer, 2019). The term "burrowing organ" should be applied to this structure. The burrowing organ is present in members of all known magelonid species [character 14(1)] but not present in any members of the outgroups [character 14(0)].

\section{Characters of body regionation (subjects 15-16)}


1114 head and "thorax" (the latter of which is characterised by the presence of capillary chaetae), and

1115 an "abdomen" comprising many segments with hooded hooks [character 15(1)] (Figs. 6A and

1116 11A). As an aside, the terms thorax and abdomen are ill-defined when applied to polychaetes

1117 overall, other than to vaguely indicate anterior-posterior distinctions along the body.

1118 Unfortunately, the characters associated with these regions are not uniformly applied across all 1119 polychaetes.

1120 The body of members of the outgroups do not have this regionation [character 15(0)].

1121 Behind the head region (subject 16), the thorax carries an achaetous first segment, followed by

1122 either eight [character 16(0), Octomagelona; Fig. 6] or nine [character 16(1), Magelona]

1123 chaetigers. Subject 16 does not apply to members of the outgroups.

1124 Characters of thoracic parapodia (subjects 17-30)

1125 Unique terminology introduced and later modified by Jones (1963, 1971, 1978) has been applied 1126 to the family, particularly related to parapodial structures (Fig. 7). Brasil (2003: fig. 4) provided 1127 a comprehensive review of this terminology and problems related to inconsistencies in applying 1128 terms. Consequently, several authors have suggested its abandonment (Rouse, 2001; Mortimer \& 1129 Mackie, 2003). Magelonid chaetigers possess biramous parapodia with lamellae in both the noto1130 and the neuropodia. Lamellae are generally postchaetal, flattened structures that range from 1131 filiform to foliaceous in shape. They encircle the chaetal bundle, attaching to a low, triangular or 1132 rounded prechaetal lamella, almost cuff-like (Fig. 8A). However, among members of some 1133 species, the lamellae are somewhat subchaetal in position, underneath the chaetal bundle and 1134 appearing somewhat U-shaped when viewed laterally (Figs. 8B, 8D). All members of all species 1135 in the ingroup and outgroups have postchaetal noto- and neuropodial lamellae in 
1136 thoracic/anterior chaetigers (subjects 17 and 19, respectively) except for Phyllochaetopterus

1137 limicolus, in which they are absent [characters 17(0) and 19(0)].

1138 The development of notopodial (subject 18) and neuropodial lamellae (subject 20) along

1139 the anterior chaetigers may be similar in all chaetigers [characters 18(0) and 20(0), respectively],

1140 such as among members of Magelona papillicornis, and M. minuta (Fig. 7A), or vary along the

1141 thorax [characters 18(1) and 20(1), respectively]. Subjects 18 and 20 are considered inapplicable

1142 to members of all species in the outgroups. The variation in degree of development can be easily

1143 observed among members of M. obockensis (Fig. 7C), and M. conversa (Fig. 7D), in both the

1144 noto- and neuropodia, whilst among members of Octomagelona bizkaiensis it is evident only in

1145 the neuropodia (Fig. 6E). The lamellae of chaetigers eight and nine often vary in comparison to

1146 those of the first seven chaetigers, e.g., M. crenulifrons, and M. johnstoni (Fig. 9I). Thus,

1147 characters of the lamellae of the first seven chaetigers were coded separately (subjects 21-30) to

1148 those for chaetiger eight (subjects 34-40), and chaetiger nine (subjects 41-49).

1149 The notopodial lamellae in chaetigers 1-7 (subject 21) may be postchaetal [character

1150 21(0); noted also for members of the outgroups, except Phyllochaetopterus limicolus, for which

1151 the subject is not applicable] or subchaetal [character 21(1)], whilst neuropodial lamellae

1152 (subject 26) may be postchaetal [character 26(0); observed for members of the outgroups, except

1153 P. limicolus, for which the subject is not applicable], subchaetal [character 26(1)] or prechaetal

1154 [character 26(2)]. Prechaetal neuropodial lamellae, such as are observed among members of

1155 Magelona conversa and M. mirabilis (Figs. 7D and 8C), are less frequent than both post- (Fig.

1156 7A) or subchaetal (Fig. 9E). The position of the thoracic neuropodial lamellae (subject 27) may

1157 be consistent throughout the thorax [character 27(0)], or may vary [character 27(1)], e.g., being

1158 prechaetal on chaetiger 1, occurring in a ventral position in the mid-thorax, and distinctly

Peer] reviewing PDF | (2021:05:61394:1:1:NEW 20 Jul 2021) 
1159 postchaetal in the posterior thorax (Figs. 8F and 8G). This subject was not considered applicable

1160 to members of the outgroups.

1161 Thoracic notopodial lamellar shape (subject 22) may be filiform, having a long, tapering 1162 structure [character 22(0), Figs. 9A, 9B and 9G] or more foliaceous [character 22(1), Figs. 9C1163 F]. The margins of the latter (subject 23) may be smooth [character 23(0)], crenulate [character 1164 23(1), e.g., M. montera, Figs. 9D and 9E] or bilobed [character 23(2), e.g., M. obockensis, Fig. $11659 \mathrm{~F}]$. All members of the outgroups are considered to have foliaceous [character 22(1)], smooth1166 edged [character 23(0)] anterior notopodia, except for members of Phyllochaetopterus limicolus 1167 for which subjects 22 and 23 are not applicable. Above the notopodial lamellae and in a slightly 1168 prechaetal position, superior dorsal lobes (subjects 24, 25, 37, 45) (dorsal medial lobes sensu 1169 Jones) may be present (Figs. 7C, 7D, 8D, 8E and 9C-F) or absent [characters 24(0), 37(0), $117045(0)]$. These structures are generally smaller than the notopodial lamellae and somewhat 1171 cirriform to digitiform in shape. However, among members of some species they may be larger 1172 and distinctly foliaceous. When present, superior dorsal lobes may be present on all thoracic 1173 chaetigers [characters $25(1), 37(1), 45(1)]$, on chaetigers 1-8 only [characters $25(1), 37(1)$, $117445(0)$ ], or only occurring on a small number of thoracic chaetigers [often starting in the mid1175 thoracic region, e.g., M. johnstoni or M. conversa, character 25(0), Fig. 7D]. Superior dorsal 1176 lobes are absent among all members of the outgroups on chaetigers 1-9 (thus subject 25 is not 1177 applicable), and subjects 24, 25, 37 and 45 are considered inapplicable for Phyllochaetopterus 1178 limicolus.

1179 The shape of thoracic neuropodial lamellae (subject 28) may be filiform [character 28(0), 1180 Figs. 7C, 8F and 8G] or foliaceous [character 28(1), Fig. 9C, also seen in members of the 1181 outgroups, excluding Phyllochaetopterus limicolus, for which the subject is not applicable]. The 
1182 distal ends (subject 29) of which may be pointed [character 29(0)], as among members of $M$.

1183 equilamellae (Figs. 8F and 8G), or distally expanded and scoop-shaped [character 29(1)] as

1184 observed among members of $M$. cincta (Figs 9H). The latter subject is not applicable to members

1185 of the outgroups. The lengths of noto- and neuropodial lamellae (subject 30) may be equivalent

1186 [character 30(0), Fig. 9G], the notopodial lamellae may be longer [character 30(1), Figs. 9D-F],

1187 or the neuropodial lamellae may be longer [character 30(2), Fig. 7D], e.g., chaetiger 8 of $M$.

1188 conversa. The thoracic notopodial lamellae among members of the outgroups, Prionospio lighti

1189 and P. ehlersi are longer than neuropodial lamellae [character 30(1)], whilst for members of Spio

1190 filicornis and Laonice cirrata they are equivalent [character 30(0)]. Subject 30 is not applicable

1191 to P. limicolus.

1192 Characters of the chaetae from chaetigers 1-8 (subjects 31-33)

1193 Capillary chaetae (subject 31) occur only in the thorax of magelonids (Figs. 6, 8, 9, 10 and 11),

1194 but many authors have undervalued the differences between them, describing them simply as

1195 limbate capillary chaetae (Hartman, 1944, 1961, 1965; Nateewathana \& Hylleberg, 1991). Jones

1196 (1977) was one of the few authors who referred to the presence of unilimbate [character 31(0),

1197 Fig. 10C] and bilimbate capillary chaetae [character 31(1)] in descriptions of members of

1198 species. For some individuals, both unilimbate and bilimbate chaetae have been recorded,

1199 however, the predominate form in each case was coded in the current analysis. Bolívar \& Lana

1200 (1986) and Blake (1996c) additionally noted some members of species possess bilimbate chaetae

1201 (subject 32) with an irregular blade [character 32(1)], such as Magelona variolamellata (Fig.

1202 10E), and Brasil (2003) additionally noted it to occur among members of species such as $M$.

1203 riojai (Fig. 10D), M. pacifica and M. pitelkai. Members of the outgroups possess unilimbate

1204 capillary chaetae [character 31(0)], whilst subject 32 is not applicable. Additional to the 
1205 limbations of capillary chaetae, the relative lengths of noto- and neurochaetae may vary (subject

1206 33). Either being equivalent in length [character 33(0)] e.g., M. nonatoi, longer in the notopodia

1207 [character 33(1)], e.g., M. sacculata, or longer in the neuropodia [character 33(2)], e.g., M.

1208 variolamellata. For members of Phyllochaetopterus limicolus, Spio filicornis and Prionospio

1209 lighti, chaetae are longer in the notopodia [character 33(1)], whilst for members of Laonice

1210 cirrata and $P$. ehlersi they are equivalent in length [character 33(0)]. In some members of

1211 magelonid species chaetae of all thoracic chaetigers are similar, however, in others the chaetae of

1212 the ninth chaetiger are modified. For this reason, the chaetae were coded collectively for the first

1213 eight chaetigers, and separately for chaetiger nine (see below).

1214 Characters of parapodia of chaetiger 8 (subjects 34-40)

1215 As described above, development of lamellae in the magelonid thorax may be similar on all

1216 chaetigers or vary between them. For members of species in which they vary, the parapodia of

1217 chaetigers 8 and 9 in particular may show larger differences in comparison to preceding

1218 chaetigers. However, the same characters that were coded for the first seven chaetigers can be

1219 applied to the posterior-most thoracic chaetigers. The notopodial lamellae (subjects 34-36) of

1220 chaetiger 8 may be postchaetal [character 34(0)] or subchaetal [character 34(1)] in position

1221 relative to the chaetal bundle, filiform [character 35(0)] or foliaceous [character 35(1)] in shape,

1222 with smooth [character 36(0)], crenulate [character 36(1)] or bilobed [character 36(2)] margins.

1223 Subjects 34-36 are considered not applicable to members of Phyllochaetopterus limicolus.

1224 However, remaining members of the outgroups possess postchaetal [character 34(0)], foliaceous

1225 [character 35(1)] parapodia with smooth margins [character 36(0)]. Superior dorsal lobes

1226 (subject 37) may be absent [character 37(0)] or present [character 37(1)]. The neuropodial

1227 lamellae (subjects 38-40) of chaetiger 8 may be postchaetal [character 38(0)], subchaetal 
1228 [character 38(1)] or prechaetal [character 38(2)] in position relative to the chaetal bundle, and

1229 may be filiform [character 40(0)] or foliaceous [character 40(1)] in shape. However, an

1230 additional postchaetal expansion (subject 39), often triangular in shape, as is seen among

1231 members of Magelona montera (Fig. 9D) is sometimes observed in the neuropodia of chaetiger 8

1232 (and 9, see below) [character 39(1)]. Subjects 38-40 are considered not applicable to members of

1233 Phyllochaetopterus limicolus. Members of Spio filicornis, Prionospio lighti, P. ehlersi and

1234 Laonice cirrata have postchaetal [character 38(0)], foliaceous [character 40(1)] neuropodia in

1235 chaetiger 8, without an additional postchaetal expansion [character 39(0)].

\section{Characters of the parapodia of chaetiger 9 (subjects 41-49)}

1237 For chaetiger 9, observed characters were coded in the same way as for chaetiger 8 . The

1238

notopodial lamellae (subjects 41, 43-44) of chaetiger 9 may be postchaetal [character 41(0)], or

1239

subchaetal [character 41(1)] in position in comparison to the notochaetae, and may be filiform

1240

[character 43(0)] or foliaceous [character 43(1)] in shape, with smooth [character 44(0)],

1241

1242

1243

1244

1245

1246

1247

1248

1249

1250 crenulate [character 44(1)] or bilobed [character 44(2)] margins. Members of the outgroups possess postchaetal [character 41(0)] notopodia chaetiger 9 which are foliaceous [character 43(1)], with smooth margins [character 44(0)]. However, subjects 41, 43 and 44 are not applicable to Phyllochaetopterus limicolus. Superior dorsal lobes (subject 45) may be present [character 45(1)] or absent [character 45(0)].

The neuropodial lamellae (subjects 46, 48) of chaetiger 9 may be postchaetal [character $46(0)$ ], subchaetal [character 46(1)] or prechaetal [character 46(2)] in position in comparison to the chaetal bundle, and filiform [character 48(0)] or foliaceous [character 48(1)] in shape. As with chaetiger 8 , an additional postchaetal expansion (subject 49) may be absent [character 49(0)] or present [character 49(1)]. Members of the outgroups possess foliaceous [character

Peer] reviewing PDF | (2021:05:61394:1:1:NEW 20 Jul 2021) 
$125148(1)$ ], postchaetal [character 46(0)] lamellae without an additional postchaetal expansion

1252 [character 49(0)], except for P. limicolus for which these subjects are not applicable.

1253 The parapodia in chaetiger 9 among members of some magelonid species may be

1254 markedly different in comparison to preceding chaetigers. For example, the lamellae in chaetiger

12559 among members of Magelona johnstoni (Fig. 9I) are much broader and lower [characters 42(0)

1256 and 47(0)] in comparison to the elongate lamellae of chaetigers $1-8$ in both the noto- and

1257 neuropodia, and the elongate lamellae of chaetiger 9 amongst members of other species, e.g., $M$.

1258 equilamellae [characters 42(1) and 47(1), Fig. 7B]. For this reason, additional subjects were

1259 added to accommodate the height of lamellae in both rami of chaetiger 9 (subjects 42 and 47).

1260 As members of Octomagelona species only possess eight thoracic chaetigers these subjects were

1261 coded as inapplicable for these taxa and additionally for members of Phyllochaetopterus

1262 limicolus. Members of Spio filicornis possess broad and low parapodia in chaetiger 9 [characters

1263 42(0) and 47(0)], whilst for members of Prionospio lighti, P. ehlersi and Laonice cirrata they are 1264 more elongate [characters 42(1) and 47(1)].

1265 Characters of the chaetae of chaetiger 9 (subjects 50-51)

1266 The chaetae of chaetiger 9 in magelonids may be similar to or vary from those of chaetigers $1-8$

1267 (subjects 50 and 51). They may be the same length [character 50(0), as in the outgroups],

1268 shorter than [character $50(1)$, or longer than those of chaetigers 1-8 [character 50(2)]. The

1269 distal ends of chaetiger 9 chaetae may be gently tapered as is seen in the preceding chaetigers

1270 [character 51(0), Figs. 8F and 8G] (observed also for members of the outgroups), or have

1271 distinctly mammiform, expanded, mucronate tips [character 51(1), Figs. 7C, 7D, 9I and 10F-H]

1272 such as among members of Magelona johnstoni and M. mirabilis. In members of other species, 
1273 the distal ends are pennoned [character 51(2), Fig. 10I], such as M. pitelkai, M. hobsonae, and M.

1274 hartmanae.

1275 Characters of the thoracic region (subjects 52-53)

1276 Whilst many authors have noted the often-marked difference between thoracic and abdominal 1277 regions in magelonids (Fig. 8B), other characteristics of the thoracic region have been largely 1278 overlooked. Mortimer (2019) noted that among members of certain magelonid species, the 1279 thoracic interparapodial margins (subject 52) may be characteristically bulbous and rounded 1280 [character 52 (1), Fig. 11A], as seen among members of Magelona alleni, whilst among 1281 members of others, such as M. johnstoni, they are straight [character 52(0), Fig. 11B]. Members 1282 of the outgroups possess straight thoracic interparapodial margins [character 52(0)]. Uebelacker \& Jones (1984) first coined the phrase “oblique lateral slits" (subject 53) in

1284

1285

1286

1287

1288

1289

1290

1291

1292

1293

1294

1295

\section{Dimensions of post-chaetiger 9 segments (subject 54)}

Uebelacker \& Jones (1984) described posterior segments that are much longer than wide [character 54(1), Fig. 12A] among members of an undescribed species, Magelona sp. H, from the Gulf of Mexico. Later, M. posterelongata was the first species with individuals formally 
1296 described with this feature. Many authors have ignored this characteristic, a problem

1297 compounded by the difficulty in collecting entire specimens. A further problem in coding this

1298 character is that abdominal chaetigers may vary in proportion along the length of the posterior

1299 region. It is believed, however, that the majority of magelonid species possess abdominal

1300 chaetigers equal in length and width, or only marginally longer than their width; a characteristic

1301 shared with members of the outgroups [character 54(0)].

1302

1303

1304

1305

1306

1307

1308

1309

1310

1311

1312

1313

1314

1315

1316

1317

1318

\section{Characters of the parapodia of post-chaetiger nine segments (subjects 55-59)}

The abdominal region of magelonids consists of many chaetigers carrying biramous parapodia.

In contrast to the thorax, the abdominal lamellae of the notopodia and neuropodia are generally symmetrical and of similar size and shape in both rami. The abdominal region starts at chaetiger

9 for members of Octomagelona (Fig. 6) and chaetiger 10 for members of Magelona (Fig. 11A) and is marked by a change in chaetal type, from capillary chaetae to hooded hooks. Abdominal lamellar shape (subject 55) varies among members of species, from triangular to rounded. They may be basally constricted [those with rounded lamellae, character 55(1), Figs. 12C, 12H], or without a basal constriction, being broad based [character 55(0), Fig. 12B]. The latter situation being generally observed among members of species possessing more triangular lamellae, tapering to pointed tips (Fig. 12D). Subject 55 is not applicable to members of

Phyllochaetopterus limicolus, however all other members of the outgroups have lamellae without a basal constriction [character 55(0)].

At the inner margins of chaetal rows, triangular to digitiform processes (subject 56) may be present [character 56(1), Figs. 12C, 12F, 12H, 12I]. Jones termed these structures dorsal medial lobes (DML) for notopodia and ventral medial lobes (VML) for neuropodia. Uebelacker \& Jones (1984) believed that they may occur universally throughout the family, but this is a 
1319 viewpoint not shared by the current authors. They are absent [character 56(0)] in members of the

1320 outgroups, however, this subject is considered not applicable to Phyllochaetopterus limicolus. In

1321 members of magelonid species, the size of the medial lobes in the abdomen varies widely, from

1322 minute and difficult to discern, to long and conspicuous structures, e.g., among members of

1323 Magelona montera. For comparison, the medial lobes were coded depending on their height

1324 relative to abdominal hooded hooks (subject 57): character 57(0) for members of species in

1325 which they are smaller than the hooks and character 57(1) when they are larger than the hooks.

1326 The latter subject is not applicable to the outgroups.

1327

The abdominal lamellae may extend behind chaetal rows (subject 58). This postchaetal

1328

expansion (previously termed the interlamella) is often more conspicuous in the anterior

1329

abdomen and when present [character 58(1), Figs. 12C, 12E and 12H] it may be rounded to

1330

triangular. Among members of species in which it is absent [character 58(0), Figs. 12B, 13D and

1331

14B], the abdominal hooded hooks arise from a distinct ridge (Figs. 12B and 13E). Postchaetal

1332

expansions are absent among members of the outgroups, whilst in members of

1333

Phyllochaetopterus limicolus the subject is considered inapplicable.

1334

As stated above, abdominal lamellae (subject 59) in magelonids are generally

1335

symmetrical in size and shape [character 59(0), Figs. 12D and 12H] as in members of the

1336

outgroups. However, in some magelonids, such as members of Magelona alleni, the lamellae are

1337

sub-equal between the two rami [character 59(1), Fig. 12G]. This subject is inapplicable to

1338

members of Phyllochaetopterus limicolus.

Characters of lateral abdominal pouches (subjects 60-65)

1340 Lateral pouches (subject 60) are present among members of some species of magelonids, located

1341 laterally between the parapodia of certain abdominal chaetigers [character 60(1)]. Their presence 
1342 [character 60(1)] or absence [character 60(0)] is often a key diagnostic feature, although their

1343 function is currently unknown (Jones, 1968; Mortimer \& Mackie, 2014). Pouches vary in

1344 morphology, direction of opening, number, and location. However, descriptions of these

1345 structures have generally been limited, often only indicated as being present or absent. Fiege et

1346 al. (2000) described two types of lateral pouch: $\Sigma$-shaped occurring in the anterior abdomen,

1347 generally paired, and opening anteriorly, whilst C-shaped pouches were noted to occur on

1348 median and posterior abdominal chaetigers, opening posteriorly and occurring in pairs or singly.

1349 Mortimer (2010) suggested these terms should be abandoned to enable variations to be better

1350 understood, and subsequently, Mortimer \& Mackie (2014) and Mortimer (2019) detailed further

1351 pouch morphologies. Following the latter authors, lateral pouches when present, were coded

1352 based on six subjects: arrangement of pouches (subject 61), direction of pouch openings

1353 (subject 62), posteriorly open lateral pouch arrangement (subject 63), lateral pouch distribution

1354 (subject 64), and margins of posteriorly open pouches (subject 65). Firstly, pouches are either

1355 all paired [character 61(0), Fig. 13C] or unpaired [character 61(1), Fig. 13B], or both types are

1356 present [character 61(2), Fig. 13A]. Secondly, both anteriorly and posteriorly opening pouches

1357 are present [character 62(1), Figs. 13A, 13E and 13G], e.g., members of Magelona johnstoni, or

1358 only posteriorly open pouches are present [character 62(0), Figs. 13B and 13C]. Posteriorly open

1359 pouches may occur on alternate segments [character 63(1), Fig. 13B], or on consecutive

1360 segments [character 63(0), Fig. 13C], or alternatively, they may be present on both consecutive

1361 and alternating chaetigers at varying points along the abdomen [character 63(2)], e.g., members

1362 of M. pulchella. Fiege et al. (2000) described the first occurrence of lateral pouches on the body

1363 as an important distinguishing character between members of species and is relatively easy to

1364 observe. In members of some species, lateral pouches are present throughout most of the 
1365 abdomen [character 64(0)], whilst in others they are present only on median and posterior

1366 chaetigers [character 64(1)], and in others restricted to the posterior abdomen only [character

1367 64(2)] (Mortimer \& Mackie, 2014). Whilst the margins of most posteriorly open pouches are 1368 smooth [character 65(0)], in members of some species, such as M. pacifica, they are medially 1369 split [character 65(1), Fig. 13H]. One of the biggest problems in coding these characters is the 1370 lack of information known about the posterior regions of many magelonids, whilst some pouches 1371 are present throughout most of the abdomen and are therefore likely to be recorded even in 1372 posteriorly incomplete specimens. For members of species in which pouches only occur in the 1373 extreme posterior region, pouches are likely to be recorded as absent if individuals are described 1374 from anterior fragments only. Lateral pouches are present [character 60(1)] in members of 1375 outgroups, Laonice cirrata and Prionospio ehlersi. These are paired [character 61(0)], 1376 posteriorly open [character 62(0)] and with smooth margins [character 65(0)]. They occur on 1377 consecutive segments [character 63(0)] on median and posterior chaetigers [character 64(1)]. 1378 Lateral pouches are absent [character $60(0)]$ in the remaining members of the outgroups.

\section{Characters of post-chaetiger 9 chaetae (subjects 66-74)}

Magelonids possess hooded hooks in the abdominal region (subject 66), located between the lamellae and medial lobes (when present). They are present [character 66(1)] in members of all magelonid taxa and members of the outgroup except Phyllochaetopterus limicolus [character 66(0)]. In magelonids, hooded hooks generally occur in one row per ramus, but recent studies suggest that they can occur in two rows, at least in the medial part of the rami (Mortimer et al., 2020) (Fig. 14B for members of M. equilamellae). Although, this may prove to be an important considered in this study. 

members of Magelona minuta and M. papillicornis, Figs. 14C and 14D] with one secondary tooth above the man fang, tridentate [character 67(1), Fig. 14E], with two secondary teeth above,

1391

1392

or polydentate [character $67(2)$ ], having three or more secondary teeth above the main fang.

Quadridentate, pentadentate, and hexodont hooks (Figs. 14F-H) have been recorded among Magelonidae, with some polydentate individuals carrying more than one type of hook. Where members of species have been recorded with more than one, the dentition which predominates was coded. For example, members of $M$. minuta are recorded to possess the odd sporadic tridentate hook (Mills \& Mortimer, 2018), but carry predominately bidentate hooks. Members of the outgroup Spio filicornis possess bidentate [character 67(0)] hooded hooks, whilst members of Prionospio lighti, P. ehlersi and Laonice cirrata possess polydentate hooded hooks [character 67(2)]. This subject is not applicable to members of Phyllochaetopterus limicolus, which have uncini.

Jones (1971) was the first author to draw attention to the fact that in members of some species the hook at the base of the lamellae (subject 68) may be smaller than the others [character 68(1), Figs. 12E and 14I]. Later it has been suggested that not only their size but also their appearance may indicate groups of closely related species (Magelona pitelkai, M. hobsonae, M. hartmanae, M. dakini, M. filiformis, M. capensis). However, Brasil (2003), upon re-examination of the holotypes of the first four species, observed no differences in shape, only differences in size. Among members of other magelonid species, the hook at the base of the lamellae is of equivalent size to the rest [character 68(0), Fig. 13D]. The subject is not applicable to members of the outgroups. 
the abdominal region of members of four undescribed species from the Gulf of Mexico;

\section{2}

Magelona sp. C, possessing an enlarged recurved hook with a minute apical tooth in each ramus;

Magelona sp. D, with enlarged hooded apical spines (Fig. 12F); Magelona sp. E, possessing

recurved spines. Hernández-Alcántara \& Solís-Weiss (2000) formally described members of two

of these species (Magelona spp. D and H) as Meredithia spinifera and M. uebelackerae,

1417 respectively, erecting the new genus based on this distinctive feature. The authors stated that

1418 "although this character is the only one that differentiates this group from the other species

1419 described in this monogeneric group, it is sufficiently distinctive to make it a valid generic level

1420 character.” However, Mortimer \& Mackie (2003) felt that stronger evidence for recognising

1421 other genera within the family was needed, preferring to follow Uebelacker \& Jones (1984) by

1422 including species with enlarged abdominal chaetae in Magelona, and synonymising Meredithia

1423 with Magelona. Two additional species with enlarged abdominal chaetae have since been

1424 described: Magelona magnahamata and Magelona falcifera. For the current analysis, the

1425 presence [character 69(1)] and absence [character 69(0)] of enlarged chaetae in the abdomen was

1426 noted as well as the morphology of the distal ends (subject 70), i.e., recurved [character 70(0),

1427 Fig. 14K], spine-like [character 70(1)], or an enlarged normal hook [character 70(2)]. Enlarged

1428 hooks are not present in members of the outgroups [character 69(0)], therefore subject 70 is not

1429 applicable (together with subject 69 for Phyllochaetopterus limicolus).

The number of hooded hooks per ramus in abdominal chaetigers (subject 71) is variable

and characters distinguished as eight or more hooks per ramus [character 71(0), e.g., members of

1432 Magelona equilamellae, Fig. 14B, and members of outgroups Prionospio lighti, P. ehlersi and 
1433 Laonice cirrata], and less than eight [character 71(1), Fig. 14J], such as among members of $M$.

1434 papillicornis and members of outgroup Spio filicornis. This separation in number was based on

1435 the examinations of specimens from a number of different species and assessing several

1436 chaetigers of the same specimen. As variations in the number of hooks have been observed along

1437 the length of the abdomen (e.g., members of M. papillicornis have a higher number of hooks in

1438 the mid-abdominal region), the number of hooks was counted in the anterior abdomen. Subject

143971 is not applicable for members of Phyllochaetopterus limicolus. Hooks may be arranged in two

1440 formations (subject 72): occurring in two groups per ramus with main fangs arranged face-to

1441 face (vis-à-vis) [character 72(0), Figs. 12C, 12G, 12H, 14B and 14J], or in unidirectional rows

1442 (vis-à-dos) with main fangs pointing in one direction [character 72(1), Fig. 13D]. Vis-à-vis

1443 orientation is more common among members of the Magelonidae, whilst vis-à-dos is present for

1444 all members of the outgroups (subject 72 is not applicable to P. limicolus).

$1445 \quad$ Neuropodia with sabre chaetae (subject 73) are present [character 73(1)] among

1446 members of the spionid outgroups. Such chaetae are absent [character 73(0)] among members of

1447 Phyllochaetopterus limicolus and all ingroup species.

1448 Internal support chaetae, or aciculae (subject 74), have been reported among members of

1449 several magelonid species. These curved and slender chaetae support the bases of the lamellae,

1450 and it is possible that they are more prevalent among members of species with larger abdominal

1451 lamellae. The proximal ends of the aciculae may overlap in the junction between the noto- and

1452 neuropodia (Figs. 12C and 12H). Notes on their presence [character 74(1)] or absence [character

$145374(0)]$, as well as their description, are poorly reported in the literature. Jones (1978) stated that

1454 all magelonid abdominal chaetigers are supported by these structures, although this is not an

1455 observation supported by the current authors. Aciculae are generally more conspicuous in larger 
1456 specimens, whilst slide preparations of parapodia may be necessary for smaller individuals. The

1457 relative obscurity of aciculae may be a factor in the limited inclusion in descriptions of

1458 specimens. Aciculae are absent in all members of the outgroups [character $74(0)$ ].

1459 Characters of body pigmentation (subjects 75-76)

1460 Among members of some species pigmentation in the posterior thorax (subject 75) is evident

1461 even in fixed material [character 75(1)], often deep reddish to brown in colour. Very little is

1462 known about this character beyond presence or absence [character $75(0)]$. When pigment is

1463 present, there are two patterns of distribution (subject 76). Among members of some species,

1464 such as Magelona alleni and M. equilamellae, the pigment forms a distinct band [character

$146576(0)$, Figs. 15A and 15C], often from chaetigers 4/5 to 8; among members of other species only

1466 light, dispersed pigmentation in posterior chaetigers is noted [character 76(1)], e.g., members of

1467 M. symmetrica. Moreover, members of Magelona fasciata Mortimer, Kongsrud \& Willassen

1468 (2021) from West Africa are noted to have distinct stripy pigmentation over much of the body

1469 (Fig. 15B). Pigmentation on the palps of members of some species, such as M. mirabilis, has

1470 been noted (see Mills \& Mortimer, 2019: fig. 4.2.6). However, insufficient information is

1471 currently available to enable coding of this character. Relevant pigmentation is absent in

1472 members of the outgroups [character 75(0)].

1473 Characters of granular bodies (subjects 77-78)

1474 The surfaces of segments can have granular bodies (subject 77) appearing as spots, distributed in 1475 a variety of patterns on both the thorax and abdomen, and remain upon fixation and preservation 1476 of material [character 77(1), Figs. 6A, 9H and 15C]. Jones (1971) felt that this characteristic had 1477 no systematic significance. However, patterns appear to be species specific, particularly those of 1478 the thoracic region. The latter may appear as transverse stripes (Fig. 16A) or distinct smaller 
1479 circular regions adjacent to the parapodia (Fig. 16B). Abdominal interparapodial areas

1480 commonly have granular bodies occurring in patches (subject 78) [character 78(1), Figs. 16C

1481 and 16D] among members of Magelonidae and may cover a large part of the lateral region

1482 between parapodia of adjacent chaetigers. Both thoracic and abdominal bodies may stain with

1483 dyes such as Rose Bengal, or be highlighted by methyl green, in which the granules appear white

1484 against the contrasting stain (Figs. 16B and 16C). Whilst staining patterns can be extremely

1485 useful in separating members of species (Figs. 11D, 11E and 16A), it was not included in the

1486 current study. However, it may prove useful in the future, as more methyl green patterns are

1487 described. Granular bodies and abdominal interparapodial areas are absent in members of the

1488 outgroups [character 77(0), character 78(0)].

1489 Tube construction (subject 79)

1490 In general, magelonids are relatively motile, burrowing more or less continually through

1491 sediments (Jumars, Kelly \& Lindsay, 2015), without constructing tubes [character 79(0)].

1492 However, members of several species are known to build distinct multi-layered tubes covered in

1493 sand [character 79(1), Fig. 16E]. Mills \& Mortimer (2019) investigated the permanency of these

1494 tube-lined burrows among members of the European species, Magelona alleni. Members of

1495 some species, such as M. filiformis, have been described living in fragile tubes of a secretion to

1496 which sand grains adhere. These are not considered as tubes per se but are believed to be the

1497 worm's response to removal from its habitat. Members of the outgroups, Spio filicornis and

1498 Phyllochaetopterus limicolus, are known to build distinct tubes [character 79(1)], whilst the

1499 situation is unknown for members of Prionospio lighti, P. ehlersi and Laonice cirrata.

1500

1501 Characters not included, but of possible future consideration 
1502

1503

1504

1505

1506

1507

1508

1509

1510

1511

1512

1513

1514

1515

1516

1517

1518

1519

1520

1521

1522

1523

1524

\section{Prostomial features}

Magelonid prostomia may carry distinct markings on either side of the dorsal muscular ridges

(Figs. 4A, 4C-E, 5A, 5B and 5E), the pattern of which is generally species specific, whilst members of other species show no obvious markings (Figs. 4G and 4H). Although this can be an important diagnostic feature, this was not included in the current analysis due to difficulties in adequately describing this character.

\section{Thoracic chaetae}

Mills \& Mortimer (2018) highlighted differences in the number of thoracic chaetae among members of different species, and additionally observed variations in number of chaetae on different chaetigers of the same animal for members of several magelonid species. They noted that members of some species, such as Magelona cincta, have distinctly splayed chaetae in the posterior thorax when compared to members of other species. Whilst these three characteristics may prove to be useful, limited information is currently available, prohibiting their use in the current study.

\section{Features of the thoracic region}

More recently, several additional characteristics of the thoracic region have been noted. Mortimer \& Mackie (2009) and Mortimer (2019) described distinct V-and X-shaped ventral markings in the mid-thoracic region of members of species such as Magelona crenulifrons and M. pulchella (Figs. 11D and 11E). Among members of other magelonid species, thoracic ventral pads/swellings have been recorded, such as those observed among members of M. mirabilis (Mortimer \& Mackie, 2014) or M. obockensis (Mortimer, 2010). These swellings may be oval to reniform in shape (Figs. 11F and 11G). However, occurrence of these two features in members of the majority of species is unknown. 
Although, the constriction at the thorax/abdomen junction can be marked and may vary

1526

1527

1528

1529

1530

1531

1532

1533

1534

1535

1536

1537

1538

1539

1540

1541

1542

1543

1544

1545

1546

1547

between species, the extent to which it is constricted can be greatly influenced by preservation

and fixation and was not considered herein. Despite this, however, it is a character worthy of

further study, and should be detailed more fully in future descriptions. Brasil (2003) indicated

that members of Octomagelona present a constriction despite lacking a 9th "thoracic" chaetiger, suggesting that the character may not simply indicate a transition between the thorax and the abdomen.

Whilst average length and the average number of chaetigers appear to be species specific, the lack of information for members of many species prohibits this as a character in the analysis at the present time. Many individuals of magelonid species are described from anterior fragments only. The breadth of individuals, however, may prove an important character. Members of species like Magelona minuta, true to their name, rarely attain widths greater than $0.5 \mathrm{~mm}$, being somewhat long and slender. Members of species such as M. alleni are distinctly broad and stout, often measuring over $1 \mathrm{~mm}$ in width (Mortimer, Kongsrud \& Willassen, 2021). Additionally, Mills \& Mortimer (2019) indicate that stouter magelonid species generally are shorter in comparison to width and have a fewer number of chaetigers. This is something which warrants further investigation.

\section{Abdominal hooded hooks}

Mills \& Mortimer (2018) highlighted differences in the angle between the main fang and secondary teeth in abdominal hooded hooks of members of several magelonid species and further suggested characteristics such as the width and roundedness of the main fang, and the angle between it and the axis of the hook shaft, as noted for example by Jones $(1963,1977)$, may prove useful in future studies. 


\section{Pygidium}

1549 Magelonids possess a pair of digitiform pygidial cirri on either side of the pygidium (Figs. 16F

1550 and 16G). Uebelacker \& Jones (1984) noted the presence of three pygidial cirri on individuals of

1551 an undescribed species, Magelona sp. B, from the Gulf of Mexico, however, it is believed that

1552 the third cirrus may actually represent the elongated, rounded tip of the pygidium itself. As this is

1553 the only magelonid that has been described with this feature, the number of pygidial cirri was not

1554 included in this study. Mills \& Mortimer (2019) noted that pygidial cirri of members of M. alleni

1555 were more truncate and triangular (Fig. 16H) in comparison to other magelonids, however, this is

1556 something that warrants further investigation.

1557 Whilst Rouse (2001) stated that the magelonid anus is terminal, early illustrations from

1558 McIntosh (1878) of members of Magelona mirabilis (possibly M. johnstoni; see Fiege, Licher \&

1559 Mackie, 2000) clearly show the anus in a distinctly ventral position. Unfortunately, for members

1560 of many species the pygidium is unknown, or the amount of information provided by authors has

1561 been relatively limited. When included in descriptions, the pygidium is often drawn from a

1562 dorsal perspective, thus conclusions about the position of the anus are often difficult to make.

1563 Mills \& Mortimer (2019) investigated the situation among members of five European species,

1564 concluding that the anus was ventral in members of four species, whilst in the latter, M. alleni, it

1565 was distinctly terminal in position (Fig. 16H). Subsequently, Mortimer, Kongsrud \& Willassen

1566 (2021) have noted that members of Magelona fasciata from West Africa also have a terminal

1567 anus. Whilst this may prove to be a valuable character in subsequent studies, the lack of

1568 information among individuals of many species precludes inclusion in the current study.

1569 Inferring phylogenetic hypotheses 
1570 Phylogenetic inferences were performed using PAUP* 4.0b10 (Swofford, 2001), with all

1571 observations weighted equally and multiple subject-predicate relations ("multistate characters")

1572 treated as non-additive (Table S1). The following command string was executed (Larkin, Neff \&

1573 Simpson, 2006; Fitzhugh, 2010b; Fitzhugh et al., 2015; Nogueira et al., 2010; Nogueira,

1574 Fitzhugh \& Hutchings, 2013): hsearch enforce $=$ no start $=$ stepwise addseq $=$ random nreps $=$

1575100000 nchuck $=5$ chuckscore $=1$; hsearch enforce $=$ no start $=$ current chuckscore $=$ no. As

1576 noted earlier in Methodological considerations, the commands used are not tantamount to what

1577 has been incorrectly called "parsimony analysis." Rather, implementation of these commands is

1578 consistent with abductive reasoning for the purpose of causally accounting for differentially

1579 shared characters by way of common causes as fully as possible. Character transformation series

1580 were examined using Mesquite 3.61 (Maddison \& Maddison, 2011).

\section{RESULTS}

1582 The phylogenetic inference using data in Table S1 produced 2,417,600 cladograms of 404 steps

1583 each. The consistency index for each is 0.243 and retention index is 0.744 . The strict consensus

1584 tree for all cladograms is shown in Fig. 17. What is notable is the mix of clades and grades

1585 within the monophyletic Magelonidae. A consequence of the overall arrangements of these

1586 phylogenetic hypotheses is that there can be no generic-level phylogenetic hypotheses that can

1587 be formally named without also incurring paraphyletic taxa. The result, as will be pointed out in

1588 the DISCUSSION, is that the only (composite) phylogenetic hypothesis that can be formally

1589 recognised is Magelonidae. The Magelonidae clade involves seven phylogenetic hypotheses

1590 referring to the following respective characters:

1591

1592

1. Shovel-shaped prostomium: absent $(0) \rightarrow$ present $(1)$

2. Nuchal organs: $\quad$ present $(1) \rightarrow$ absent $(0)$ 
1593

1594

1595

1596

1597

1598

1599

1600

1601

1602

1603

1604

1605

1606

1607

1608

1609

1610

1611

1612

1613

1614

1615

8. Prostomial ridges: $\quad$ absent $(0) \rightarrow$ present $(1)$

10. Palp origin: $\quad$ dorsal $(0) \rightarrow$ ventral $(1)$

11. Palp surface: $\quad$ non-papillate $(0) \rightarrow$ papillate $(1)$

14. Burrowing organ: $\quad$ absent $(0) \rightarrow$ present $(1)$

15. Body regionation: non-magelonid $(0) \rightarrow$ magelonid-like $(1)$.

The present results indicate that Octomagelona cannot be maintained, given that the clade is nested within Magelona. And while the arrangements of the phylogenetic hypotheses among all the cladograms impose severe limits that only allow for formally recognising Magelonidae, there are no phylogenetic hypotheses to which the type genus Magelona refer. The implications of these results will be addressed in the DISCUSSION.

In addition to the Magelonidae, there are 20 additional clades, indicated by letters a through $\mathbf{t}$ in Fig. 17, from which phylogenetic hypotheses deserve mention. None of these clades can be formally named, given the various grade groups also present among the cladograms.

Whilst serving as synapomorphies for these clades, those characters that are homoplasious (including reversals and convergence) are denoted by an asterisk $(*)$ :

Clade a -22 . Chaetigers 1-7 notopodial lamellae shape: foliaceous (1) $\rightarrow$

$$
\text { filiform }(0)^{*}
$$

26. Chaetigers 1-7 neuropodial lamellae position relative to neurochaetae: postchaetal $(0) \rightarrow$ subchaetal $(1)^{*}$

28. Chaetigers $1-7$ neuropodial lamellae shape: foliaceous $(1) \rightarrow$ filiform $(0)^{*}$

Clade b - 5. Prostomial horns: present $(1) \rightarrow$ absent $(0)^{*}$

20. Development of neuropodia along thorax: different in some chaetigers, 
1616

1617

1618

1619

1620

1621

1622

1623

1624

1625

1626

1627

1628

1629

1630

1631

1632

1633

1634

1635

1636

1637

1638
$(1) \rightarrow$ all similar $(0)^{*}$

26. Chaetigers 1-7 neuropodial lamellae position relative to neurochaetae: subchaetal $(1) \rightarrow$ postchaetal $(0)^{*}$

30. Chaetigers 1-7 lengths of noto- and neuropodial lamellae: notopodial longer $(1) \rightarrow$ equivalent $(0)^{*}$

Clade c - 4. Prostomium distal shape: straight (2) $\rightarrow$ triangular (0)*

6. Shape of prostomial horns: rudimentary $(1) \rightarrow \operatorname{distinct~}(0)^{*}$

46. Chaetiger 9 neuropodial lamellae position: postchaetal $(0) \rightarrow$ subchaetal $(1)^{*}$

Clade d - 67. Post-chaetiger 9 noto- and neuropodial hooded hooks dentition: bidentate $(0) \rightarrow$ tridentate $(1)^{*}$

Clade e -16 . Number of anterior body region chaetigers: nine $(1) \rightarrow$ eight $(0)$

18. Development of notopodia along thorax: all similar $(0) \rightarrow$ different in some chaetigers $(1)^{*}$

Clade f - 29. Chaetigers 1-7 neuropodial filiform lamellae shape distal ends:

pointed (0) $\rightarrow$ distally expanded/scoop shaped (1)

60. Post-chaetiger 9 lateral pouches: absent $(0) \rightarrow$ present $(1)^{*}$

Clade g - 22. Chaetigers 1-7 notopodial lamellae shape: filiform (0) $\rightarrow$ foliaceous $(1)^{*}$

35. Chaetiger 8 notopodial lamellae shape: filiform $(0) \rightarrow$ foliaceous $35(1)^{*}$

55. Post-chaetiger 9 lamellae shape: without basal constriction $(0) \rightarrow$ with basal constriction $(1)^{*}$

Clade h -12 . Number of rows of proximal palp papillae: $10-14(2) \rightarrow 4-8(1)^{*}$

43. Chaetiger 9 notopodial lamellae shape: filiform $(0) \rightarrow$ foliaceous $(1)^{*}$ 
75. Pigmentation in posterior thorax: present $(1) \rightarrow$ absent $(0)^{*}$

1640

Clade i - 18. Development of notopodia along thorax: different in some chaetigers (1) $\rightarrow$ all similar $(0)^{*}$

45. Chaetiger 9 dorsal superior lobes: absent $(0) \rightarrow$ present $(1)^{*}$

1643

Clade j - 38. Chaetiger 8 neuropodial lamellae position: subchaetal (1) $\rightarrow$ prechaetal

60. Post-chaetiger 9 lateral pouches: absent $(0) \rightarrow$ present $(1)^{*}$

Clade $\mathbf{k}-22$. Chaetigers 1-7 notopodial lamellae shape: foliaceous $(1) \rightarrow$ filiform $(0)^{*}$

57. Post-chaetiger 9 dorsal medial lobes length: smaller than hooks $(0) \rightarrow$ longer than hooks $(1)^{*}$

68. Post-chaetiger 9 hooded hooks adjacent to notopodial subchaetal or neuropodial suprachaetal lamellae: same size $(0) \rightarrow$ smaller than rest $(1)^{*}$

Clade 1 - 46. Chaetiger 9 neuropodial lamellae position: subchaetal (1) $\rightarrow$ prechaetal

Clade $\mathbf{m}-4$. Prostomium distal shape: straight (2) $\rightarrow$ rounded (1)

5. Prostomial horns: present $(1) \rightarrow$ absent $(0)^{*}$

1657

42. Chaetiger 9 notopodial lamellae height: elongate $(1) \rightarrow \operatorname{low}(0)^{*}$

50. Lengths of chaetiger 9 fascicles relative to chaetigers $1-8$ fascicles: chaetigers 1-8 (0) $\rightarrow$ mucronate (1) 
1662

1663

1664

1665

1666

1667

1668

1669

1670

1671

1672

1673

1674

1675

1676

1677

1678

1679

1680

1681

1682

1683

1684
55. Post-chaetiger 9 lamellae shape: with basal constriction $(1) \rightarrow$ without basal constriction (0)*

61. Post-chaetiger 9 lateral pouch arrangement: unpaired $(1) \rightarrow$ both paired and unpaired (2)*

62. Direction of lateral pouch openings: posteriorly $(0) \rightarrow$ posteriorly and anteriorly (1)*

Clade n - 13. Number of rows of distal palp papillae: four $(1) \rightarrow t$ wo $(0)^{*}$

Clade o - 36. Chaetiger 8 margins of foliaceous notopodial lamellae: smooth $(0) \rightarrow$ bilobed (2)

44. Chaetiger 9 notopodial foliaceous lamellae margins: smooth $(0) \rightarrow$ crenulate $(1)^{*}$

Clade p - 72. Post-chaetiger 9 arrangement of hooded hooks: vis-à-vis $(0) \rightarrow v i s-\grave{a}-d o s$ $(1)^{*}$

Clade q - 52. Shape of thoracic interparapodial margins: straight $(0) \rightarrow$ rounded, bulbous (1)*

60. Post-chaetiger 9 lateral pouches: present $(1) \rightarrow$ absent $(0)^{*}$

Clade $\mathbf{r}-\quad 26$. Chaetigers 1-7 neuropodial subchaetal lamellae position relative to neurochaetae: varying in position along thorax $(1) \rightarrow$ same position along thorax $(0)^{*}$

41. Chaetiger 9 notopodial lamellae positions: postchaetal $(0) \rightarrow$ subchaetal $(1)^{*}$

Clade s - $\quad$ 57. Post-chaetiger 9 dorsal medial lobes length: smaller than hooks $(0) \rightarrow$ longer than hooks $(1)^{*}$ 
1685

1686

1687

1688

1689

1690

1691

1692

1693

1694

1695

1696

1697

1698

1699

1700

1701

1702

1703

1704

1705
Clade $\mathbf{t}-\quad$ 7. Prostomium dimensions: longer than wide $(0) \rightarrow$ wider than long $(2)^{*}$

33. Chaetigers 1-8 lengths of noto- and neuropodial capillary chaetae: equivalent $(0) \rightarrow$ neuropodial longer $(2)^{*}$

\section{DISCUSSION}

A point mentioned in the RESULTS is that only one composite phylogenetic hypothesis can be formally recognised, i.e., Magelonidae. There can be no phylogenetic hypothesis(es) to which the name Magelona refers that is not redundant with Magelonidae. From a nomenclatural, as opposed to strictly scientific perspective, this assertion is contrary to what is required by the International Code of Zoological Nomenclature (ICZN; 1999): at least one formal name at the rank of genus must be established relative to the ranks of family and species. The present results offer another good example (see also Fitzhugh, 2008a, 2010b; Nogueira, Fitzhugh \& Rossi, 2010; Nogueira et al., 2017) of the conflict that can occur between the science of biological systematics and a mandated international nomenclature system that is not entirely aligned with the goal of that science. Compromise between these two positions currently favours the nomenclatural system, but by properly acknowledging that formal taxon names should be defined in terms of being explanatory hypotheses (cf. Methodological considerations), the conflict between naming and scientific practice can be somewhat mitigated. Emendations of the formal names Magelonidae, Magelona, and Octomagelona in relation to the phylogenetic hypotheses inferred in this study are presented below.

\section{Morphological characters in future specimen descriptions}


1706 Various authors have discussed the "crucial morphological characters" in differentiating

1707 members of magelonid species. Jones (1963), in his review of magelonids of the Gulf of Mexico

1708 listed six: (1) the fine structure of the hooded hooks of the posterior region (subject 67); (2) the

1709 presence or absence of prostomial horns (subject 5); (3) the presence or absence of medial

1710 lamellae in the posterior region (subject 56); (4) the presence or absence of specialised chaetae of

1711 various types on chaetiger 9 (subject 51); (5) the morphology of the anterior lateral lamellae

1712 (subjects 18-30, 34-49); and (6) the relative dimensions of the prostomium (subject 7). Blake

1713 (1996c) listed seven “principal diagnostic characters important in differentiating species," adding

1714 to Jones' list the following: (7) presence or absence of dorsal median lobes on thoracic notopodia

1715 (subjects 24, 37, 45, superior dorsal lobes); (8) presence and location of lateral pouches between

1716 abdominal segments (subjects 60, 64); and (9) the presence/absence and form of interlamellae on

1717 abdominal parapodia (herein termed the postchaetal expansion behind chaetal rows, subject 58).

1718 Brasil (2003: fig. 23) concluded that the position and form of noto- and neuropodial lamellae,

1719 and the division of the thorax into three different blocks of segments (i.e., A - all anterior

1720 chaetigers with identical morphology; B - first eight chaetigers being identical but possessing a

1721 ninth chaetiger having a distinct morphology; and C - in which the first seven identical

1722 chaetigers differ from chaetigers eight and nine) reflected the relationships found within clades

1723 and sub-clades within the family.

1724 Of the characters previously mentioned, the current results suggest those of particular

1725 importance to be included in future descriptions of members of species are: (1) the

1726 presence/absence of prostomial horns (in addition to their form, i.e., distinct or rudimentary); (2)

1727 the relative dimensions of the prostomium; (3) the morphology of the anterior lamellae,

1728 including presence/absence of superior dorsal lobes; (4) the presence/absence of specialised 
1729 chaetae on chaetiger 9; and (5) the presence of lateral abdominal pouches. As highlighted by

1730 Brasil (2003), the thoracic lamellae are extremely diagnostic. Great care must be taken to fully

1731 describe and illustrate all thoracic chaetigers in descriptions, taking into account the size, shape

1732 and position of thoracic lamellae and whether/how they vary along the thorax. Often variations

1733 in position of the lamellae may be subtle between thoracic parapodia, particularly that of filiform

1734 subchaetal neuropodial lamellae. It is particularly important to examine the parapodia of

1735 chaetigers 8 and 9.

1736 In addition to the characters already highlighted, the prostomial distal shape (subject 3),

1737 the number of prostomial ridges (subject 9), the shape of thoracic interparapodial margins

1738 (subject 52), the arrangement of abdominal lateral pouches (subject 63) and the arrangement of

1739 abdominal hooded hooks (subject 72) warrant further investigation and inclusion in descriptions.

1741 Systematics

1742 Magelonidae Cunningham \& Ramage, 1888 (1865), emended

1743 Type genus. Magelona F. Müller, 1858, by monotypy.

1744 Definition. A composite phylogenetic hypothesis (Fig. 17), causally accounting for (a) presence

1745 of a shovel-shaped prostomium, (b) absence of nuchal organs, (c) presence of prostomial ridges,

1746 (d) ventral palps with (e) papillate surfaces, (f) presence of a burrowing organ, and (g)

1747 magelonid-like body regionation.

1748

Within a reproductively isolated population of individuals in the past, the following

1749

causal events occurred: $\left(a^{\prime}\right)$ the presence of a shovel-shaped prostomium [character 1(1)]

1750 originated by unspecified mechanism(s) among individuals with a rounded prostomium 
1751 [character 1(0)], subsequent to which the novel character became fixed in the population by an 1752 unspecified mechanism(s); ( $\left.b^{\prime}\right)$ the loss of nuchal organs [character 2(1)] originated by

1753 unspecified mechanism(s) among individuals with nuchal organs [character 2(0)], subsequent to

1754 which the novel character became fixed in the population by an unspecified mechanism(s); $\left(\mathrm{c}^{\prime}\right)$

1755 the presence of prostomial ridges [character 8(1)] originated by unspecified mechanism(s)

1756 among individuals with no ridges [character 8(0)], subsequent to which the novel character

1757 became fixed in the population by an unspecified mechanism(s); ( $\left.d^{\prime}\right)$ the presence of ventrally

1758 inserted palps [character 10(1)] originated by unspecified mechanism(s) among individuals with

1759 dorsal palps [character 10(0)], subsequent to which the novel character became fixed in the

1760 population by an unspecified mechanism(s); ( $\left.\mathrm{e}^{\prime}\right)$ the presence of palps with papillae [character

1761 11(1)] originated by unspecified mechanism(s) among individuals with smooth palps [character

$176211(0)$ ], subsequent to which the novel character became fixed in the population by an unspecified

1763 mechanism $(s) ;\left(f^{\prime}\right)$ the presence of a burrowing organ [character $14(1)$ ] originated by unspecified

1764 mechanism(s) among individuals without such an organ [character 14(0)], subsequent to which

1765 the novel character became fixed in the population by an unspecified mechanism $(\mathrm{s}) ;\left(\mathrm{g}^{\prime}\right)$ the

1766 magelonid-like body [character 15(1)] originated by unspecified mechanism(s) among

1767 individuals without such body regionation [character 15(0)], subsequent to which the novel

1768 character became fixed in the population by an unspecified mechanism(s). Following character

1769 origin/fixation events $\left(\mathrm{a}^{\prime}\right)-\left(\mathrm{g}^{\prime}\right)$ was a population splitting event by unspecified mechanism(s)

1770 leading to individuals to which subsequent phylogenetic and specific hypotheses refer.

1771 Remarks. Results of the phylogenetic inferences by Brasil (2003: figs. 45 and 46; Fig. 18)

1772 acknowledged the monophyly of Magelonidae based on three of the synapomorphies also

1773 referred to in this study (cf. RESULTS): presence of a spade-shaped prostomium [character 
1774 1(1); phylogenetic hypothesis a' in the above Definition] and ventral insertion of papillated palps

1775 [characters 10(1), 11(1); phylogenetic hypotheses $\mathrm{d}^{\prime}$ and $\mathrm{e}^{\prime}$, respectively, in the above

1776 Definition]. Fauchald \& Rouse (1997: 103) stated evidence for monophyly of the Magelonidae

1777 as "Palps with rounded cross-section and a subdistal expanded area covered with papillae.

1778 Prostomium shovel-shaped." They additionally added that "chaetiger 9 often modified with

1779 unusual postchaetal lobes or different chaetae from those segments in front or behind it or both."

1780 This does not, however, follow for all members of species within the Magelonidae.

1781 The most basal group in the phylogenetic study by Brasil (2003) (Fig. 18: clade I) was

1782 that containing members of five species: Magelona californica, M. minuta, M. pettiboneae, M.

1783 papillicornis and Magelona sp. C of Uebelacker \& Jones (1984). Members of these species

1784 possess postchaetal lamellae [characters 21(0), 26(0), 34(0), 38(0), 41(0), 46(0)] of equivalent

1785 size [character 30(0)] in both rami of thoracic chaetigers. Clade b in the current study (Fig. 17)

1786 contains the same five species, along with members of five additional species: M. falcifera, M.

1787 fauchaldi, M. magnahamata, M. phyllisae and M. pygmaea. As well as the characters highlighted

1788 by Brasil (2003), individuals in this clade possess smooth [characters 23(0), 36(0), 44(0)],

1789 filiform [characters 22(0), 28(0), 35(0), 40(0), 43(0), 48(0)] lamellae without superior dorsal

1790 lobes [characters $24(0), 37(0), 45(0)]$. They also have prostomia the widths approximately

1791 equivalent to their lengths [character 7(1)], with straight [character 4(2)] and smooth [character

$17923(0)$ ] prostomial anterior margins, but only one pair of prostomial ridges [character $9(0)]$. As the

1793 names of two species within the clade highlight, i.e., M. minuta and M. pygmaea, members of

1794 these species rarely attain the sizes seen in members of other magelonid species and are slender

1795 and thread-like. No lateral abdominal pouches have been recorded among members of these

1796 species [character 66(0)], although as noted above (cf. Character descriptions) this should be 
1797 accepted with caution since lateral abdominal pouches are likely underreported within the

1798 family. As noted by Mills \& Mortimer (2018) for members of M. minuta, granular bodies

1799 [subject 77(1)] appear as distinct transverse stripes in the thoracic region, and spots or stripes of 1800 this kind are certainly reported in over half of these species. This is a character worthy of further 1801 investigation. members of eight species: Magelona mirabilis, M. johnstoni, M. riojai, M. crenulata, Magelona sp. B of Uebelacker \& Jones (1984), M. obockensis, M. jonesi and M. sacculata. The synapomorphies of the clade include the presence of mucronate chaetae [character 51(1)] and abdominal hooded hooks in a vis-à-dos orientation [character 72(1)], the latter of which is uncommon amongst members of Magelonidae. Clade m (Fig. 17) in the present study includes all the above species (except M. jonesi which will be discussed below) and additionally members of M. conversa, M. debeerei, M. parochilis, Magelona sp. A of Uebelacker \& Jones (1984) and M. tinae. Members of these species possess longer than wide prostomia [character 7(0)], with rounded [character 4(1)], smooth anterior margins [character 3(0)], carrying two pairs of prostomial ridges [character $9(1)]$ but lacking prostomial horns [character 5(0)]. The development of lamellae along the thorax is different [characters 18(1), 20(1)], particularly the lamellae of chaetiger 9 which are low and broad [characters 42(0), 47(0)] in comparison to the elongate lamellae of preceding chaetigers. In addition to the chaetae of chaetiger 9 being mucronate, they are shorter than those occurring on chaetigers $1-8$ [character $50(1)]$. Lateral abdominal pouches are always present [character 60(1)] and whilst members of several species within the clade possess both anteriorly and posteriorly open pouches [characters $62(1)$ ], only the latter is present in members of other species [character 62(0)]. Clade $\mathbf{m}$ is further divided into 
1820 clades $\mathbf{o}$ and $\mathbf{p}$ (Fig. 17), separating the species based on arrangement of abdominal hooks (clade 1821 o with vis-à-vis and clade $\mathbf{p}$ with vis-à-dos). Clade $\mathbf{m}$ contains members of the species referred 1822 as a "Magelona mirabilis" group noted by several previous authors (Mortimer \& Mackie, 2003; 1823 Clarke et al., 2010; Zhou \& Mortimer, 2013). Clarke et al. (2010) additionally suggesting the 1824 arrangement of abdominal hooks separated members of species within the group.

As noted above, Magelona jonesi in the present study is plesiomorphic to all magelonid species in clade a (Fig. 17). However, despite possessing tapering chaetae in chaetiger 9 [character 51(0)], similar to preceding chaetigers, in the analysis of Brasil (2003) members of $M$. jonesi occurred in clade VIII.4, the synapomorphies of which were the presence of mucronate chaetae [character 51(1)] and abdominal hooded hooks in vis-à-dos orientation. Members of this species are in need of redescription and this may help to resolve the situation in a future study. It is perhaps the orientation of the abdominal hooded hooks which is in most need of examination. Whilst Hartmann-Schröder (1980) illustrated the abdominal hooks in a vis-à-dos orientation, she made no mention of that orientation in her description. Looking at her neuropodial figures (Hartmann-Schröder, 1980: figs. 116 and 117), several hooks are drawn facing anteriorly. It has been recently highlighted by Mortimer et al. (2020) that $M$. filiformis, a species also originally recorded as possessing vis-à-dos hooks and occurring in clade VIII.3 of Brasil (2003: fig. 47; Fig. 18) along with M. pacifica, has in fact a vis-à-vis orientation. This misinterpretation of orientation can happen in members of species in which the hooks are not split equally between the two groups of a ramus, particularly if the quality of the material is poor. This warrants further clarification for $M$. jonesi and also $M$. pacifica. Unfortunately for the latter species, the abdominal hooks in the type material are mostly all broken (Mortimer et al., 2012) making it extremely difficult to discern. This may explain why these three species, M.jonesi, M. filiformis 
1843 and $M$. pacifica were part of clade VIII.2 with members of species possessing mucronate 1844 chaetae in Brasil's (2003) study.

Clade $\mathbf{k}$ in the current results (Fig. 17) contains members of five species: Magelona

1846

1847

1848

1849

1850

1851

1852

1853

1854

1855

1856

1857

1858

1859

1860

1861

1862

1863

1864

1865

dakini, M. filiformis, M. hartmanae, M. hobsonae and M. pitelkai. They share similarities in possessing prostomia which are longer than wide [character 7(0)], with straight [character 4(2)], smooth anterior margins [character 3(0)] formed into rudimentary horns [character $6(0)$ ], and which carry two pairs of prostomial ridges [character 9(1)]. Individuals have similar development of lamellae along the thorax in the notopodia [character 18(0)] but varying development in the neuropodia [character 20(1)]. They possess smooth edged [characters 23(0), 36(0), 44(0)], filiform thoracic lamellae [characters 22(0), 28(0), 35(0), 40(0), 43(0), 48(0)] which are larger in the notopodia [character 31(1)], and basally constricted abdominal lamellae [character 55(1)]. Posteriorly open lateral abdominal pouches are reported [character 60(1)] in all but one species, $M$. hobsonae, however members of this species are only known from short anterior fragments, so this character needs verification. Members of three species, M. hartmanae, M. hobsonae and M. pitelkai, within this clade also possess pennoned chaetae of chaetiger 9 [character 51(2)].

Perhaps worth of noting is clade n (Fig. 17), which includes members of species possessing prostomia with distinct horns [character 6(1)], triangular anterior margins [character $4(0)$ ] and two pairs of prostomial ridges [character 9(1)]. Specimens also possess foliaceous notopodial thoracic lamellae [characters 22(1), 35(1), 43(1)] which are larger than the neuropodial lamellae [character 30(1)]. Superior dorsal lobes are present on chaetigers 1-8 [characters 24(1), 37(1)]. The thoracic neuropodial lamellae are filiform [characters 28(0), 40(0),48(0)] with additional postchaetal expansions on chaetigers 8 and 9 [characters 39(1), 
1866 49(1)] (N.B. the latter needs verifying in Magelona anuheone). Abdominal lamellae are rounded 1867 with basal constrictions [character 55(1)]. Whilst nothing more can be concluded from clade $\mathbf{r}$ 1868 (Fig. 17), which contains numerous polytomies, characters such as prostomial width may prove 1869 to be important characters in other clades. Clade t contains members of four species (Fig. 17), 1870 M. berkeleyi, M. lenticulata, M. wilsoni and Magelona sp. J of Uebelacker \& Jones (1984), 1871 which all have wide prostomia [character 7(2)], rounded bulbous thoracic interparapodial 1872 margins [character 52(1)], and lack abdominal lateral pouches [character 60(0)].

\section{Magelona F. Müller, 1858, emended}

Maea Johnston, 1865 (see below)

Rhynophylla Carrington, 1865

1877

1878

1879

1880

1881

1882

1883

1884

1885

1886

1887

1888

Meredithia Hernández-Alcántara \& Solís-Weiss, 2000

Octomagelona Aguirrezabalaga, Ceberio \& Fiege, 2001

Definition. Pursuant to ICZN (International Commission on Zoological Nomenclature, 1999) Article 12.1, the definition of Magelona is identical to that provided for the emended family-rank name Magelonidae, provided above (Fig. 17).

Remarks. The monotypic name Magelona can only be defined as referring to the same phylogenetic hypotheses that define the name Magelonidae, in accordance with ICZN (International Commission on Zoological Nomenclature, 1999) Article 12.1's requirement that all names published before 1931 "must be accompanied by a description or a definition of the taxon that it denotes." This means that from a scientific perspective the name Magelona is an empirically empty placeholder that is only recognised to satisfy the requirement that species-rank names, as epithets, be binomial. 
members of species possessing large hooded recurved spines on abdominal chaetigers [Table 3:

1891

1892

1893

1894

1895

1896

1897

1898

1899

1900

1901

1902

1903

1904

1905

1906

1907

1908

1909

1910

1911

character 69(1)], adding the two species M. spinifera and M. uebelackerae. However, the nature of the enlarged chaetae differ among members of the two species; members of $M$. spinifera possess enlarged spines [Table 3: character 70(1)], whilst members of M. uebelackerae possess unidentate, enlarged re-curved hooks [Table 3: character $70(0)$ ]. The descriptions of specimens with enlarged abdominal chaetae, but which differ greatly in other aspects (e.g., lacking prostomial horns and in the nature of the thoracic lamellae), called the validity of the genus into question (Mortimer \& Mackie, 2003). Subsequently in the phylogenetic analysis performed by Brasil (2003) it was concluded that Meredithia is paraphyletic, which is in agreement with the current results. Herein, members of species possessing enlarged chaetae appear in three separate clades (Fig. 17: clades b, c and r), and the two species originally assigned to Meredithia are split between clades c and r. Magelona falcifera, M. magnahamata and Magelona sp. C of Uebelacker \& Jones (1984) (clade b) are all species with members lacking prostomial horns, having similar thoracic development with postchaetal, filiform lamellae in both the noto- and neuropodia but in lacking both thoracic superior dorsal lobes and abdominal lateral pouches, whilst M. uebelackerae, Magelona sp. E of Uebelacker \& Jones (1984) (clade c) and $M$. spinifera (clade r) all possess distinct prostomial horns, have different thoracic development, with variations between the noto- and neuropodia in the thoracic region, but which possess subchaetal neuropodial lamellae. The present results therefore further support the synonymisation of Meredithia with Magelona.

Results of the phylogenetic inferences by Brasil (2003: fig. 45) additionally shed doubt on the validity of Octomagelona, with O. bizkaiensis and an undescribed species from Mexico 
1912 (not considered in this study) as a paraphyletic group nested within Magelona and closely related 1913 to species such as M. variolamellata, M. equilamellae, Magelona sp. I of Uebelacker \& Jones 1914 (1984) and M. polydentata. This finding is in agreement with the current analysis, indicating that 1915 Octomagelona cannot be maintained (Fig. 17). Whilst members of Octomagelona may differ 1916 from other members of Magelona in possessing only eight thoracic chaetigers, they share 1917 similarities with members of some species in terms of possessing a prostomium which is wider 1918 than long [character 7(2)], with rudimentary horns [character 6(0)], but with only one pair of 1919 prostomial ridges [character 9(0)], filiform subchaetal thoracic lamellae in the noto- and 1920 neuropodia [characters 21(1), 22(0), 26(1), 28(0)], without superior dorsal lobes [characters 1921 24(0), 37(0), 45(0)] and abdominal lamellae without basal constrictions [character 55(0)]. As discussed above Johnston (1865) erected the genus Maea for the species M. mirabilis Johnston, 1865, later referred to Magelona. Whilst only one composite phylogenetic hypothesis can be formally recognised from the current results, the type species of the genus, Maea mirabilis, appears in both consensus trees (that of the current results and Brasil, 2003) in a clade clearly different from the one including the type species of Magelona, M. papillicornis F. Müller 1858. If, in future studies, clade m (a 'Magelona mirabilis' group) is formally recognised, then this may see the re-establishment of Maea.

\section{ACKNOWLEDGMENTS}

1932 The authors would like to thank Kimberley Mills (Amgueddfa Cymru - National Museum Wales 1933 and School of Earth and Environmental Sciences, Cardiff University), Andrew Mackie and 1934 James Turner (Amgueddfa Cymru - National Museum Wales) for provision of images used 
1935 within this publication. Special thanks to the three reviewers, who offered highly constructive

1936 comments that greatly improved the quality of the manuscript.

1937

1938

\section{REFERENCES}

1939

1940

1941

1942

1943

1944

Achinstein P. 1970. Inference to scientific laws. In: Stuewer RH, ed. Volume V: historical and philosophical perspectives of science. Minnesota studies in the philosophy of science. Minneapolis: University of Minnesota Press 87-111.

Achinstein P. 2001. The book of evidence. New York: Oxford University Press.

Aguado MT, Glasby CJ, Schroeder PC, Weigert A, Bleidorn C. 2015. The making of a branching annelid: an analysis of complete mitochondrial genome and ribosomal data of Ramisyllis multicaudata. Scientific Reports 5:12072.

Aguirrezabalaga F, Ceberio A, Fiege D. 2001. Octomagelona bizkaiensis (Polychaeta: Magelonidae) a new genus and species from the Capbreton Canyon (Bay of Biscay, northeast Atlantic). Journal of the Marine Biological Association of the United Kingdom 81:221-224.

Aliseda A. 2006. Abductive reasoning: logical investigations into discovery and explanation. Dordrecht: Springer.

Allen SR. 2016. A critical introduction to properties. New York: Bloomsbury Academic.

Alston WP. 1993. The reliability of sense perception. Ithaca: Cornell University Press.

Andrade SCS, Novo M, Kawauchi GY, Worsaae K, Pleijel F, Giribet G, Rouse GW. 2015. Articulating "Archiannelids": phylogenomics and annelid relationships, with emphasis on meiofaunal taxa. Molecular Biology and Evolution 32:2860-2875. 
1957 Anjum RL, Mumford S. 2018. Causation in science and the methods of scientific discovery.

$1958 \quad$ New York: Oxford University Press.

1959 Archibald JK, Mort ME, Crawford DJ. 2003. Bayesian inference of phylogeny: a non-

1960 technical primer. Taxon 52:187-191.

1961 Armstrong DM. 1997. A world of states of affairs. New York: Cambridge University Press.

1962 Assis LCS. 2014. Testing evolutionary hypotheses: from Willi Hennig to angiosperm phylogeny 1963 group. Cladistics 30:240-242.

1964 Audi R. 1998. Epistemology: a contemporary introduction to the theory of knowledge. New $1965 \quad$ York: Routledge.

Auletta G, Ellis GFR, Jaeger L. 2008. Top-down causation by information control: From a philosophical problem to a scientific research programme. Journal of the Royal Society Interface 5:1159-1172. The scientific nature of geomorphology: proceedings of the 27th Binghamton symposium in

Baker VR. 1996. Hypotheses and geomorphological reasoning. In: Rhoads BL, Thorn CE, eds. geomorphology held 27-29 September 1996. New York: Wiley 57-85.

Barker SF. 1957. Induction and hypothesis. New York: Cornell University Press.

Barnes E. 1994. Why P rather than Q? The curiosities of fact and foil. Philosophical Studies 73:35-53.

Bartolomaeus T. 1995. Secondary monociliarity in the Annelida: monociliated epidermal cells in larvae of Magelona mirabilis (Magelonida). Microfauna Marina 103:327-332.

Beckers P, Helm C, Bartolomaeus T. 2019. The anatomy and development of the nervous system in Magelonidae (Annelida) - insights into the evolution of the annelid brain. BMC Evolutionary Biology 19:173. 
1980

1981

1982

1983

1984

1985

1986

1987

1988

1989

1990

1991

1992

1993

1994

1995

1996

1997

1998

1999

2000

2001

Biswas S, Akey JM. 2006. Genomic insights into positive selection. Trends in Genetics 22:437446.

Blake JA. 1996a. Family Chaetopteridae Malmgren, 1867. In: Blake JA, Hilbig B, Scott PH, eds. Taxonomic atlas of the benthic fauna of the Santa Maria Basin and Western Santa Barbara Channel, volume 6: the Annelida. Part 3: Polychaeta: Orbiniidae to Cossuridae. Santa Barbara: Santa Barbara Museum of Natural History 233-251.

Blake JA. 1996b. Family Spionidae Cunningham and Ramage, 1888. In: Blake JA, Hilbig B, Scott PH, eds. Taxonomic atlas of the benthic fauna of the Santa Maria Basin and Western Santa Barbara Channel, volume 6: the Annelida. Part 3: Polychaeta: Orbiniidae to Cossuridae. Santa Barbara: Santa Barbara Museum of Natural History 81-223.

Blake JA. 1996c. Family Magelonidae Cunningham and Ramage, 1888. In: Blake JA, Hilbig B, Scott PH, eds. Taxonomic atlas of the benthic fauna of the Santa Maria Basin and Western Santa Barbara Channel, volume 6: the Annelida. Part 3: Polychaeta: Orbiniidae to Cossuridae. Santa Barbara: Santa Barbara Museum of Natural History 252-261.

Bolívar GA, Lana PC. 1986. Magelonidae (Annelida: Polychaeta) do litoral sudeste do Brasil. Neritica 1:131-147.

Borda E, Kudenov JD, Bienhold C, Rouse GW. 2012. Towards a revised Amphinomidae (Annelida, Amphinomida): description and affinities of a new genus and species from the Nile Deep-sea Fan, Mediterranean Sea. Zoologica Scripta 41:307-325.

Brasil AC dos S. 2003. Filogenia de Magelonidae Cunningham \& Ramage, 1888 (Annelida Polychaeta) com base na morfologia externa. Doctoral dissertation. Universidade Federal do Paraná. 
2002 Bremer K. 1988. The limits of amino acid sequence data in angiosperm phylogenetic

2003

2004

2005

2006

2007

2008

2009

2010

2011

2012

2013

2014

2015

2016

2017

2018

2019

2020

2021

2022

2023

2024 reconstruction. Evolution 42:795-803.

Bremer K. 1994. Branch support and tree stability. Cladistics 10:295-304.

Bromberger S. 1966. Why-questions. In: Colodny RG, ed. Mind and cosmos: Essays in contemporary science and philosophy. University of Pittsburgh series in the philosophy of science, volume 3. Pittsburgh: University of Pittsburgh Press 86-111.

Brower, AVZ. 2018. Statistical consistency and phylogenetic inference: a brief review. Cladistics 34:562-567.

Burton RB. 2000. The problem of control in abduction. Transactions of the Charles S. Peirce Society 36:149-156.

Callier V. 2018. Theorists debate how 'neutral' evolution really is. Quanta. Available from: https://www.quantamagazine.org/neutral-theory-of-evolution-challenged-by-evidence-fordna-selection-20181108/.

Campbell DT. 1974. Downward causation in hierarchically organized biological systems. In: Ayala FJ, Dobzhansky T, eds. Studies in the philosophy of biology: reduction and related problems. Berkeley: University of California Press 179-186.

Capa M, Parapar J, Hutchings P. 2012. Phylogeny of Oweniidae (Polychaeta) based on morphological data and taxonomic revision of Australian fauna. Zoological Journal of the Linnean Society 166:236-278.

Capa M, Parapar J, Hutchings P. 2019. 4.1 Oweniidae Rioja, 1917. In: Purschke G, Böggemann, M, Westheide W, eds. Volume 1: Annelida basal groups and Pleistoannelida, Sedentaria I. Boston: De Gruyter 91-112.

Carnap R. 1950. Logical foundations of probability. Chicago: University of Chicago Press. 
2025

2026

2027

2028

2029

2030

2031

2032

2033

2034

2035

2036

2037

2038

2039

2040

2041

2042

2043

2044

2045

2046

Chen H, Parry LA, Vinther J, Zha, D, Hou X, Ma X. 2020. A Cambrian crown annelid reconciles phylogenomics and the fossil record. Nature Available from: https://doi.org/10.1038/s41586-020-2384-8.

Clarke DT, Paterson GLJ, Florence WK, Gibbons MJ. 2010. A new species of Magelona (Polychaeta: Magelonidae) from southern Namibia. African Natural History 6:77-82.

Cleland CE. 2001. Historical science, experimental science, and the scientific method. Geology 29:987-990.

Cleland CE. 2002. Methodological and epistemic differences between historical science and experimental science. Philosophy of Science 69:474-496.

Cleland CE. 2009. Philosophical issues in natural history and its historiography. In: Tucker A, ed. A companion to the philosophy of history and historiography. Oxford: Wiley-Blackwell $44-62$.

Cleland CE. 2011. Prediction and explanation in historical natural science. British Journal for the Philosophy of Science 62:551-582.

Cleland CE. 2013. Common cause explanation and the search for a smoking gun. In: Baker VR, ed. Rethinking the fabric of geology. The Geological Society Special Papers 502:1-9.

Copi IM, Cohen C. 1998. Introduction to logic. Upper Saddle River: Prentice-Hall.

Cunningham JT, Ramage GA. 1888. The Polychaeta Sedentaria of the Firth of Forth. Transactions of the Royal Society of Edinburgh 33:635-684.

Curd MV. 1980. The logic of discovery: An analysis of three approaches. In: Nickles T, ed. Scientific discovery, logic and rationality. Dordrecht: D. Reidel Publishing Company 201219.

Peer) reviewing PDF | (2021:05:61394:1:1:NEW 20 Jul 2021) 
2047 Currie A. 2018. Rock, bone, and ruin: an optimist's guide to the historical sciences. Cambridge:

2048

2049

2050

2051

2052

2053

2054

2055

2056

2057

2058

2059

2060

2061

2062

2063

2064

2065

2066

2067

2068

2069 The MIT Press.

Daston L, Galison P. 2007. Objectivity. New York: Zone Books.

Davies PCW. 2012. The epigenome and top-down causation. Interface Focus 2:42-48.

Davis JI. 1995. A phylogenetic structure for the monocotyledons, as inferred from chloroplast DNA restriction site variation, and a comparison of measures of clade support. Systematic Botany 20:503-527.

Edwards AWF. 1972. Likelihood. New York: Cambridge University Press

Efron B. 1979. Bootstrap methods: Another look at the jackknife. The Annals of Statistics 7:126.

Efron B, Halloran E, Holmes S. 1996. Bootstrap confidence levels for phylogenetic trees. Proceedings of the National Academy of Science 93:7085-7090.

Efron B, Gong G. 1983. A leisurely look at the bootstrap, the jackknife, and cross-validation. The American Statistician 37:36-48.

Efron B, Tibshirani RJ. 1993. An introduction to the bootstrap. New York: Chapman \& Hall.

Ellis G. 2013. Time to turn cause and effect on their heads. New Scientist 2930:28-29.

Ellis GFR. 2008. On the nature of causation in complex systems. Transactions of the Royal Society of South Africa 63:69-84.

Ellis GFR. 2012. Top-down causation and emergence: some comments on mechanisms. Interface Focus 2:126-140.

Ellis GFR, Noble D, O'Connor T. 2011. Top-down causation: An integrating theme within and across the sciences? Interface Focus 2:1-3.

Fann KT. 1970. Peirce's theory of abduction. The Hague: Martinus Nijhoff. 
2070 Farris JS. 1983. The logical basis of phylogenetic analysis. In: Platnick NI, Funk VA, eds.

2071 Advances in cladistics, volume 2: proceedings of the second meeting of the Willi Hennig

2072 society. New York: Columbia University Press 7-36.

2073 Fauchald K, Jumars PA. 1979. The diet of worms: a study of polychaete feeding guilds.

2074 Oceanography and Marine Biology Annual Review 17: 93-284.

2075 Fauchald K, Rouse G. 1997. Polychaete systematics: past and present. Zoologica Scripta

$2076 \quad 26: 71-138$

2077 Felsenstein J. 1978. Cases in which parsimony or compatibility methods will be positively

2078 misleading. Systematic Zoology 27:401-410.

2079 Felsenstein J. 1981. Evolutionary trees from DNA sequences: a maximum likelihood approach.

$2080 \quad$ Journal of Molecular Evolution 17:368-376.

2081 Felsenstein J. 1985. Confidence limits on phylogenies: an approach using the bootstrap.

$2082 \quad$ Evolution 39:783-791.

2083 Felsenstein J. 2004. Inferring phylogenies. Sunderland: Sinauer Associates Inc.

2084 Fetzer JH. 1993. Philosophy of science. New York: Paragon House.

2085 Fetzer JH, Almeder RF. 1993. Glossary of epistemology/philosophy of science. New York:

2086 Paragon House.

2087 Fiege D, Licher F, Mackie ASY. 2000. A partial review of the European Magelonidae

2088 (Annelida: Polychaeta): Magelona mirabilis redefined and M. johnstoni sp. nov.

2089 distinguished. Journal of the Marine Biological Association of the United Kingdom

$2090 \quad \mathbf{8 0}: 215-234$.

2091

2092

Findlay JN. 1936. Relational properties. Australasian Journal of Psychology and Philosophy 14:176-190. 
2093 Fisher RA. 1934. Statistical methods for research workers. Edinburgh: Oliver \& Boyd.

2094 Fitzhugh K. 2005a. Les bases philosophiques de l'inférence phylogénétique: une vue 2095 d'ensemble. Biosystema 24:83-105.

2096 Fitzhugh K. 2005b. The inferential basis of species hypotheses: the solution to defining the term 2097 'species'. Marine Ecology 26:155-165.

2098

2099

2100

2101

2102

2103

2104

2105

2106

2107

2108

2109

2110

2111

2112

2113

2114

2115

Fitzhugh K. 2006a. The abduction of phylogenetic hypotheses. Zootaxa 1145:1-110.

Fitzhugh K. 2006b. The 'requirement of total evidence' and its role in phylogenetic systematics. Biology and Philosophy 21:309-351.

Fitzhugh K. 2006c. The philosophical basis of character coding for the inference of phylogenetic hypotheses. Zoologica Scripta 35:261-286.

Fitzhugh K. 2008a. Abductive inference: implications for 'Linnean' and 'phylogenetic' approaches for representing biological systematization. Evolutionary Biology 35:52-82.

Fitzhugh K. 2008b. Fact, theory, test and evolution. Zoologica Scripta 37:109-113.

Fitzhugh K. 2008c. Clarifying the role of character loss in phylogenetic inference. Zoologica Scripta 37:561-569.

Fitzhugh K. 2009. Species as explanatory hypotheses: refinements and implications. Acta Biotheoretica 57:201-248.

Fitzhugh K. 2010a. Evidence for evolution versus evidence for intelligent design: parallel confusions. Evolutionary Biology 37:68-92.

Fitzhugh K. 2010b. Revised systematics of Fabricia oregonica Banse, 1956 (Polychaeta: Sabellidae: Fabriciinae): an example of the need for a uninomial nomenclatural system. Zootaxa 2647:35-50.

Fitzhugh K. 2012. The limits of understanding in biological systematics. Zootaxa 3435:40-67. 
2116 Fitzhugh K. 2013. Defining 'species', 'biodiversity', and 'conservation' by their transitive

2117 relations. In: Pavlinov IY, ed. The species problem-Ongoing problems. New York:

$2118 \quad$ InTech 93-130.

2119 Fitzhugh K. 2014. Character mapping and cladogram comparison versus the requirement of total evidence: does it matter for polychaete systematics? Memoirs of Museum Victoria 71:67-78.

Fitzhugh K. 2015. What are species? Or, on asking the wrong question. The Festivus 47:229239.

2124

2125

2126

2127

2128

2129

2130

2131

2132

2133

2134

2135

2136

2137

2138

Fitzhugh K. 2016a. Ernst Mayr, causal understanding, and systematics: an example using sabelliform polychaetes. Invertebrate Biology 135:302-313.

Fitzhugh K. 2016b. Sequence data, phylogenetic inference, and implications of downward causation. Acta Biotheoretica 64:133-160.

Fitzhugh K. 2016c. Dispelling five myths about hypothesis testing in biological systematics. Organisms Diversity \& Evolution 16:443-465.

Fitzhugh K. 2016d. Phylogenetic hypotheses: neither testable nor falsifiable. Evolutionary Biology 43:257-266.

Fitzhugh K. 2021. Phylogenetic inference and the misplaced premise of substitution rates. Acta Biotheoretica. DOI 10.1007/s10441-021-09412-4.

Fitzhugh K, Nogueira JMM, Carrerette O, Hutchings P. 2015. An assessment of the status of Polycirridae genera (Annelida: Terebelliformia) and evolutionary transformation series of characters within the family. Zoological Journal of the Linnean Society 174:666-701.

Francescotti R. 2014. Intrinsic/extrinsic: a relational account defended. In: Francescotti RM, ed. Companion to intrinsic properties. Berlin: De Gruyter 175-198. 
2139 Gabbay DM, Woods J. 2005. The reach of abduction: insight and trial. A practical logic of 2140 cognitive systems, volume 2. Amsterdam: Elsevier.

2141 Gaukroger S. 2012. Objectivity: a very short introduction. New York: Oxford University Press.

2142 Glasby CJ, Schroeder PC, Aguado MT. 2012. Branching out: a remarkable new branching

2143

2144

2145

2146

2147

2148

2149

2150

2151

2152

2153

2154

2155

2156

2157

2158

2159

2160

2161

syllid (Annelida) living in a Petrosia sponge (Porifera: Demospongiae). Zoological Journal of the Linnean Society 164:481-497.

Godfrey-Smith P. 2003. Theory and reality: an introduction to the philosophy of science. Chicago: University of Chicago Press.

Gonzalez BC, Martínez A, Borda E, Iliffe TM, Eibye-Jacobsen D, Worsaae K. 2018. Phylogeny and systematics of Aphroditiformia. Cladistics 34:225-259.

Gonzalez BC, Martínez A, Worsaae K \& Osborn K. 2021. Morphological convergence and adaptation in cave and pelagic scale worms (Polynoidae, Annelida). Scientific Reports 11:10718.

Goto R. 2016. A comprehensive molecular phylogeny of spoon worms (Echiura, Annelida): Implications for morphological evolution, the origin of dwarf males, and habitat shifts. Molecular Phylogenetics and Evolution 99:247-260.

Goto R, Okamoto T, Ishikawa H, Hamamura Y, Kato M. 2013. Molecular phylogeny of echiuran worms (Phylum: Annelida) reveals evolutionary pattern of feeding mode and sexual dimorphism. PLOS One 8:e56809.

Gracia JJE. 1988. Individuality: an essay on the foundations of metaphysics. Albany: State University of New York Press.

Griffiths P, Stotz K. 2013. Genetics and philosophy: an introduction. New York: Cambridge University Press.

Peer] reviewing PDF | (2021:05:61394:1:1:NEW 20 Jul 2021) 
2162 Haber M. 2011. Phylogenetic inference. In: Tucker A, ed. A companion to the philosophy of 2163 history and historiography. Malden: Wiley-Blackwell 231-242.

2164 Hacking I. 1965. Logic of statistical inference. New York: Cambridge University Press.

2165 Hacking I. 2001. An introduction to probability and inductive logic. New York: Cambridge $2166 \quad$ University Press.

2167 Halanych KM. 2004. The new view of animal phylogeny. Annual Review of Ecology and 2168 Evolutionary Systematics 35:229-256.

2169 Halanych KM. 2016. How our view of animal phylogeny was reshaped by molecular 2170 approaches: lessons learned. Organisms Diversity \& Evolution 16:319-328.

2171

2172

2173

2174

2175

2176

2177

2178

2179

2180

2181

2182

2183

2184

Hanson NR. 1958. Patterns of discovery: an inquiry into the conceptual foundations of science. New York: Cambridge University Press.

Hartman O. 1944. Polychaetous annelids from California, including two new genera and nine new species. Allan Hancock Pacific Expeditions 10:239-304.

Hartman O. 1961. Polychaetous annelids from California. Allan Hancock Pacific Expeditions 25:1-226.

Hartman O. 1965. Deep-water benthic polychaetous annelids off New England to Bermuda and other North Atlantic areas. Occasional Papers of the Allan Hancock Foundation 28:1-378.

Hartman O. 1971. Abyssal polychaetous annelids from the Mozambique Basin off southeast Africa, with a compendium of abyssal polychaetous annelids from world-wide areas. Journal of the Fisheries Research Board of Canada 28:1407-1428.

Hartmann-Schröder G. 1980. Die Polychaeten der tropischen Nordwestküste Australiens (zwischen Port Samson im Norden und Exmouth im Süden) In: Hartmann-Schroeder G, Hartmann G, eds. Zur Kenntnis des Eulitorals der australischen Küsten unter besonder 
2185

2186

2187

2188

2189

2190

2191

2192

2193

2194

2195

2196

2197

2198

2199

2200

2201

2202

2203

2204

2205

2206

2207

Berücksichtigung der Polychaeten und Ostracoden. Mitteilungen aus dem Hamburgischen zoologischen Museum und Institut. 77:41-110.

Hausman DM. 1998. Causal asymmetries. New York: Cambridge University Press.

Heath T A, Hedtke SM, Hillis DM. 2008. Taxon sampling and the accuracy of phylogenetic analysis. Journal of Systematics and Evolution 46:239-257.

\section{Helm C, Beckers P, Bartolomaeus T, Drukewitz SH, Kourtesis I, Weigert A, Purschke G,} Worsaae K, Struck TH, Bleidorn C. 2018. Convergent evolution of the ladder-like ventral nerve cord in Annelida. Frontiers in Zoology 15. Available from: https://doi.org/10.1186/s12983-018-0280-y.

Hempel CG. 1962. Deductive nomological vs. statistical explanation. In: Feigl H, Maxwell G, eds. Minnesota studies in the philosophy of science, volume 3. Minneapolis: University of Minnesota Pres 98-169.

Hempel CG. 1965. Aspects of scientific explanation and other essays in the philosophy of science. New York: The Free Press.

Hempel CG. 1966. Recent problems of induction. In: Colodny RG, ed. Mind and cosmos. Pittsburgh: University of Pittsburgh Press 112-134.

Hempel CG. 2001. The philosophy of Carl G. Hempel: studies in science, explanation, and rationality. In: Fetzer JH, ed. New York: Oxford University Press.

Hennig W. 1966. Phylogenetic systematics. Urbana: University of Illinois Press.

Hernández-Alcántara P, Solís-Weiss V. 2000. Magelonidae from the Mexican Pacific and northern Gulf of Mexico, with the description of a new genus (Meridithia) and four new species. In: Reish DJ, Lana P, eds. Proceedings of the 6th international polychaete conference, Curitiba, Brazil, 1998. Bulletin of Marine Science 67:625-644. 
2208 Hey J. 1999. The neutralist, the fly and the selectionist. Trends in Ecology \& Evolution 14:35-

2209

2210

2211

2212

2213

2214

2215

2216

2217

2218

2219

2220

2221

2222

2223

2224

2225

2226

2227

2228

2229 38.

Hoffmann M. 1995. Problems with Peirce's concept of abduction. Foundations of Science 4:271-305.

Holmes S. 2003. Bootstrapping phylogenetic trees: theory and methods. Statistical Science 18:241-255.

Howson C, Urbach P. 1993. Scientific reasoning: the Bayesian approach. Chicago: Open Court.

Hoyningen-Huene P. 2013. Systematicity: the nature of science. New York: Oxford University Press.

Huelsenbeck JP, Crandall KA. 1997. Phylogeny estimation and hypothesis testing using maximum likelihood. Annual Review of Ecology and Systematics 28:437-466.

Huelsenbeck JP, Ronquist F. 2001. MrBayes: Bayesian inference of phylogeny. Bioinformatics 17:754-755.

Huelsenbeck JP, Ronquist F, Nielsen R, Bollback JP. 2001. Bayesian inference of phylogeny and its impact on evolutionary biology. Science 294:2310-2314.

Hurst LD. 2002. The $\mathrm{Ka} / \mathrm{Ks}$ ratio: diagnosing the form of sequence evolution. Trends in Genetics 18:486-487.

International Commission on Zoological Nomenclature. 1999. International code of zoological nomenclature. London: The International Trust for Zoological Nomenclature.

Jaeger L, Calkins ER. 2011. Downward causation by information control in micro-organisms. Interface Focus; 2:26-41. 
2230 Jeffares B. 2008. Testing times: regularities in the historical sciences. Studies in History and 2231 Philosophy of Biological and Biomedical Sciences 39:469-475.

2232

2233

2234

2235

2236

2237

2238

2239

2240

2241

2242

2243

2244

2245

2246

2247

2248

2249

2250

2251

Johnston GA. 1865. Catalogue of the British non-parasitical worms in the collection of the British Museum. London: Trustees of the British Museum.

Jones ML. 1963. Four new species of Magelona (Annelida, Polychaeta) and a redescription of Magelona longicornis Johnson. American Museum Novitates 2164:1-31.

Jones ML. 1968. On the morphology, feeding, and behavior of Magelona sp. Biological Bulletin 134:272-297.

Jones ML. 1971. Magelona berkeleyi n. sp. from Puget Sound (Annelida: Polychaeta) with a further redescription of Magelona longicornis Johnson and a consideration of recently described species of Magelona. Journal of the Fisheries Research Board of Canada 28: $1445-1454$.

Jones ML. 1977. A redescription of Magelona papillicornis F. Müller. In: Reish DJ, Fauchald K, eds. Essays on polychaetous annelids in memory of Dr. Olga Hartman. Los Angeles: Allan Hancock Foundation, University of Southern California 247-266.

Jones ML. 1978. Three new species of Magelona (Annelida, Polychaeta) and a redescription of Magelona pitelkai Hartman. Proceedings of the Biological Society of Washington 91:336363.

Josephson JR, Josephson SG, eds. 1994. Abductive inference: computation, philosophy, technology. New York: Cambridge University Press.

Jukes TH, Cantor CR. 1969. Evolution of protein molecules. In: Munro HN, ed. Mammalian protein metabolism. New York: Academic Press 21-132. 
2252 Jumars PA, Kelly, MD, Lindsay SM. 2015. Diet of worms emended: an update of polychaete 2253 feeding guilds. Annual Review of Marine Science 7:497-520.

2254

2255

2256

2257

2258

2259

2260

2261

2262

2263

2264

2265

2266

2267

2268

2269

2270

2271

2272

2273

Kapitan T. 1997. Peirce and the structure of abductive inference. In: Houser N, Roberts DD, Evra JV, eds. Studies in the logic of Charles Sanders Peirce. Bloomington: Indiana University Press 477-496.

Kapli P, Yang Z, Telford MJ. 2020. Phylogenetic tree building in the genomic age. Nature Reviews Genetics 21:428-444.

Klienhans MG, Buskes CJJ, de Regt HW. 2005. Terra incognita: explanation and reduction in Earth science. International Studies in the Philosophy of Science 19:289-317.

Klienhans MG, Buskes CJJ, de Regt HW. 2010. Philosophy of Earth science. In: Allhoff F, ed. Philosophies of the sciences: a guide. Oxford: Wiley-Blackwell 213-236.

Kneale W, Kneale M. 1964. The development of logic. New York: Oxford University Press.

Kobayashi G, Goto R, Takano T, Kojima S. 2018. Molecular phylogeny of Maldanidae (Annelida): multiple losses of tube-capping plates and evolutionary shifts in habitat depth. Molecular Phylogenetics and Evolution 127:332-344.

Koonin EV. 2012. The logic of chance: the nature and origin of biological evolution. Upper Saddle River: FTS Press.

Laland KN, Sterelny K, Odling-Smee J, Hoppitt W, Uller T. 2011. Cause and effect in biology revisited: Is Mayr's proximate-ultimate dichotomy still useful? Science 334:15121516.

Langeneck J, Barbieri M, Maltagliati F, Castelli A. 2019. Molecular phylogeny of Paraonidae (Annelida). Molecular Phylogenetics and Evolution 136:1-13. 
2274 Lankester ER. 1870. II.- On the use of the term homology in modern zoology, and the

2275 distinction between homogenetic and homoplastic agreements. Annals and Magazine of

$2276 \quad$ Natural History 6:34-43.

2277 Larkin LL, Neff JL, Simpson BB. 2006. Phylogeny of the Callandrena subgenus of Andrena

2278

2279

2280

2281

2282

2283

2284

2285

2286

2287

2288

2289

2290

2291

2292

2293

2294

2295

2296

Lemoine F, Entfellner J-BD, Wilkinson E, Correia D, Felipe MD, De Oliveira T, Gascuel

O. 2018. Renewing Felsenstein's phylogenetic bootstrap in the era of big data. Nature 556:452-456.

Linquist S, Doolittle WF, Palazzo AF. 2020. Getting clear about the F-word in genomics. PLOS Genetics 16:e1008702.

Lipton P. 2004. Inference to the best explanation. New York: Routledge.

Lipton P. 2005. Testing hypotheses: prediction and prejudice. Science 307:219-221.

Lloyd EA. 1988. The structure and confirmation of evolutionary theory. Princeton: Princeton University Press.

Longino HE. 1979. Evidence and hypothesis: an analysis of evidential relations. Philosophy of Science 46:35-56.

Lovell LL, Fitzhugh K. 2020. Taking a closer look: an SEM review of Levinsenia species (Polychaeta: Paraonidae) reported from California. Zootaxa 4751:257-275.

Maddison WP, Maddison DR. 2011. Mesquite: a modular system for evolutionary analysis. Version 3.61. Available from: http://mesquiteproject.com. 
2297 Magnani L. 2001. Abduction, reason, and science: processes of discovery and explanation. New

$2298 \quad$ York: Kluwer Academic.

2299

2300

2301

2302

2303

2304

2305

2306

2307

2308

2309

2310

2311

2312

2313

2314

2315

2316

2317

2318

2319

Magnani L. 2009. Abductive cognition: the epistemological and eco-cognitive dimensions of hypothetical reasoning. Berlin: Springer-Verlag.

Magnani L. 2017. The abductive structure of scientific creativity: an essay on the ecology of cognition. Berlin: Springer-Verlag.

Mahner M, Bunge M. 1997. Foundations of biophilosophy. New York: Springer.

Martínez M, Esposito M. 2014. Multilevel causation and the extended synthesis. Biological Theory 9:209-220.

Martínez M, Moya A. 2011. Natural selection and multi-level causation. Philosophy, Theory, and Practice in Biology 3:e202.

Marwick P. 1999. Interrogatives and contrasts in explanation theory. Philosophical Studies 96:183-204.

Mayr E. 1961. Cause and effect in biology. Science 131:1501-1506.

Mayr E. 1993. Proximate and ultimate causation. Biology and Philosophy 8:95-98.

McDonald JH, Kreitman M. 1991. Adaptive protein evolution at the Adh locus in Drosophila. Nature 351:652-654.

McIntosh WC. 1877. On the structure of Magelona. Proceedings of the Royal Society of London, 25(178):559-564.

McIntosh WC. 1878. Beiträge zur Anatomie von Magelona. Zeitschrift für Wissenschaftliche Zoologie 31:401-472.

McIntosh WC. 1879. On the circulatory system of Magelona. Journal of Anatomy and Physiology 13:331-345. 
2320 McIntosh WC. 1911. On the structure of Magelona. Annals and Magazine of Natural History,

2321 Series 8 7:417-457. [Translation of McIntosh, 1878].

2322

2323

2324

2325

2326

2327

2328

2329

2330

2331

2332

2333

2334

2335

2336

2337

2338

2339

2340

2341

Meißner K, Bick A, Bastrop R. 2011. On the identity of Spio filicornis (O.F. Müller, 1776)— with the designation of a neotype, and the description of two new species from the North East Atlantic Ocean based on morphological and genetic studies. Zootaxa 2815:1-27.

Mills K, Mortimer K. 2018. Redescription of Magelona minuta Eliason, 1962 (Annelida), with discussions on the validity of Magelona filiformis minuta. Zootaxa 4527:541-559.

Mills K, Mortimer K. 2019. Observations on the tubicolous annelid Magelona alleni (Magelonidae), with discussions on the relationship between morphology and behaviour of European magelonids. Journal of the Marine Biological Association of the United Kingdom 99:715-727.

Mortimer K. 2010. Magelonidae (Polychaeta) from the Arabian Peninsula: A review of known species, with notes on Magelona tinae from Thailand. Zootaxa 2628:1-26.

Mortimer K. 2019. 4.2 Magelonidae Cunningham \& Ramage, 1888. In: Purschke G, Böggemann M, Westheide W, eds. Volume 1: Annelida basal groups and Pleistoannelida, Sedentaria I. Boston: De Gruyter 112-131.

Mortimer K, Cassà S, Martin D, Gil J. 2012. New records and new species of Magelonidae (Polychaeta) from the Arabian Peninsula, with a re-description of Magelona pacifica and a discussion on the magelonid buccal region. Zootaxa 3331:1-43.

Mortimer K, Kongsrud JA, Willassen E. 2021. Integrative taxonomy of West African Magelona (Annelida: Magelonidae): species carrying posterior thoracic pigmentation. Zoological Journal of the Linnean Society 
2342 Mortimer K, Mackie ASY. 2003. The Magelonidae (Annelida: Polychaeta) from the

2343 Seychelles, with the description of three new species. In: Sigvaldadóttir E, Mackie ASY,

2344

2345

2346

2347

2348

2349

2350

2351

2352

2353

2354

2355

2356

2357

2358

2359

2360

2361

2362

2363

Mortimer K, Mackie ASY. 2014. Morphology, feeding and behaviour of British Magelona (Annelida: Magelonidae), with discussions on the form and function of abdominal lateral pouches. Memoirs of Museum Victoria 71:177-201.

Mortimer K, Mills K, Jordana E, Pinedo S, Gil J. 2020. A further review of European Magelonidae (Annelida), including redescriptions of Magelona equilamellae and Magelona filiformis. Zootaxa 4767:89-114.

Mundy NI. 2016. Population genomics fits the bill: genetics of adaptive beak variation in Darwin's finches. Molecular Ecology 25:5265-5266.

Nateewathana A, Hylleberg J. 1991. Magelonid polychaetes from Thailand, the Andaman Sea, with descriptions of eight new species. In: Petersen ME, Kirkegaard JB, eds. Systematics, biology and morphology of world Polychaeta. Proceedings of the 2nd international polychaete conference, Copenhagen, 1986. Ophelia Supplement 5:169-184.

Neta R. 2008. What evidence do you have? The British Journal for the Philosophy of Science 59:89-119. 
2364 Nickles T. 1980. Introductory essay: scientific discovery and the future of philosophy of science.

2365 In: Nickles T, ed. Scientific discovery, logic and rationality. Dordrecht: D. Reidel

2366 Publishing Company 1-59.

2367 Nogueira JMM, Carrerette O, Hutchings P, Fitzhugh K. 2018. Systematic review of the

2368

2369

2370

2371

2372 species of the family Telothelepodidae Nogueira, Fitzhugh \& Hutchings, 2013 (Annelida:

\section{3}

2374

2375

2376

2377

2378

2379

2380

2381

2382

2383

2384

2385

Polychaeta), with descriptions of three new species. Marine Biology Research 14:217-257.

Nogueira JMM, Fitzhugh K, Hutchings P. 2013. The continuing challenge of phylogenetic relationships in Terebelliformia (Annelida: Polychaeta). Invertebrate Systematics 27:186238.

Nogueira JMM, Fitzhugh K, Hutchings P, Carrerette O. 2017. Phylogenetic analysis of the family Telothelepodidae Nogueira, Fitzhugh \& Hutchings, 2013 (Annelida: Polychaeta). Marine Biology Research 13:671-692.

Nogueira JMM, Fitzhugh K, Rossi MCS. 2010. A new genus and new species of fan worms (Polychaeta: Sabellidae) from Atlantic and Pacific Oceans - the formal treatment of taxon names as explanatory hypotheses. Zootaxa 2603:1-52.

Nola R, Sankey H. 2007. Theories of scientific method: an introduction. Ithaca; McGill-Queen's University Press.

Norton JD. 2003. A material theory of induction. Philosophy of Science. 70:647-670.

Nygren A, Parapar J, Pons J, Meißner K, Bakken T, Kongsrud JA, Oug E, Gaeva D, Sikorski A, Johansen RA, Hutchings PA, Lavesque N, Capa M. 2018. A mega-cryptic species complex hidden among one of the most common annelids in the North East Atlantic. PLOS One 13:e198356.

Peer] reviewing PDF | (2021:05:61394:1:1:NEW 20 Jul 2021) 
2386 Okasha S. 2012. Emergence, hierarchy and top-down causation in evolutionary biology.

$2387 \quad$ Interface Focus 2:49-54.

2388 Orrhage L. 1966. Über die anatomie des zentralen nervensystemes der sedentären polychaeten. 2389 Arkiv för zoologi 19:99-133.

2390

2391

2392

2393

2394

2395

2396

2397

2398

2399

2400

2401

2402

2403

2404

2405

2406

2407

2408

Park W. 2017. Abduction in context: the conjectural dynamics of scientific reasoning. Berlin: Springer-Verlag.

Parry LA, Edgecombe GD, Eibye-Jacobsen D, Vinther J. 2016. The impact of fossil data on annelid phylogeny inferred from discrete morphological characters. Proceedings of the Royal Society B 283:20161378. Available from: http://dx.doi.org/10.1098/rspb.2016.1378.

Patrick B, Helm C, Bartolomaeus T. 2019. The anatomy and development of the nervous system in Magelonidae (Annelida) - Insights into the evolution of the annelid brain. $B M C$ Evolutionary Biology 19:173. Available from: https://doi.org/10.1186/s12862-019-1498-9.

Peirce CS. 1878. Illustrations of the logic of science. Sixth paper-Deduction, induction, and hypothesis. Popular Science Monthly 13:470-482.

Peirce CS. 1902. Reasoning. In: Baldwin JA, Rand B, eds. Dictionary of philosophy and psychology: prefatory note. Text, Le-Z. Addenda: indices. I. Greek terms. II. Latin terms. III. German terms. IV. French terms. V. Italian terms. New York: The Macmillan Company 426-428.

Peirce CS. 1931. Collected papers of Charles Sanders Peirce, volume 1, principles of philosophy. In: Hartshorne C, Weiss P, Burks A, eds. Cambridge: Harvard University Press.

Peirce CS. 1932. Collected papers of Charles Sanders Peirce, volume 2, elements of logic. In: Hartshorne C, Weiss P, Burks A. eds. Cambridge: Harvard University Press. 
2409 Peirce CS. 1933a. Collected papers of Charles Sanders Peirce, volume 3, exact logic. In:

2410 Hartshorne C, Weiss P, Burks A, eds. Cambridge: Harvard University Press.

2411

2412

2413

2414

2415

2416

2417

2418

2419

2420

2421

2422

2423

2424

2425

2426

2427

2428

2429

2430

Peirce CS. 1933b. Collected papers of Charles Sanders Peirce, volume 4, the simplest mathematics. In: Hartshorne C, Weiss P, Burks A, eds. Cambridge: Harvard University Press.

Peirce CS. 1934. Collected papers of Charles Sanders Peirce, volume 5, pragmatism and pragmaticism. In: Hartshorne C, Weiss P, Burks A, eds. Cambridge: Harvard University Press.

Peirce CS. 1935. Collected papers of Charles Sanders Peirce, volume 6, scientific metaphysics. In: Hartshorne C, Weiss P, Burks A. eds. Cambridge: Harvard University Press.

Peirce CS. 1958a. Collected papers of Charles Sanders Peirce, volume 7, science and philosophy. In: Hartshorne C, Weiss P, Burks A, eds. Cambridge: Harvard University Press.

Peirce CS. 1958b. Collected papers of Charles Sanders Peirce, volume 8, correspondence and bibliography. In: Burks A, ed. Cambridge: Harvard University Press.

Petrov DA. 2014. Searching for adaptation in the genome. In: Losos JB, Baum DA, Futuyma DJ, Hoekstra HE, Lenski RE, Moore AJ, Peichel CL, Schluter D, Whitlock MC, eds. The Princeton guide to evolution. Princeton: Princeton University Press 466-474.

Popper KR. 1983. Objective knowledge: an evolutionary approach. New York: Oxford University Press.

Popper KR. 1992. Realism and the aim of science. New York: Routledge.

Potochnik A. 2017. Idealization and the aims of science. Chicago: University of Chicago Press. 
2431

2432

2433

2434

2435

2436

2437

2438

2439

2440

2441

2442

2443

2444

2445

2446

2447

2448

2449

2450

2451

2452

2453

Potochnik A. 2020. What constitutes an explanation in biology? In: Kampourakis K, Uller T, eds. Philosophy of science for biologists. New York: Cambridge University Press 21 $-35$.

Pouyet F, Aeschbacher S, Thiéry A, Excoffier L. 2018. Background selection and biased gene conversion affect more than $95 \%$ of the human genome and bias demographic inferences. eLife 7:e36317.

Psillos S. 2002. Simply the best: a case for abduction. In: Kakas AC, Sadri F, eds. Computational logic: logic programming and beyond. New York: Springer 605-625.

Psillos S. 2007. Philosophy of science A-Z. Edinburgh: University Press.

Psillos S. 2011. An explorer upon untrodden ground: Peirce on abduction. In: Gabbay D, Hartmann S, Woods J, eds. The handbook of the history of logic, volume 10, inductive logic. Oxford: Elsevier 117-151.

Purschke G. 1997. Ultrastructure of nuchal organs in polychaetes (Annelida) - New results and review. Acta Zoologica 78:123-143.

Purschke G. 2005. Sense organs in polychaetes (Annelida). Hydrobiologia 535/536:53-78.

Radashevsky VI, Malyar VV, Pankova VV, Gambi MC, Giangrande A, Keppel E, Nygren A, Al-Kandari M, Carlton JT. 2020. Disentangling invasions in the sea: molecular analysis of a global polychaete species complex (Annelida: Spionidae: Pseudopolydora paucibranchiata). Biological Invasions. Available from: https://doi.org/10.1007/s10530020-02346-x.

de Regt HW, Leonelli S, Eigner K. 2009. Focusing on scientific understanding. In: de Regt H, Leonelli S, Eigner K, eds. Scientific understanding: philosophical perspectives. Pittsburgh: University of Pittsburgh Press 1-17. 
2454 Reilly FE. 1970. Charles Peirce's theory of scientific method. New York: Fordham University 2455 Press.

2456

2457

2458

2459

2460

2461

2462

2463

2464

2465

2466

2467

2468

2469

2470

2471

2472

2473

2474

2475

2476

Reiss J, Sprenger J. 2017. Scientific objectivity. In: The Stanford encyclopedia of philosophy (Winter 2017 edition). Zalta EN, ed. Available from: https://plato.stanford.edu/archives/win2017/entries/scientific-objectivity/.

Rescher N. 1970. Scientific explanation. New York: The Free Press.

Rescher N. 1978. Peirce's philosophy of science: critical studies in his theory of induction and scientific method. Notre Dame: University of Notre Dame Press.

Rindal E, Brower AVZ. 2011. Do model-based phylogenetic analyses perform better than parsimony? A test with empirical data. Cladistics 27:331-334.

Ronquist F, van der Mark P, Huelsenbeck JP. 2009. Bayesian phylogenetic analysis using MrBayes. In: Lemey P, Salemi M, Vandamme A-M, eds. The phylogenetic handbook: a practical approach to phylogenetic analysis and hypothesis testing. New York: Cambridge University Press 210-266.

Rouse GW. 2001. Magelona Müller, 1858. In: Rouse GW, Pleijel F, authors. Polychaetes. Oxford: Oxford University Press 261-263.

Salas A. 2019. The natural selection that shapes our genomes. Forensic Science International: Genetics 39:57-60.

Salmon WC. 1967. The foundations of scientific inference. Pittsburgh: University of Pittsburgh Press.

Salmon WC. 1984a. Logic. Englewood Cliffs: Prentice-Hall, Inc.

Salmon WC. 1984b. Scientific explanation and the causal structure of the world. Princeton: Princeton University Press. 
2477 Salmon WC. 1989. Four decades of scientific explanation. In: Kitcher P, Salmon WC, eds.

2478 Scientific explanation. Minnesota studies in the philosophy of science, volume XIII.

2479 Minneapolis: University of Minnesota Press 3-219.

2480 Salmon WC. 1998. Causality and explanation. New York: Oxford University Press.

2481 Salthe SN. 1985. Evolving hierarchical systems: their structure and representation. New York:

2482 Columbia University Press.

2483 San Martín G, Álvarez-Campos P, Kondo Y, Núñez J, Fernández-Álamo MA, Pleijel F,

2484 Goetz FE, Nygren A, Osborn K. 2020. New symbiotic association in marine annelids:

2485 ectoparasites of comb jellies. Zoological Journal of the Linnean Society. 191:672-694.

2486 Sawyer SA. 1994. Inferring selection and mutation from DNA sequences: the McDonald-

2487 Kreitman test revisited. In: Golding B, ed. Non-neutral evolution: theories and molecular

2488 data. Dordrecht: Springer 77-87.

2489 Schmidt HA, von Haeseler A. 2009. Phylogenetic inference using maximum likelihood

2490 methods. In: Lemey P, Salemi M, Vandamme A-M, eds. The phylogenetic handbook: a

2491

2492 practical approach to phylogenetic analysis and hypothesis testing. New York: Cambridge University Press 181-198.

2493

Schurz G. 2005. Explanations in science and the logic of why-questions: discussion of the Halonen-Hintikka-approach and alternative proposal. Synthese 143:49-178.

2495

2496

Schurz G. 2008. Patterns of abduction. Synthese 164:201-234.

Scotland RW, Olmstead RG, Bennett JR. 2003. Phylogeny reconstruction: the role of morphology. Systematic Biology 52:539-548. 2019. Diversity, distribution and phylogeny of Hesionidae (Annelida) colonizing whale 
2500

2501

2502

2503

2504

2505

2506

2507

2508

2509

2510

2511

2512

2513

2514

2515

2516

2517

2518

2519

2520

2521

falls: new species of Sirsoe and connections between ocean basins. Frontiers in Marine Science. Available from: https://doi.org/10.3389/fmars.2019.00478.

Sider T. 1996. Intrinsic properties. Philosophical Studies 83:1-27.

Sintonen M. 2004. Reasoning to hypotheses: where do questions come? Foundations of Science 9:249-266.

Sneath PHA, Sokal RR. 1973. Numerical taxonomy: the principles and practice of numerical classification. San Francisco: WH Freeman.

Sober E. 1975. Simplicity. New York: Oxford University Press.

Sober E. 1984. The nature of selection: evolutionary theory in philosophical focus. Cambridge: MIT Press.

Sober E. 1986. Explanatory presupposition. Australasian Journal of Philosophy 64:143-149.

Sober E. 1988. Reconstructing the past: parsimony, evolution, and inference. New York: MIT Press.

Sober E. 1994. From a biological point of view: essays in evolutionary biology. Cambridge: Cambridge University Press.

Sokal RR, Sneath PHA. 1963. Principles of numerical taxonomy. San Francisco: WH Freeman.

Soltis PS, Soltis DE. 2003. Applying the bootstrap in phylogeny reconstruction. Statistical Science 18:256-267.

Spencer AR. 2020. American pragmatism: an introduction. New York: Polity.

Stiller J, Tilic E, Rousset V, Pleijel F, Rouse GW. 2020. Spaghetti to a tree: a robust phylogeny for Terebelliformia (Annelida) based on transcriptomes, molecular and morphological data. Biology 9:73-100. 
2522 Strahler AN. 1992. Understanding science: an introduction to concepts and issues. Buffalo:

2523 Prometheus Books.

2524 Strawson PF. 1971. Individuals: an essay in descriptive metaphysics. New York: Routledge.

2525 Struck TH, Golombek A, Weigert A, Franke FA, Westheide W, Purschke G, Bleidorn C,

2526 Halanych KM. 2015. The evolution of annelids reveals two adaptive routes to the

2527 interstitial realm. Current Biology 25:1993-1999.

2528 Struck TH, Paul C, Hill N, Hartmann S, Hösel C, Kube M, Lieb B, Meyer A, Tiedemann R,

2529 Purschke G, Bleidorn C. 2011. Phylogenomic analyses unravel annelid evolution. Nature

$2530 \quad$ 471:95-98.

2531

2532

2533

2534

2535

2536

2537

2538

2539

2540

2541

2542

2543

Sullivan J, Joyce P. 2005. Model selection in phylogenetics. Annual Review of Ecology and Systematics 36:445-466.

Swofford DL. 2001. PAUP*. Phylogenetic analysis using parsimony (*and other methods). Version 4.0b10. Sunderland: Sinauer Associates.

Swofford DL, Olsen GJ, Waddell PJ, Hillis DM. 1996. Phylogenetic inference. In: Hillis DM, Moritz C, Mable BK, eds. Molecular systematics. Sunderland: Sinauer Associates 407514.

Thagard P. 1988. Computational philosophy of science. Cambridge: MIT Press.

Thagard P. 2004. Rationality and science. In: Mele A, Rawlings P, eds. Handbook of rationality. Oxford: Oxford University Press 363-379.

Tilic E, Sayyari E, Stiller J, Mirarab S, Rouse GW. 2020. More is needed - Thousands of loci are required to elucidate the relationships of the 'flowers of the sea' (Sabellida, Annelida). Molecular Phylogenetics and Evolution 151:doi.org/10.1016/j.ympev.2020.106892. 
2544 Tucker A. 2004. Our knowledge of the past: a philosophy of historiography. New York:

2545 Cambridge University Press.

2546 Tucker A. 2011. Historical science, over- and underdetermined: a study of Darwin's inference 2547 of origins. The British Journal for the Philosophy of Science 62:805-829.

2548 Turner D. 2007. Making prehistory: historical science and the scientific realism debate. New 2549 York: Cambridge University Press.

2550

2551

2552

2553

2554

2555

2556

2557

2558

2559

2560

2561

2562

2563

2564

2565

Uebelacker JM, Jones ML. 1984. Family Magelonidae. In: Uebelacker JM, Johnson PG, eds. Taxonomic guide to the polychaetes of the northern Gulf of Mexico. Final report to the Minerals Management Service, contract 14-12-001-29091. Barry A. Vittor and Associates, Mobile, Alabama 7.1-7.29.

Uller T, Laland KN. 2019. Evolutionary causation. In: Uller T, Laland KN, eds. Evolutionary causation: biological and philosophical reflections. Cambridge: The MIT Press 1-12.

Van Fraassen BC. 1990. The scientific image. New York: Clarendon Press.

Vrba E, Eldredge N. 1984. Individuals, hierarchies and processes: towards a more complete evolutionary theory. Paleobiology 10:146-171.

Walker SI. 2014. Top-down causation and the rise of information in the emergence of life. Information 5:424-39.

Walker SI, Cisneros L, Davies PCW. 2012. Evolutionary transitions and top-down causation. Proceedings of Artificial Life 13:283-290.

Walton D. 2004. Abductive reasoning. Tuscaloosa: The University of Alabama Press.

Weigert A, Bleidorn C. 2016. Current status of annelid phylogeny. Organisms Diversity \& Evolution 16:345-362. 
2566 Weigert A, Golombek A, Gerth M, Schwarz F, Struck TH, Bleidorn C. 2016. Evolution of

2567 mitochondrial gene order in Annelida. Molecular Phylogenetics and Evolution 94:196-206.

2568 Weigert A, Helm C, Meyer M, Nickel B, Arendt D, Hausdorf B, Santos SR, Halanych KM,

2569 Purschke G, Bleidorn C, Struck TH. 2014. Illuminating the base of the annelid tree using

$2570 \quad$ transcriptomics. Molecular Biology and Evolution 31:1391-401.

2571 Wilson DP. 1958. The polychaete Magelona alleni n. sp. and a re-assessment of Magelona

2572 cincta Ehlers. Journal of the Marine Biological Association of the United Kingdom

$2573 \quad 37: 617-626$.

2574 Wilson DP. 1959. The polychaete Magelona filiformis sp. nov. and notes on other species of Magelona. Journal of the Marine Biological Association of the United Kingdom 38:547-556.

Wilson DP. 1982. The larval development of three species of Magelona (Polychaeta) from localities near Plymouth. Journal of the Marine Biological Association of the United Kingdom 62:385-401.

Wilson WA. 2017. The myth of scientific objectivity. Available from:

2581 https://www.firstthings.com/article/2017/11/the-myth-of-scientific-objectivity.

Yu L, Boström C, Franzenburg S, Bayer T, Dagan T, Reusch TBH. 2020. Somatic genetic drift and multilevel selection in a clonal seagrass. Nature Ecology \& Evolution 4:952-962.

Zhang Z, Yu J. 2006. Evaluation of six methods for estimating synonymous and nonsynonymous substitution rates. Genomics Proteomics Bioinformatics 4:173-181. 


\section{Table $\mathbf{1}$ (on next page)}

Forms of questions leading to ab-, de-, and inductive inferences, and respective answers provided by those inferences. 
1 Table 1. Forms of questions leading to ab-, de-, and inductive inferences, and respective

2 answers provided by those inferences.

\begin{tabular}{ccc}
\hline Question & Inferential Reaction & Conclusion (= answer) \\
\hline 'Why is $Y$ the case in contrast to & Abduction, cf. (1) & Explanatory hypothesis \\
\hline 'What consequence(s) are & Deduction, cf. (2) & Potential test evidence \\
expected if hypothesis $h$ is true?' & & Hypothesis confirmation / \\
\hline 'Should hypothesis $h$ be & Induction, cf. (3) & disconfirmation \\
accepted as true?' & &
\end{tabular}

3

4 


\section{Table 2 (on next page)}

Sources from which character data were obtained for this study. Museum abbreviations are explained in the text. 
1 Table 2. Sources from which character data were obtained for this study. Museum

2 abbreviations are explained in the text.

\begin{tabular}{|c|c|}
\hline Species & Material \\
\hline M. alexandrae Magalhães, Bailey- & Original description plus photos provided by \\
\hline Brock \& Watling, 2018 & the authors \\
\hline \multirow[t]{2}{*}{ M. alleni Wilson, 1958} & Holotype: BMNH 1958.5.2.1 \\
\hline & Paratypes: BMNH 1958.5.2.2-10 \\
\hline M. annulata Hartmann-Schröder, 1962 & Original description \\
\hline M. anuheone Magalhães, Bailey-Brock & Original description plus photos provided by \\
\hline \& Watling, 2018 & the authors \\
\hline M. berkeleyi Jones, 1971 & Original description \\
\hline M. californica Hartman, 1944 & Original description \\
\hline \multirow[t]{2}{*}{ M. cepiceps Mortimer \& Mackie, 2006} & Holotype: NMW.Z.2000.020.0209 \\
\hline & Paratype: NMW.Z.2000.020.0208 \\
\hline M. cerae Hartman \& Reish, 1950 & Original description \\
\hline M. cincta Ehlers, 1908 & Holotype (ZMHB 4531) \\
\hline M. cinthyae Magalhães, Bailey-Brock & Original description plus photos provided by \\
\hline \& Watling, 2018 & the authors \\
\hline \multirow[t]{2}{*}{ M. conversa Mortimer \& Mackie, 2003} & Holotype: NMW.Z.2000.020.0001 \\
\hline & Paratypes: NMW.Z.2000.020.0002-0007 \\
\hline \multirow[t]{2}{*}{ M. cornuta Wesenberg-Lund, 1949} & Holotype: (ZMUC-POL-969; two abdominal \\
\hline & slide preparations ZMUC-POL-963) \\
\hline M. crenulata Bolívar \& Lana, 1986 & Original description \\
\hline
\end{tabular}




\begin{tabular}{|c|c|}
\hline M. crenulifrons Gallardo, 1968 & Paratypes: (ZMUC-POL-1416- 1421) \\
\hline M. dakini Jones, 1978 & Original description \\
\hline $\begin{array}{l}\text { M. debeerei Clarke, Paterson, Florence } \\
\text { \& Gibbons, } 2010\end{array}$ & Original description \\
\hline M. equilamellae Harmelin, 1964 & Syntypes: SMF 4675 \\
\hline M. falcifera Mortimer \& Mackie, 2003 & $\begin{array}{l}\text { Holotype: NMW.Z.2000.020.0009 } \\
\text { Paratypes: NMW.Z.2000.020.0008, } \\
\text { NMW.Z.2000.020.0010-0017 }\end{array}$ \\
\hline $\begin{array}{l}\text { Magelona fasciata Mortimer et al. } \\
\text { (2021) }\end{array}$ & $\begin{array}{l}\text { Holotype: ZMBN132144 } \\
\text { Paratypes: ZMBN; AC-NMW }\end{array}$ \\
\hline M. fauchaldi Shakouri, Mortimer \& & Holotype: NMW.Z.2015.012.0002a \\
\hline Dehani, 2017 & $\begin{array}{l}\text { Paratypes: NMW.Z.2015.012.0001-0002; } \\
\text { NMW.Z.2010.037.0002-0006 }\end{array}$ \\
\hline M. filiformis Wilson, 1959 & $\begin{array}{l}\text { Holotype: BMNH 1959.4.2.1 } \\
\text { Paratypes: BMNH 1959.4.2.2-10 }\end{array}$ \\
\hline
\end{tabular}

M. gemmata Mortimer \& Mackie, 2003 Holotype: NMW.Z.2000.020.0019

Paratypes: NMW.Z.2000.020.0018;

NMW.Z.2000.020.0020

Magelona guineaensis Mortimer et al. Holotype: ZMBN132137

Paratypes: ZMBN; AC-NMW

\begin{tabular}{ll}
\hline M. hartmanae Jones, 1978 & Original description \\
\hline M. hobsonae Jones, 1978 & Original description \\
\hline M. johnstoni Fiege, Licher \& Mackie, & Cited material from original description from
\end{tabular}




\begin{tabular}{|c|c|}
\hline 2000 & NMW collections \\
\hline M. jonesi Hartmann-Schröder, 1980 & Original description \\
\hline M. lenticulata Gallardo, 1968 & Original description \\
\hline M. lusitanica Mortimer, Gil \& Fiege, & Holotype: SMF 9246/1 \\
\hline \multirow[t]{2}{*}{2011} & Paratypes: MB29-000176-000181; \\
\hline & NMW.Z.2010.010.0001-0006; SMF 9245/1 \\
\hline Magelona mackiei Mortimer et al. & Holotype: ZMBN107309 \\
\hline$(2021)$ & Paratypes: ZMBN; AC-NMW \\
\hline M. magnahamata Aguado \& San & Original description \\
\hline \multicolumn{2}{|l|}{ Martín, 2004} \\
\hline \multirow[t]{3}{*}{ M. mahensis Mortimer \& Mackie, 2006} & Holotype: NMW.Z.2000.020.0188 \\
\hline & Paratypes: NMW.Z.2000.020.0176-0187; \\
\hline & NMW.Z.2000.020.0189-0193 \\
\hline M. marianae Hernández-Alcántara \& & Original description \\
\hline \multicolumn{2}{|l|}{ Solís-Weiss, 2000} \\
\hline \multirow[t]{2}{*}{ M. minuta Eliason, 1962} & Holotype: NHMG Polych. 11491 \\
\hline & Additional material: USNM 52510 \\
\hline \multirow[t]{2}{*}{ M. mirabilis (Johnston, 1865) } & Cited material from original description from \\
\hline & NMW collections \\
\hline M. montera Mortimer, Cassà, Martin \& & Holotype: MNHN A895 \\
\hline \multicolumn{2}{|l|}{ Gil, 2012} \\
\hline Magelona nanseni Mortimer et al. & Holotype: ZMBN132141 \\
\hline$(2021)$ & Paratypes: ZMBN; AC-NMW \\
\hline
\end{tabular}




\begin{tabular}{|c|c|}
\hline M. nonatoi Bolívar \& Lana, 1986 & Original description \\
\hline M. obockensis Gravier, 1905 & Syntypes, MNHN Type 1357 \\
\hline M. pacifica Monro, 1933 & Syntypes: BMNH Type 1933.7.10.65/70 \\
\hline M. papillicornis F. Müller, 1858 & Redescription (Jones, 1977) \\
\hline M. parochilis Zhou \& Mortimer, 2013 & $\begin{array}{l}\text { Holotype: ECSFRI100532 } \\
\text { Paratypes: ECSFRI100533-535; } \\
\text { NMW.Z.2012.033.0001 }\end{array}$ \\
\hline $\begin{array}{l}\text { M. paulolanai Magalhães, Bailey-Brock } \\
\text { \& Watling, } 2018\end{array}$ & $\begin{array}{l}\text { Original description plus photos provided by } \\
\text { the authors }\end{array}$ \\
\hline M. pettiboneae Jones, 1963 & Original description \\
\hline M. phyllisae Jones, 1963 & Original description \\
\hline Magelona picta Mortimer et al. (2021) & $\begin{array}{l}\text { Holotype: ZMBN107338 } \\
\text { Paratype: ZMBN115737 }\end{array}$ \\
\hline M. pitelkai Hartman, 1944 & Original description, Jones (1978) \\
\hline M. polydentata Jones, 1963 & Original description \\
\hline $\begin{array}{l}\text { M. posterelongata Bolívar \& Lana, } \\
1986\end{array}$ & Original description \\
\hline M. pulchella Mohammad, 1970 & Holotype: BMNH 1969.391 \\
\hline M. pygmaea Nateewathana \& & Paratype: PMBC 4220 \\
\hline Hylleberg, 1991 & $\begin{array}{l}\text { Additional material: PMBC 4234; PMBC } \\
\text { 4227; PMBC } 4241\end{array}$ \\
\hline M. riojai Jones, 1963 & Original description \\
\hline
\end{tabular}


M. sacculata Hartman, $1961 \quad$ Holotype: NHMLA: LACM-AHF POLY 596

M. sinbadi Mortimer, Cassà, Martin \& $\quad$ Holotype: NMW.Z.2010.037.0001

Gil, 2012

M. spinifera (Hernández-Alcántara \& Original description

Solís-Weiss, 2000)

M. symmetrica Mortimer \& Mackie, Holotype: NMW.Z.2000.020.0175

2006

M. tehuanensis Hernández-Alcántara \& Original description

Solís-Weiss, 2000

M. tinae Nateewathana \& Hylleberg, $\quad$ Paratypes: PMBC 3180; PMBC 4251; PMBC 1991

4253; PMBC 4254

M. uebelackerae (Hernández-Alcántara Original description

\& Solís-Weiss, 2000)

M. variolamellata Bolívar \& Lana, Original description

1986

M. wilsoni Glémarec, $1967 \quad$ Paratypes: MNHN Poly Type 1415

\begin{tabular}{ll}
\hline Magelona sp. A $\quad$ Uebelacker \& Jones, 1984
\end{tabular}

Magelona sp. B Uebelacker \& Jones, 1984

Magelona sp. C $\quad$ Uebelacker \& Jones, 1984

Magelona sp. D $\quad$ Uebelacker \& Jones, 1984

Magelona sp. E $\quad$ Uebelacker \& Jones, 1984

Magelona sp. F Uebelacker \& Jones, 1984

Magelona sp. G $\quad$ Uebelacker \& Jones, 1984 


\begin{tabular}{ll}
\hline Magelona $\mathrm{sp} . \mathrm{H}$ & Uebelacker \& Jones, 1984 \\
\hline Magelona $\mathrm{sp} . \mathrm{I}$ & Uebelacker \& Jones, 1984 \\
\hline Magelona $\mathrm{sp.} \mathrm{J}$ & Uebelacker \& Jones, 1984 \\
\hline Magelona sp. K & Uebelacker \& Jones, 1984 \\
\hline Magelona sp. L & Uebelacker \& Jones, 1984 \\
\hline O. bizkaiensis Aguirrezabalaga, Ceberio & Holotype: MNCN 16.01/6887 \\
\& Fiege, 2001 & Paratype: SMF 10025 \\
\hline Octomagelona sp. (West Africa) & AC-NMW
\end{tabular}




\section{Table 3(on next page)}

Characters, as observation statements represented by subject-predicate relations, not 'characters' and 'states' (Fitzhugh, 2006c, 2008c), used in this study. 
1 Table 3. Characters, as observation statements represented by subject-predicate relations,

2 not 'characters' and 'states' (Fitzhugh, 2006c, 2008c), used in this study.

3 1. Shovel-shape prostomium: (0) absent; (1) present.

4 2. Nuchal organs: (0) absent; (1) present.

5 3. Prostomium distal margin: (0) smooth; (1) crenulate; (2) medially indented.

6 4. Prostomium distal shape: (0) triangular; (1) rounded; (2) straight.

7 5. Prostomial horns (including rudimentary): (0) absent; (1) present.

8 6. Shape of prostomial horns [cf. character 5(1)]: (0) rudimentary; (1) distinct.

9 7. Prostomium dimensions: (0) longer than wide; (1) as wide as long; (2) wider than long.

10 8. Prostomial ridges: (0) absent; (1) present.

119 . Number of prostomial ridges [cf. character 8(1)]: (0) a pair; (1) two pairs.

12 10. Palp origin: (0) dorsal; (1) ventral.

13 11. Palp surface: (0) non-papillate; (1) papillate.

14 12. Number of rows of proximal palp papillae [cf. character 11(1)]: (0) 2; (1) 4-8; (2) 10-14.

15 13. Number of rows of distal palp papillae [cf. character 11(1)]: (0) 2; (1) 4; (2) more.

16 14. Burrowing organ: (0) absent; (1) present.

17 15. Body regionation: (0) non-magelonid; (1) magelonid-like.

18 16. Number of anterior body region chaetigers [cf. character 15(1)]: (0) 8; (1) 9.

19 17. Notopodial postchaetal lamellae: (0) absent; (1) present.

20 18. Development of notopodia along thorax: (0) all similar; (1) different in some chaetigers.

21 19. Neuropodial postchaetal lamellae: (0) absent; (1) present.

22 20. Development of neuropodia along thorax: (0) all similar; (1) different in some chaetigers.

23 21. Chaetigers 1-7 position of notopodial lamellae relative to notochaetae: (0) postchaetal; (1) 
24

25

subchaetal.

22. Chaetigers 1-7 notopodial lamellae shape: (0) filiform; (1) foliaceous.

23. Chaetigers 1-7 margins of foliaceous notopodial lamellae [cf. character 22(1)]: (0) smooth; (1) crenulate; (2) bilobed.

24. Chaetigers 1-7 dorsal superior lobes: (0) absent; (1) present.

25. Superior dorsal lobes [cf. character 24(1)]: (0) absent on some chaetigers between 1-7; (1) present on chaetigers $1-7$.

26. Chaetigers 1-7 neuropodial lamellae position relative to neurochaetae: (0) postchaetal; (1) subchaetal; (2) prechaetal.

27. Chaetigers 1-7 neuropodial subchaetal lamellae position relative to neurochaetae [cf. character 26(1)]: (0) same position along thorax; (1) varying in position along thorax.

28. Chaetigers 1-7 neuropodial lamellae shape: (0) filiform; (1) foliaceous.

29. Chaetigers 1-7 neuropodial filiform lamellae shape distal ends [cf. character 28(0)]: (0) pointed; (1) distally expanded/scoop shaped.

30. Chaetigers 1-7 lengths of noto- and neuropodial lamellae: (0) equivalent; (1) notopodial longer; (2) neuropodial longer.

31. Chaetigers 1-8 limbations of capillary chaetae: (0) unilimbate; (1) bilimbate.

32. Chaetigers 1-8 margins of bilimbate capillary chaetae [cf. character 31(1)]: (0) smooth; (1) irregular blade.

33. Chaetigers 1-8 lengths of noto- and neuropodial capillary chaetae: (0) equivalent; (1) notopodial longer; (2) neuropodial longer.

34. Chaetiger 8 notopodial lamellae position relative to notochaetae: (0) postchaetal; (1) subchaetal. 
47 35. Chaetiger 8 notopodial lamellae shape: (0) filiform; (1) foliaceous.

48 36. Chaetiger 8 margins of foliaceous notopodial lamellae [cf. character 35(1)]: (0) smooth; (1) crenulate; (2) bilobed.

50 37. Chaetiger 8 superior dorsal lobes: (0) absent; (1) present.

51 38. Chaetiger 8 neuropodial lamellae position: (0) postchaetal; (1) subchaetal; (2) prechaetal.

52 39. Chaetiger 8 neuropodia: (0) without additional postchaetal expansion; (1) with an additional 53 postchaetal expansion.

54 40. Chaetiger 8 neuropodial lamellae shape: (0) filiform; (1) foliaceous.

55 41. Chaetiger 9 notopodial lamellae positions: (0) postchaetal; (1) subchaetal.

56 42. Chaetiger 9 notopodial lamellae height [cf. character 41(0)]: (0) low; (1) elongate.

57 43. Chaetiger 9 notopodial lamellae shape: (0) filiform; (1) foliaceous.

44. Chaetiger 9 notopodial foliaceous lamellae margins [cf. 43(1)]: (0) smooth; (1) crenulate; (2) bilobed.

45. Chaetiger 9 superior dorsal lobes: (0) absent; (1) present.

46. Chaetiger 9 neuropodial lamellae position: (0) postchaetal; (1) subchaetal; (2) prechaetal.

47. Chaetiger 9 neuropodial lamellae height [cf. character 46(0)]: (0) low; (1) elongate.

48. Chaetiger 9 neuropodial lamellae shape: (0) filiform; (1) foliaceous.

49. Chaetiger 9 neuropodia: (0) without additional postchaetal expansion; (1) with additional postchaetal expansion.

50. Lengths of chaetiger 9 fascicles relative to chaetigers 1-8 fascicles: (0) same length as chaetae in chaetigers $1-8$; (1) shorter than chaetae in chaetigers $1-8$; (2) longer than chaetae in chaetigers $1-8$.

69 51. Distal ends of chaetae in chaetiger 9: (0) gently tapered, similar to chaetigers 1-8; (1) 
mucronate; (2) pennoned.

71 52. Shape of thoracic interparapodial margins: (0) straight; (1) rounded, bulbous.

53. Dorso-lateral grooves, anterior chaetigers: (0) absent; (1) present.

54. Dimensions of post-chaetiger 9 segments: (0) as long as wide; (1) longer than wide.

55. Post-chaetiger 9 lamellae shape: (0) without basal constriction; (1) with basal constriction.

75

56. Post-chaetiger 9 dorsal and ventral medial lobes: (0) absent; (1) present.

57. Post-chaetiger 9 dorsal and ventral medial lobes sizes [cf. character 56(1) partim]: (0) smaller than hooks; (1) longer than hooks.

58. Post-chaetiger 9 postchaetal expansion behind chaetal rows: (0) absent; (1) present.

59. Relative sizes of post-chaetiger 9 noto- and neuropodial postchaetal lamellae: (0) same size; (1) different size.

60. Post-chaetiger 9 lateral pouches: (0) absent; (1) present.

61. Post-chaetiger 9 lateral pouch arrangement [cf. character 60(1)]: (0) paired; (1) unpaired; (2) both paired and unpaired.

62. Direction of lateral pouch openings [cf. character 60(1)]: (0) posteriorly; (1) posteriorly and anteriorly.

63. Post-chaetiger 9 posteriorly open lateral pouch arrangement [cf. character 62(0)]: (0) on consecutive segments; (1) on alternating segments; (2) on both consecutive and alternating segments.

64. Post-chaetiger 9 lateral pouches distribution [cf. character 60(1)]: (0) throughout most abdominal chaetigers; (1) median and posterior abdominal chaetigers only; (2) posterior abdomen only.

65. Margins of posteriorly-open pouches [cf. character 62(0)]: (0) smooth; (1) medially split. 
93 66. Post-chaetiger 9 noto- and neuropodial hooded hooks: (0) absent; (1) present.

94 67. Post-chaetiger 9 noto- and neuropodial hooded hooks dentition [cf. character 66(1)]: (0)

$95 \quad$ bidentate; (1) tridentate; (2) polydentate.

96 68. Post-chaetiger 9 hooded hooks adjacent to notopodial subchaetal or neuropodial suprachaetal lamellae [cf. character 66(1)]: (0) same size; (1) smaller than rest.

69. Post-chaetiger 9 enlarged hooded hooks: (0) absent; (1) present.

70. Post-chaetiger 9 enlarged hooded hooks distal ends [cf. character 69(1)]: (0) recurved; (1) spine-like; (2) enlarged normal hook.

71. Post-chaetiger 9 number of hooded hooks per ramus [cf. character 66(1)]: (0) 8 or more; (1) less than 8 .

72. Post-chaetiger 9 arrangement of hooded hooks [cf. character 66(1)]: (0) vis-à-vis; (1) vis-àdos.

73. Neuropodial sabre chaetae: (0) absent; (1) present.

74. Post-chaetiger 9 noto- and neuropodial internal 'aciculae': (0) absent; (1) present.

75. Pigmentation in posterior thorax: (0) absent; (1) present.

76. Pigmentation pattern in posterior thorax [cf. character 75(1): (0) discreet band; (1) dispersed, not forming band.

77. Granular bodies on surfaces of segments: (0) absent; (1) present.

111 78. Granular bodies within segments as abdominal interparapodial patches: (0) absent; (1)

112 present.

113 79. Tube construction: (0) absent; (1) present. 
Figure 1

Classes of hypotheses in systematics. Relations between the eight classes $(\mathrm{A}-\mathrm{H})$ of explanatory hypotheses commonly inferred in biological systematics (adapted from Fitzhugh, 2013: fig. 1, 2016b: fig. 1; based on Hennig, 1966: fig. 6).

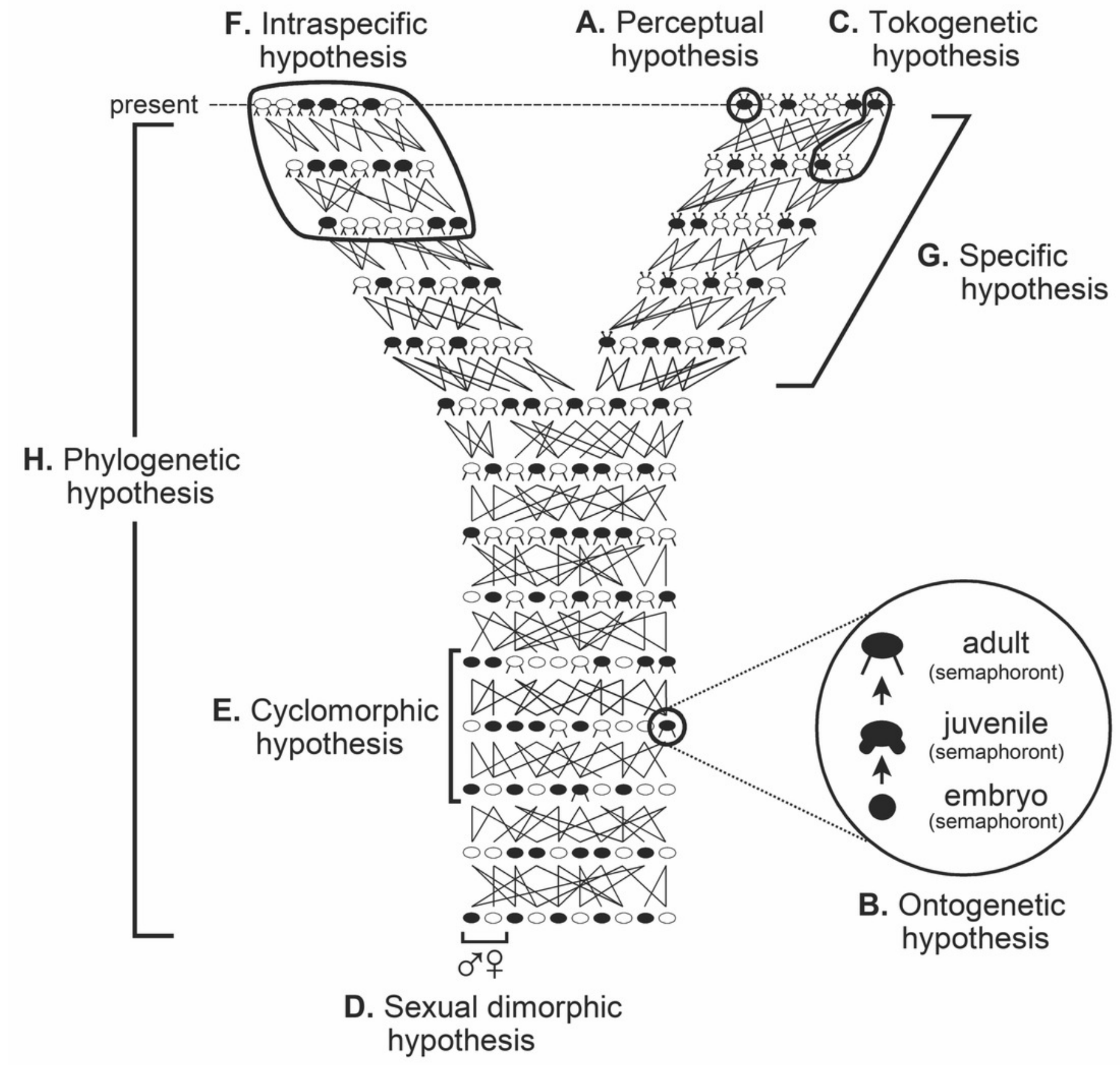




\section{Figure 2}

Observation statements, why-questions, and data matrix.

A data matrix used to infer phylogenetic hypotheses implies the why-questions to which inferences lead to answers as phylogenetic hypotheses, implied by cladograms (Fig. 1). (A) Observation statements, as subject-predicate relations, and contrastive why-questions implied by a data matrix. (B) The contrastive form of why-questions is maintained in a data matrix through the inclusion of outgroups, distinguishing foil and fact. Modified from Fitzhugh (2016b: fig. 3). 

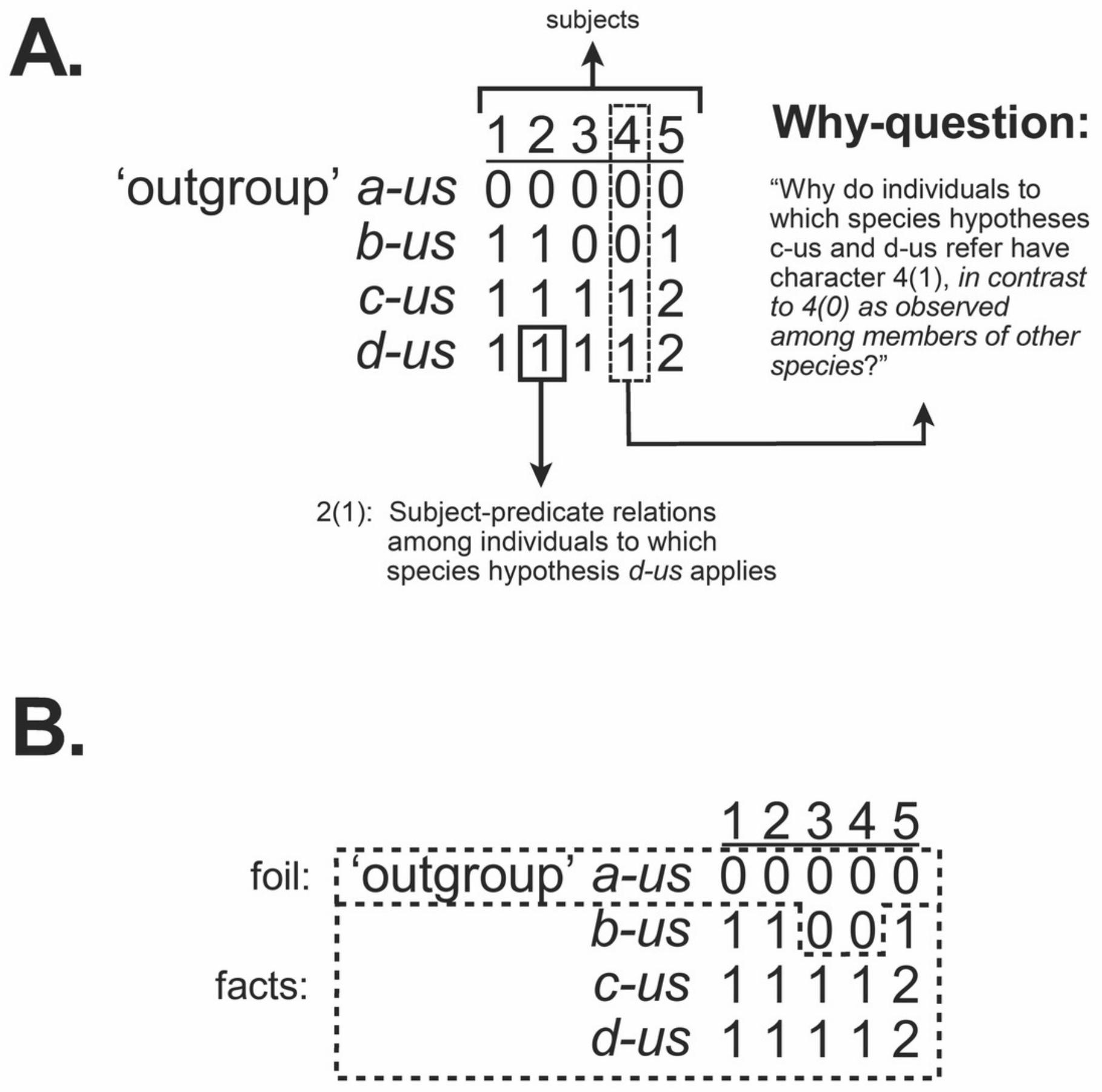
Figure 3

Explanatory hypotheses implied by cladograms.

Cladograms imply two general classes of explanatory hypotheses (see also Fig. 1) - specific and phylogenetic - causally accounting for differentially shared characters. Inferences of specific hypotheses are distinct from phylogenetic inferences (cf. Fitzhugh, 2005b, 2009, $2013,2015)$, but both typically offer vague explanations with largely unspecified causes. Modified from Fitzhugh (2016b: fig. 2).

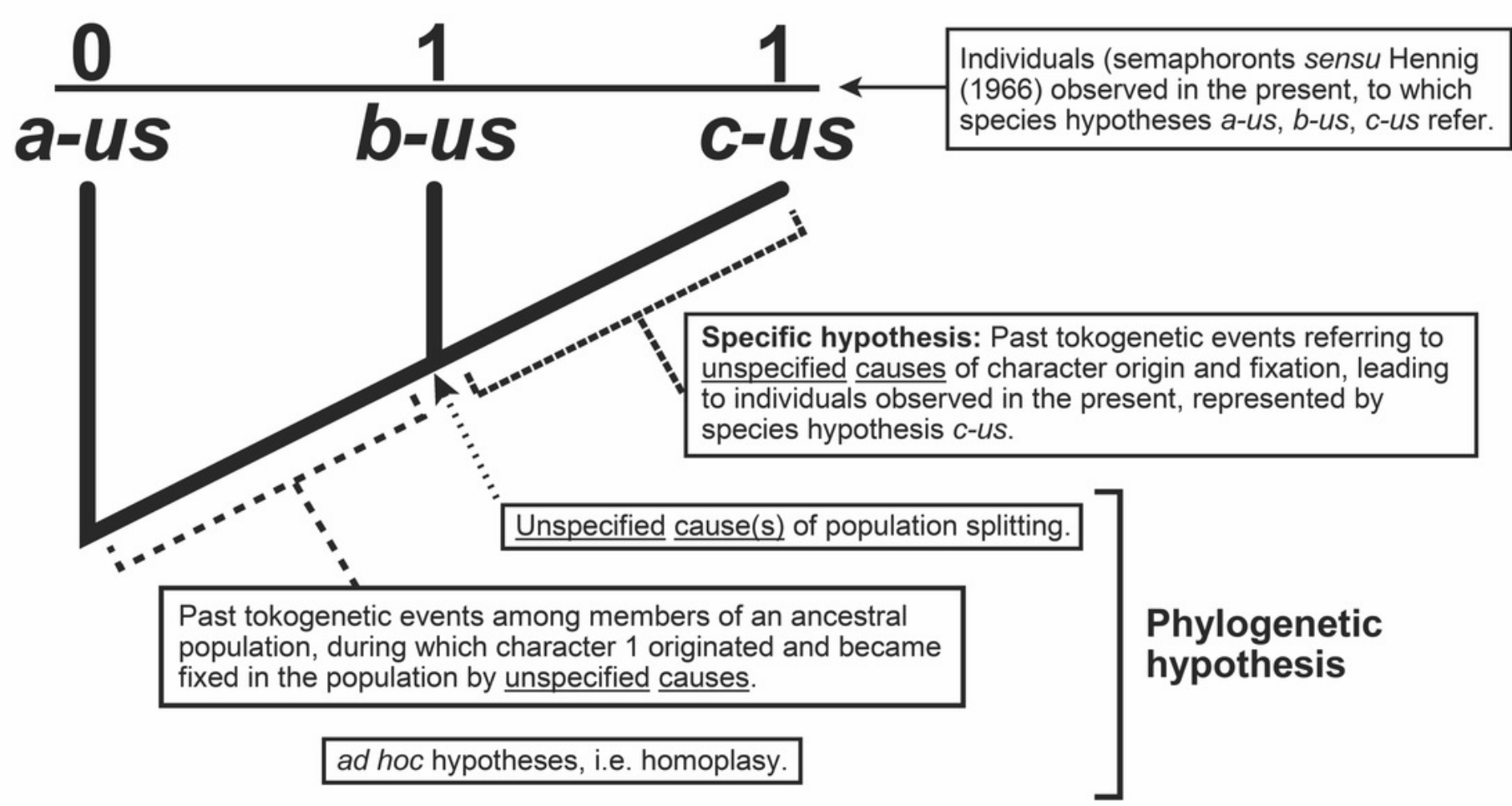




\section{Figure 4}

Magelonid prostomial characters.

A) smooth distal margin of Magelona obockensis (Kuwait, BMNH:ZB.1971.54; photo by J.

Turner); (B) distinctly crenulate distal margin of M. crenulifrons from Hong Kong

(NMW.Z.2007.033.0001); (C) minutely crenulate margin of M. wilsoni from the Gulf of Lions

(NMW.Z.2010.010.0008); (D) medially indented distal margin of M. symmetrica from the

Seychelles, holotype, from Mortimer \& Mackie, 2006); (E) triangular distal margin of $M$.

sinbadi from Iran (holotype, NMW.Z.2010.037.0001); (F) rounded distal margin of $M$.

johnstoni from Berwick-upon-Tweed (NMW.Z.2013.037.0008); (G-H) straight distal margins

(often termed 'rudimentary horns') of M. alleni from Morocco (NMW.Z.2021.001.0001) and M.

equilamellae from Ebro Delta, Catalonia. A-E, G, H, dorsal views; F, ventral view; $A, E, G$, stained with methyl green; $\mathrm{H}$, stained with Rose Bengal. $\mathrm{BO}=$ burrowing organ, $\mathrm{IM}=$ indented margin, $\mathrm{IR}=$ inner ridges, $\mathrm{OR}=$ outer ridges, $\mathrm{PB}=$ palp base, $\mathrm{PH}=$ prostomial horns, $\mathrm{Pp}=$ palp, $\mathrm{Pr}=$ prostomium, $\mathrm{RH}=$ rudimentary horns . 

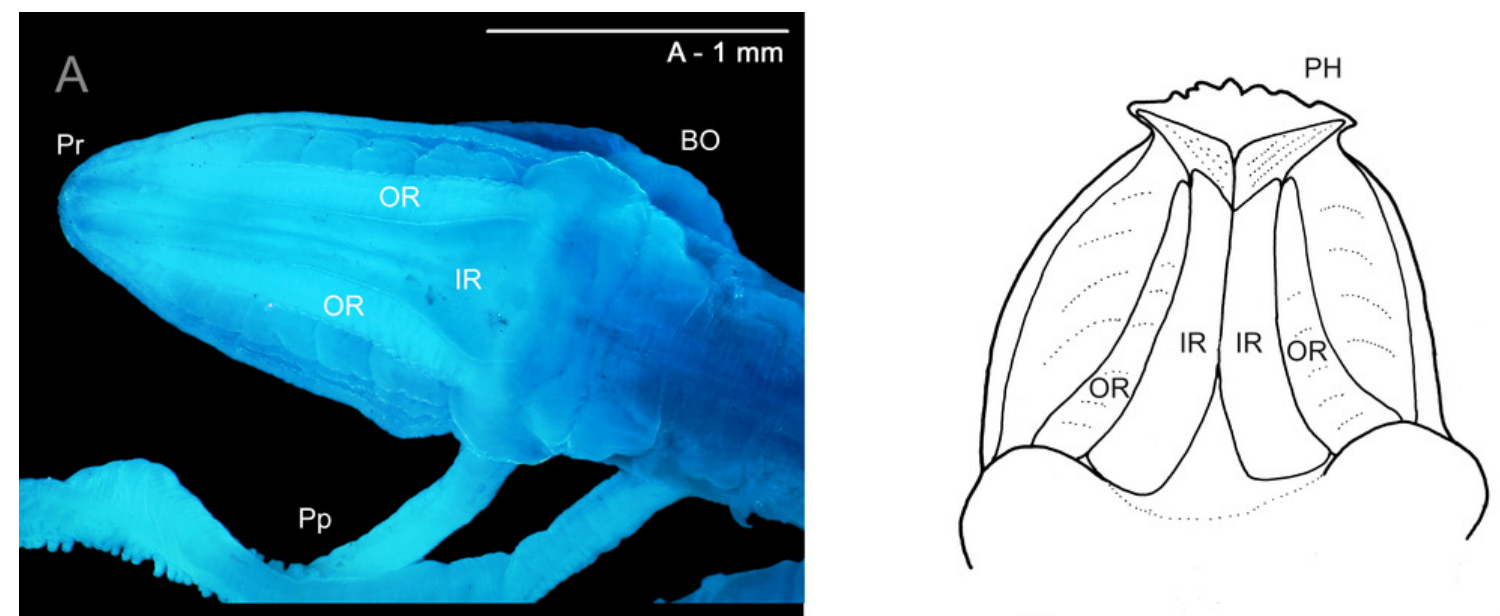

B
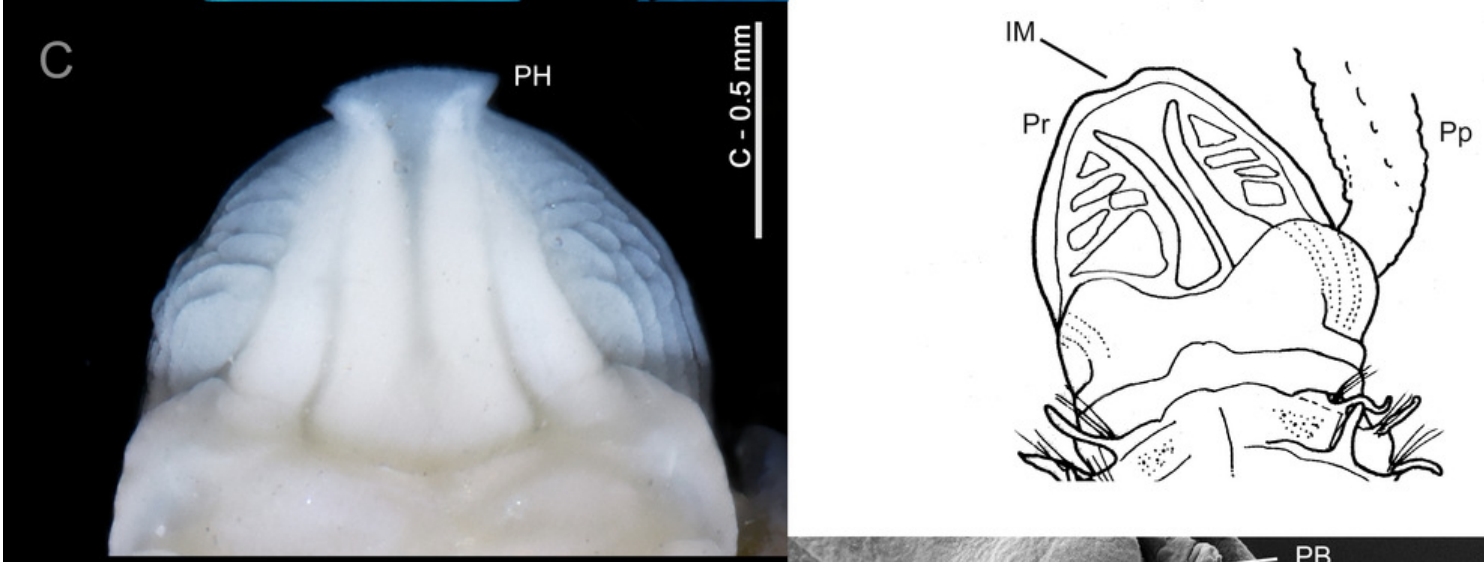

퇴

염

E
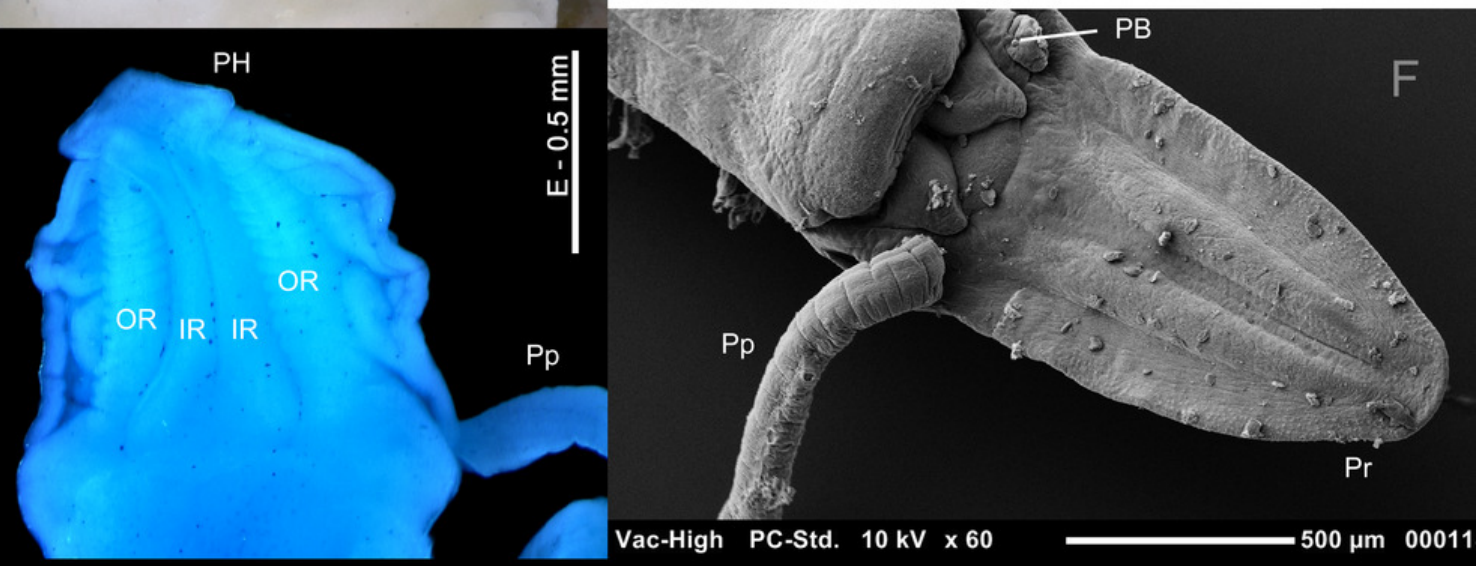

G

Vac-High PC-Std. $10 \mathrm{kV} \times 60$

$500 \mu \mathrm{m} 00011$

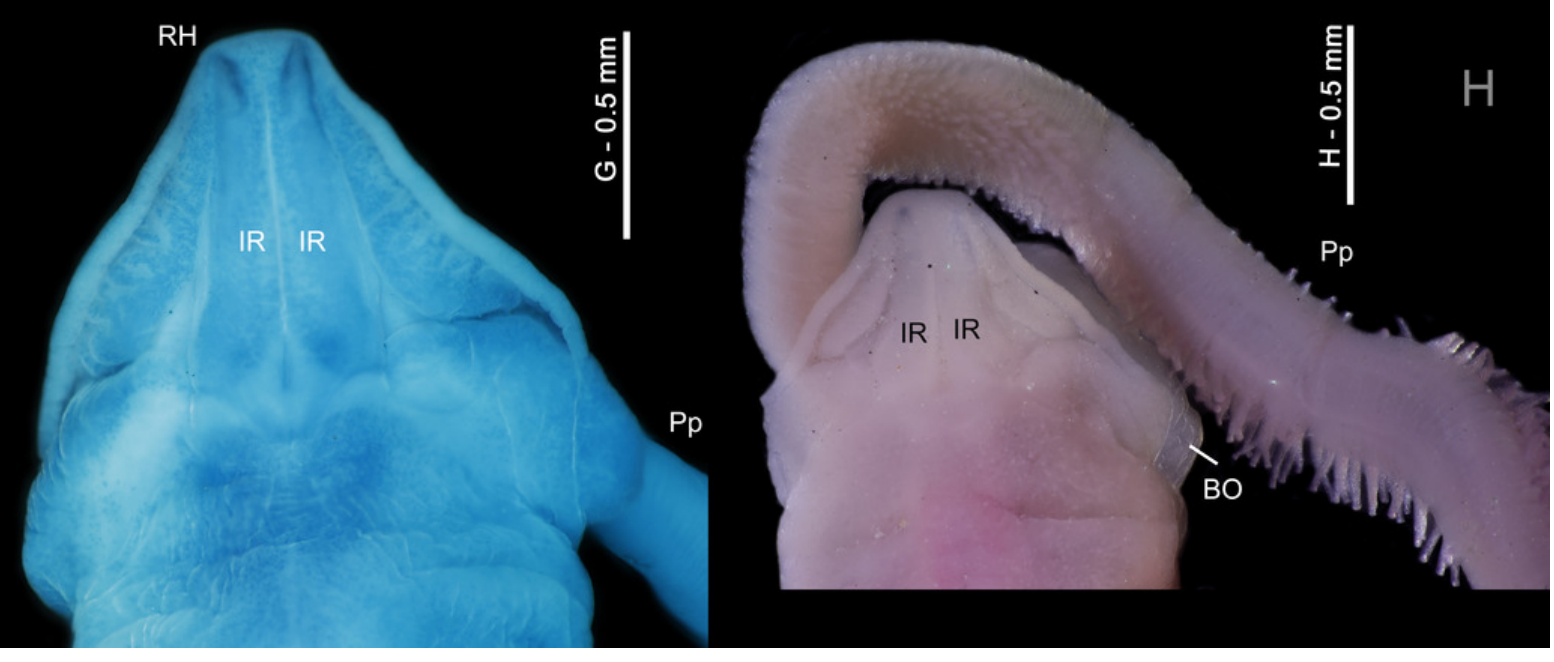

PeerJ reviewing PDF | (2021:05:61394:1:1:NEW 20 Jul 2021) 


\section{Figure 5}

Magelonid anterior end and palp characters.

(A) prostomium and first chaetiger of Magelona pacifica from Panamá (syntype, BMNH Type 1933.7.10.65/70, dorsal view); (B) prostomium and first three chaetigers of $M$. montera from Gulf of Aqaba (holotype MNHN TYPE 1548, dorso-lateral view, stained with methyl green, photo by J. Turner); (C) prostomium and first three chaetigers of M. filiformis from Salcombe, England (paratype, BMNH 1959.4.2.6-10, dorso-lateral view); (D) prostomium of $M$. posterelongata from Paranaguá Bay, Brazil (dorsal view); (E) prostomium and first chaetiger of Magelona nanseni from Nigeria (Holotype, ZMBN132141, dorsal view); (F) mid-palp region of M. johnstoni from Berwick-upon-Tweed (NMW.Z.2013.037.0008c); (G) prostomium and anterior thorax of $M$. johnstoni from Berwick-upon-Tweed, showing ventrally inserted papillate palps, and partially everted burrowing organ (NMW.Z.2013.037.0008b); (H) distal palp end of M. alleni from Swansea (NMW.Z.2012.022.0001, SEM by K. Mills). Ach = achaetous first segment, $\mathrm{BO}=$ burrowing organ, $\mathrm{IR}=$ inner ridges, $\mathrm{OR}=$ outer ridges, $\mathrm{PH}=$ prostomial horns, $\mathrm{Pp}=$ palp, $\mathrm{Pr}=$ prostomium, $\mathrm{RH}=$ rudimentary horns. Numbers indicate chaetiger number. 


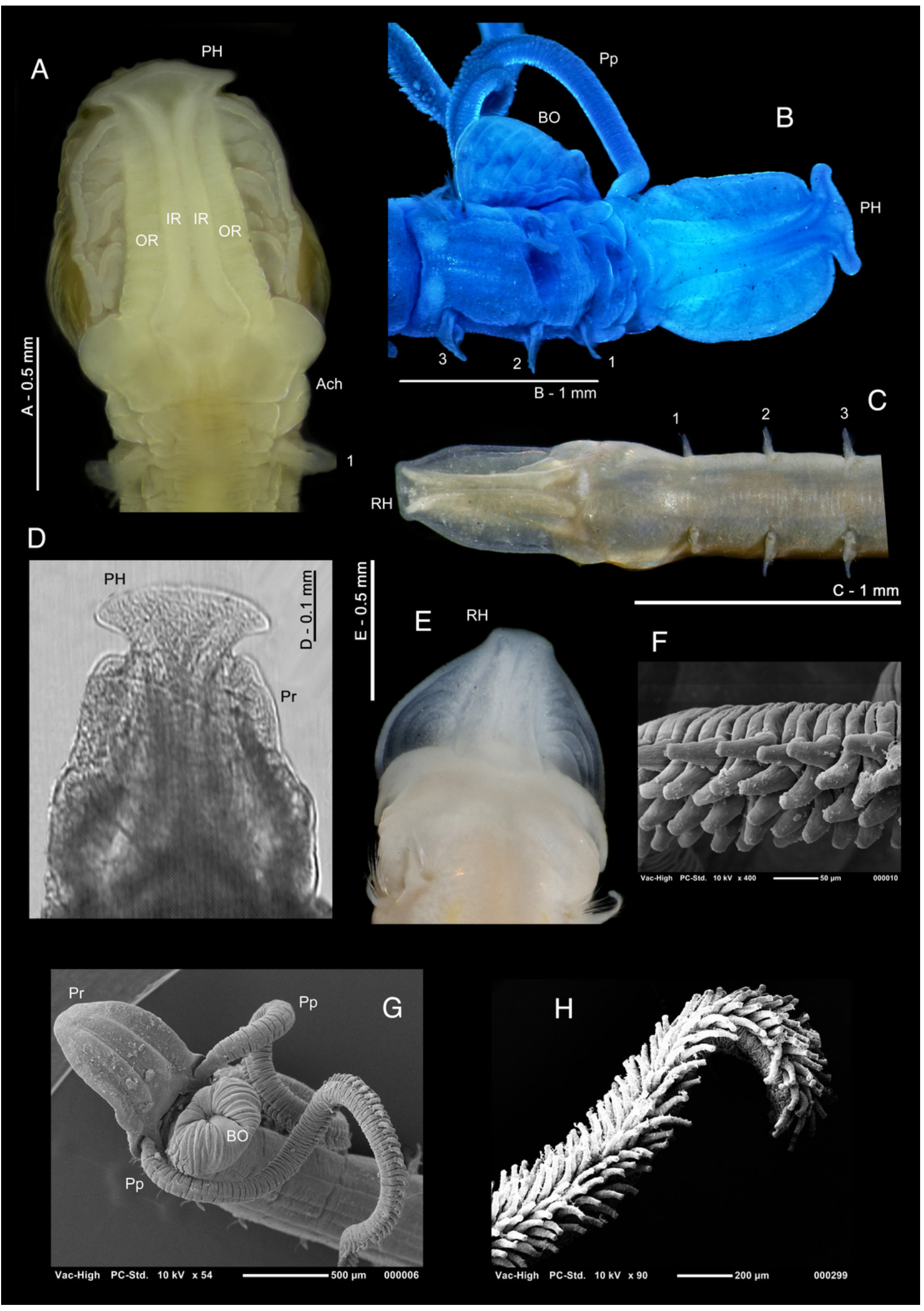

Peerj reviewing PDF | (2021:05:61394:1:1:NEW 20 Jul 2021) 
Figure 6

Octomagelona.

Octomagelona: (A, C-F) anterior of an undescribed species from West Africa (dorsal, ventral, antero-dorsal, postero-dorsal and lateral views respectively); (B) Octomagelona bizkaiensis from Capbreton Canyon (holotype, MNCN 16.01/6887, dorsal view). Ab = abdomen, $\mathrm{Ach}=$ achaetous first segment, $\mathrm{Pr}=$ prostomium, $\mathrm{Th}=$ thorax. 


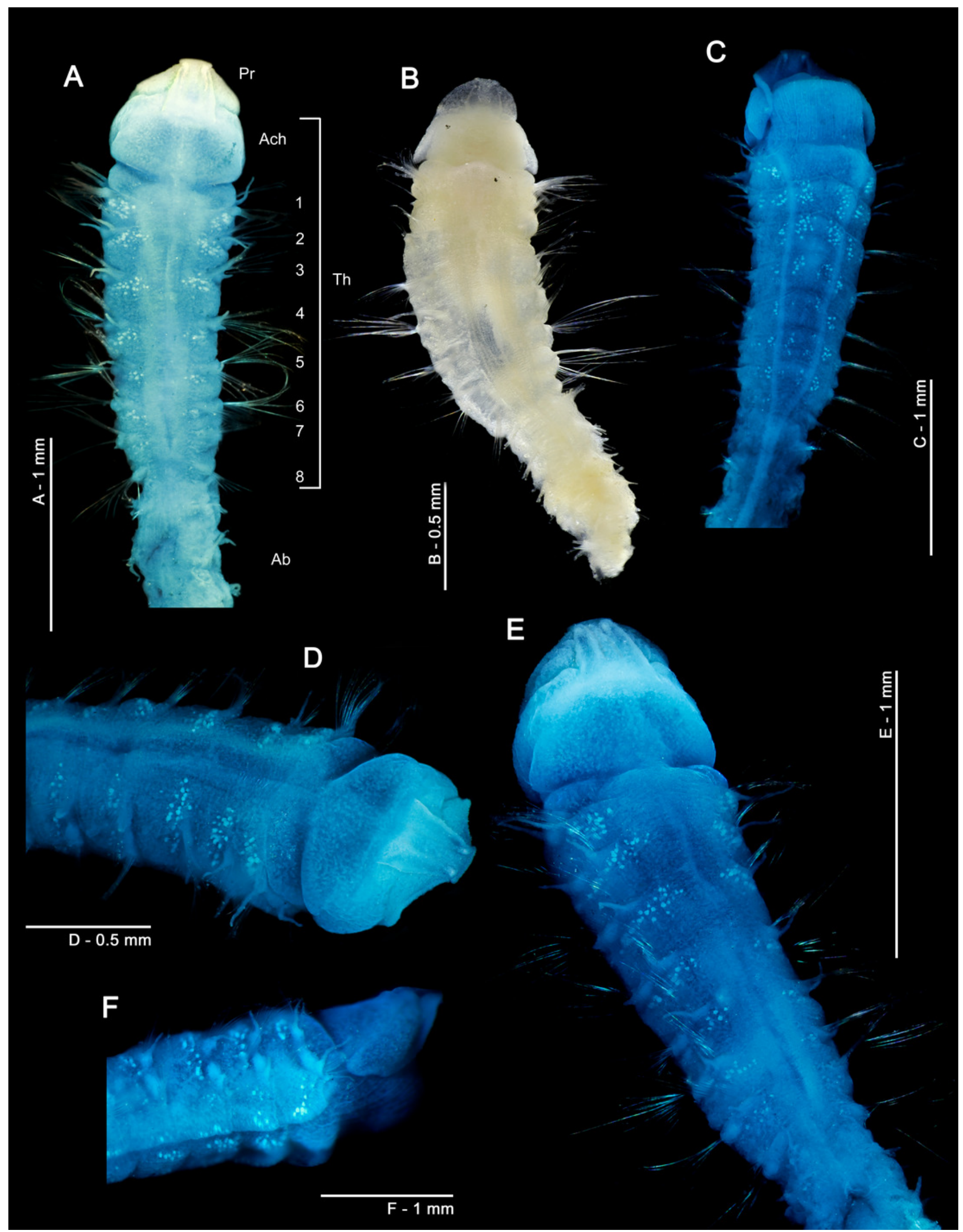




\section{Figure 7}

Development of magelonid thoracic parapodia.

(A) left-hand parapodia of chaetigers 1, 5, 8 and 9 of Magelona minuta from Öresund, Sweden (USNM 52510, anterior views); (B) parapodia of chaetigers 1, 6, 8 and 9 of $M$. equilamellae from France (syntype, SMF 4675, anterior views); (C) parapodia of chaetigers 2 , 3, 4 and 9 of M. obockensis from Obock, Red Sea (syntype, MNHN Type 1357, anterior views); (D) left-hand parapodia of chaetigers 1, 5, 8 and 9 of M. conversa from Iran, NMW.Z.2010.037.0007, anterior views). 

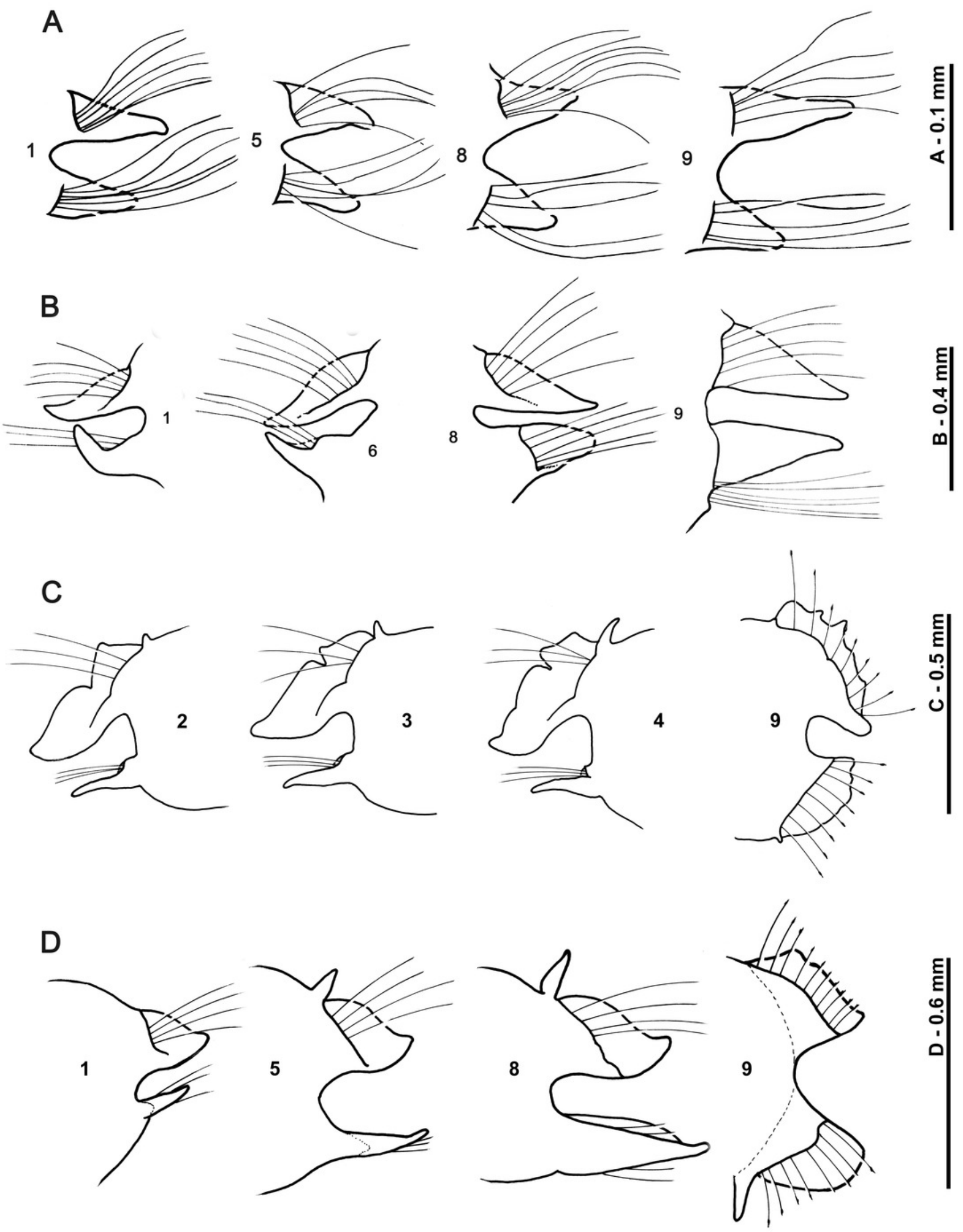


\section{Figure 8}

Magelonid thoracic parapodia.

(A) thoracic postchaetal notopodial lamellae of Magelona mirabilis from Berwick-upon-Tweed (anterior view, SEM by K. Mills); (B) chaetigers 7-10 of M. alleni from Morocco

(NMW.Z.2021.001.0001, lateral view, stained with methyl green); (C) thoracic prechaetal neuropodial lamellae of M. mirabilis from Berwick-upon-Tweed (posterior view, SEM by K. Mills); (D) subchaetal notopodial lamellae of M. riojai from Corora Grande, Rio de Janeiro, Brazil; (E) left-hand parapodia of chaetiger 8 of $M$. conversa from Iran, (NMW.Z.2010.037.0007, anterior view); (F) right-hand parapodia of chaetigers 2-4 of $M$. equilamellae from Ebro Delta, Catalonia (NMW.Z.2019.100.0012-14, lateral view, SEM by K. Mills); (G) left-hand parapodia of chaetigers 7-9 of same specimen (SEM by K. Mills). Noto = notopodial, Neuro $=$ neuropodia, Pre $=$ prechaetal, Post $=$ postchaetal, $S D L=$ superior dorsal lobe. Numbers indicate chaetiger number. 

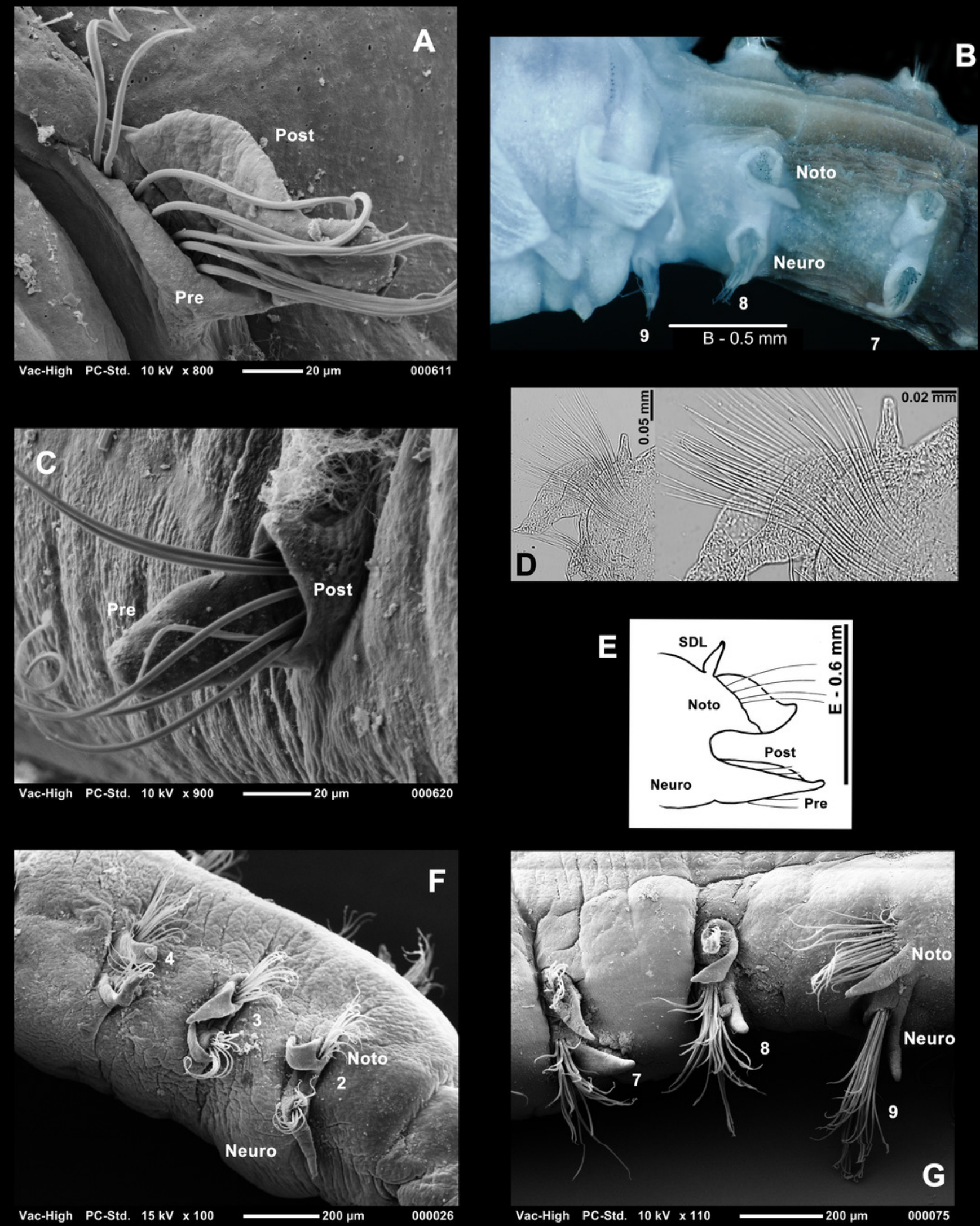


\section{Figure 9}

Magelonid thoracic parapodia.

(A) right-hand parapodia of chaetiger 4 of Magelona fauchaldi from Iran (paratype, NMW.Z.2015.012.0002b, antero-lateral view); (B) right-hand notopodia of M. equilamellae from Ebro Delta, Catalonia (NMW.Z.2019.100.0012-14,anterior view, SEM by K. Mills); (C) foliaceous thoracic lamellae of M. sp. 2 from the Brazilian coast (from Brasil, 2003,anterior view); (D-E) parapodia of chaetigers 8 and 4 of $M$. montera respectively from Gulf of Aqaba (holotype, MNHN TYPE 1548, anterior views); (F) right-hand parapodia of chaetiger 2 of $M$. obockensis from Obock, Red Sea (syntype, MNHN Type 1357, anterior view); (G) right-hand parapodia of chaetiger 8 of $M$. symmetrica from the Seychelles(holotype, NMW.Z.2000.020.0175, anterior view); (H) distally expanded and scoop-shaped neuropodial lamellae of chaetigers 1-3 of Magelona sp. cf. M. cincta from Iran, NMW.Z.2015.012.0004, posterolateral view, stained with methyl green); (I) notopodia of chaetigers 9 and 10 of $M$. johnstoni from Berwick-upon-Tweed (anterior view). Noto $=$ notopodia, Neuro $=$ neuropodia, Pre $=$ prechaetal, Post $=$ postchaetal, $\mathrm{SDL}=$ superior dorsal lobe . 

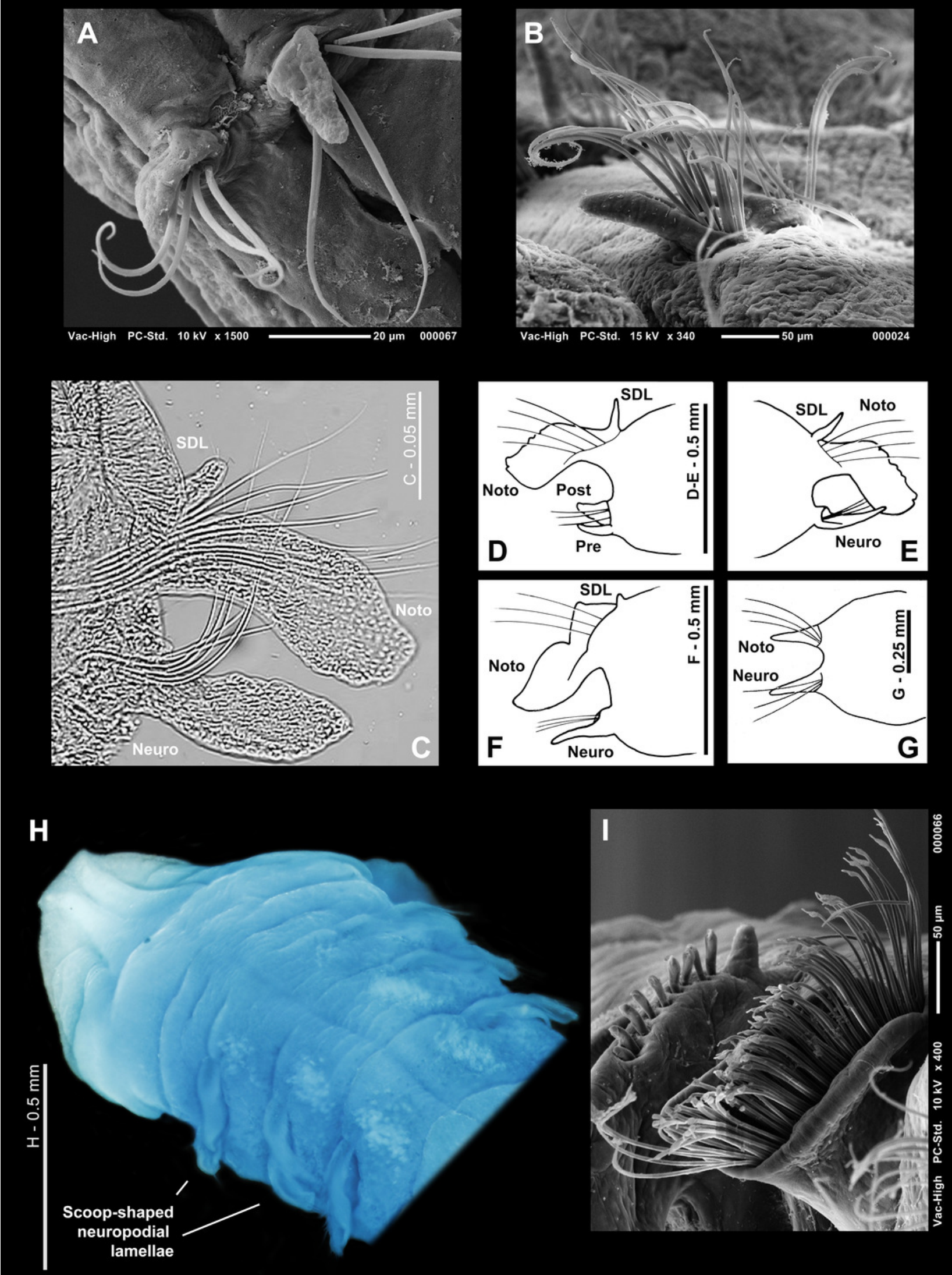

Peer) reviewing PDF | (2021:05:61394:1:1:NEW 20 Jul 2021) 


\section{Figure 10}

Magelonid thoracic chaetae.

(A) first five chaetigers, showing thoracic capillary chaetae in noto- and neuropodia, of Magelona equilamellae from Ebro Delta, Catalonia; dorsal view. SEM by K. Mills; (B) righthand notopodia of chaetiger 5 (anterior view) of M. equilamellae from Ebro Delta, Catalonia, SEM by K. Mills; (C) unilimbate capillary chaetae of M. minuta from Öresund, Sweden (USNM 52510); (D) bilimbate capillary chaetae with irregular blades from chaetiger 4 of M. riojai from Coroa Grande, Rio de Janeiro, Brazil; (E) bilimbate capillary chaeta with irregular blade from chaetiger 2 of M. variolamellata from Paranaguá Bay, Brazil; (F-G) mucronate chaetae from chaetiger 9 of M. riojai from Coroa Grande, Rio de Janeiro, Brazil; $(\mathrm{H})$ the same from M. johnstoni from Berwick-upon-Tweed (NMW.Z.2013.037.0011b); (I) pennoned chaetae from chaetiger 9 of M. pitelkai, M. hobsonae, M. hartmanae (respectively), modified from Jones (1978). 

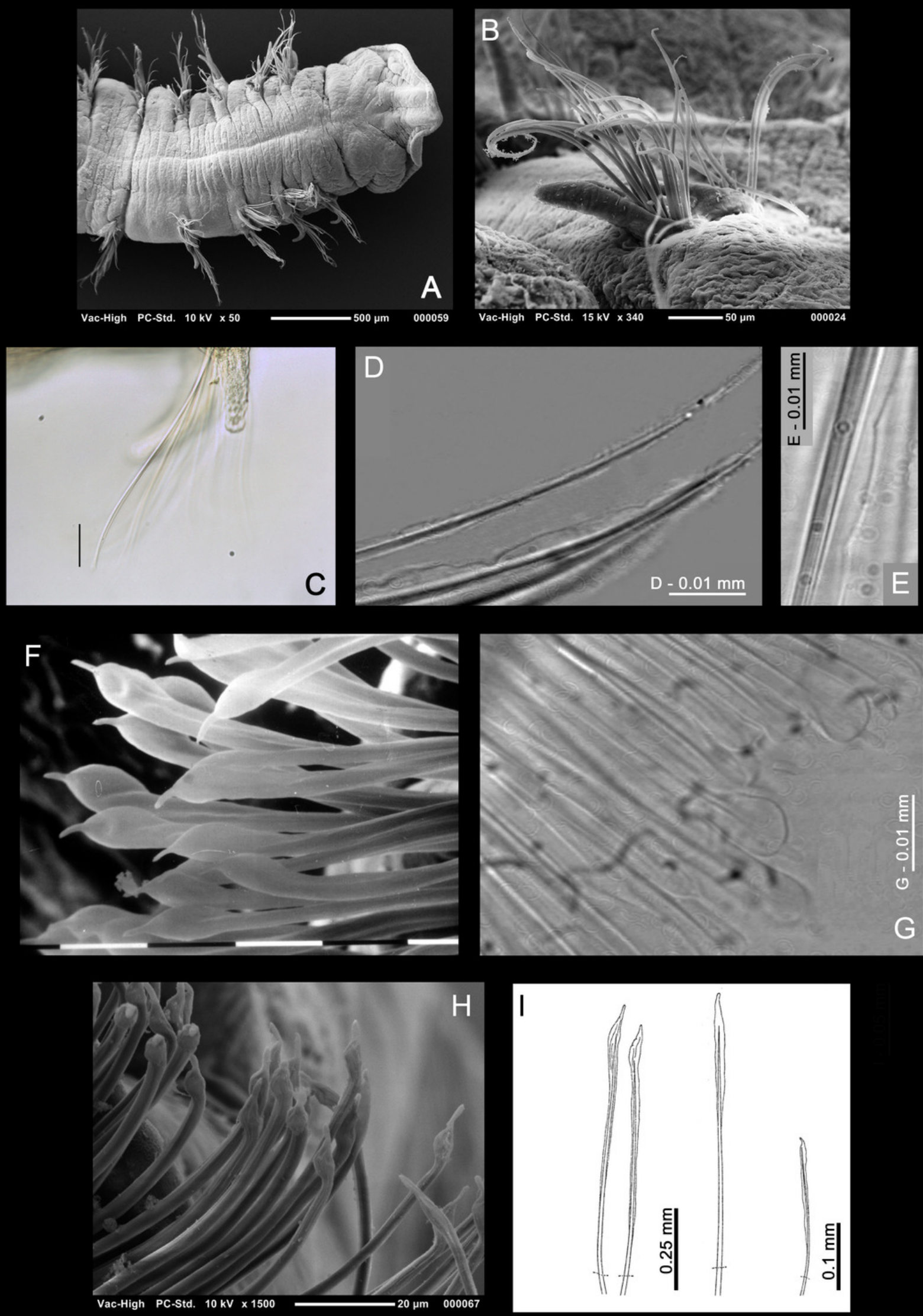


\section{Figure 11}

Magelonid thoracic region.

(A) characteristically bulbous and rounded thoracic chaetigers of Magelona alleni from Rame Head, England (holotype, BMNH 1958.5.2.1, dorsal view); (B) anterior end of M. johnstoni from Berwick-upon-Tweed (NMW.Z. 2013.037.0001, dorsal view, photo by A.S.Y. Mackie) showing straight thoracic interparapodial margins; (C) anterior end of M. variolamellata from Paranaguá Bay, Brazil (dorsal view) showing oblique lateral slits; (D) anterior end of $M$. crenulifronsfrom Hong Kong (ventral view, from Mortimer \& Mackie, 2009) showing V-shaped ventral marking in the mid-thoracic region and methyl green staining pattern; (E) anterior end of M. pulchella from Kuwait (holotype, BMNH 1969.391, ventral view) showing X-shaped ventral marking in the mid-thoracic region, stained with methyl green; $(F)$ thoracic ventral pads/swellings of $M$. mirabilis from Berwick-upon-Tweed in the mid to posterior thorax (NMW.Z.2013.037.0020, ventral view, photo by A.S.Y. Mackie); (G) posterior thorax of M. obockensis from Obock, Red Sea (syntype, MNHN Type 1357, ventral view) showing ventral swellings/pads. $A c h=$ achaetous first segment, $B O=$ burrowing organ, $D S=$ dorsal slits, $\mathrm{Pp}$ $=$ palp, $\mathrm{Pr}=$ prostomium, $\mathrm{Th}=$ thorax, $\mathrm{V}=$ ventral $\mathrm{V}$-shaped marking, $\mathrm{VS}=$ ventral swellings, $X=$ ventral $X$-shaped marking. 


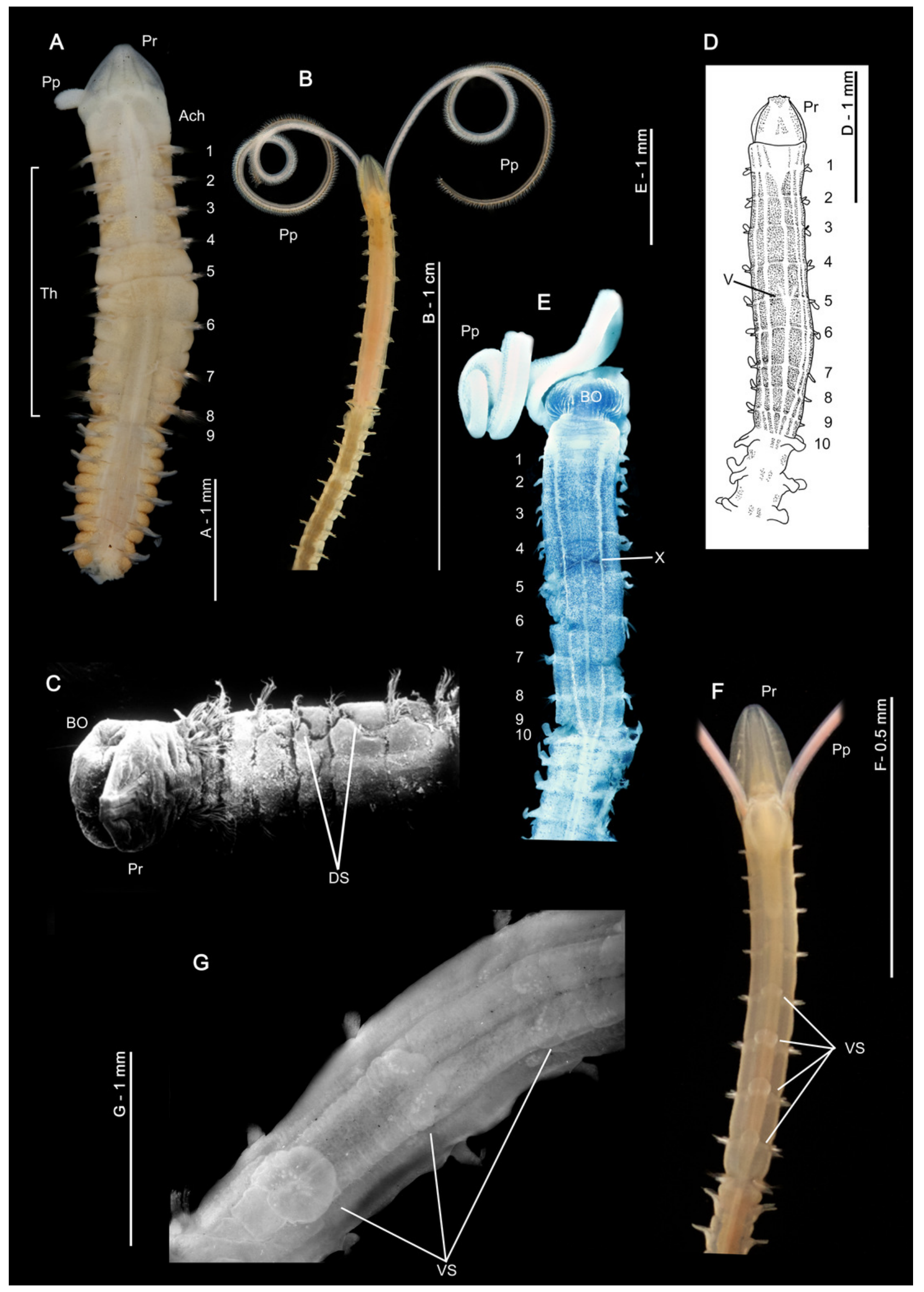

PeerJ reviewing PDF | (2021:05:61394:1:1:NEW 20 Jul 2021) 


\section{Figure 12}

Magelonid abdominal chaetigers.

(A) wider than long abdominal chaetigers of Magelona posterelongata from Paranaguá Bay, Brazil (lateral view, scale $1 \mathrm{~mm}$ ); (B) right-hand parapodia of chaetigers 10 and 11 of $M$. johnstoni from Berwick-upon-Tweed (NMW.Z.2013.037.0011b, anterior view), showing anteriorly open pouch; (C) left-hand parapodia of chaetiger 10 of M. crenulifrons from Iran (NMW.Z.2010.037.0034b, anterior view); (D) right-hand parapodia of chaetigers 9-11 of $M$. equilamellae from Ebro Delta, Catalonia, lateral view, SEM by K. Mills; (E) abdominal parapodium of M. sp. 2 from the Brazilian coast (from Brasil, 2003) anterior view; (F) righthand parapodia of abdominal chaetiger of M. sp. D from the Gulf of Mexico of Uebelacker \& Jones (1984) (modified from that publication); (G) left-hand parapodia of chaetiger 11 of $M$. alleni from Morocco (NMW.Z.2021.001.0001) showing sub-equal lateral lamellae; $(\mathrm{H})$ righthand parapodia of an abdominal chaetiger of M. sp. 2 from the Brazilian coast (from Brasil, 2003, anterior view); (I) thoracic-abdominal junction of M. filiformis from Salcombe, England (paratype, BMNH 1959.4.2.6-10, ventro-lateral view). $A C=$ acicular chaetae, $A H=$ abdominal hooks, $\mathrm{DF}=$ dorsal flap, $\mathrm{DML}=$ dorsal medial lobe, $\mathrm{LO}=$ lateral organ, Neuro $=$ neuropodia, Noto $=$ notopodia, $\mathrm{PE}=$ postchaetal extension of the lamellae, $\mathrm{PM}$, pouch membrane, $\mathrm{SAH}=$ small abdominal hook, $\mathrm{US}=$ unidentate spine, $\mathrm{VF}=$ ventral flap, $\mathrm{VML}=$ ventral medial lobe. Numbers indicate chaetiger number. 


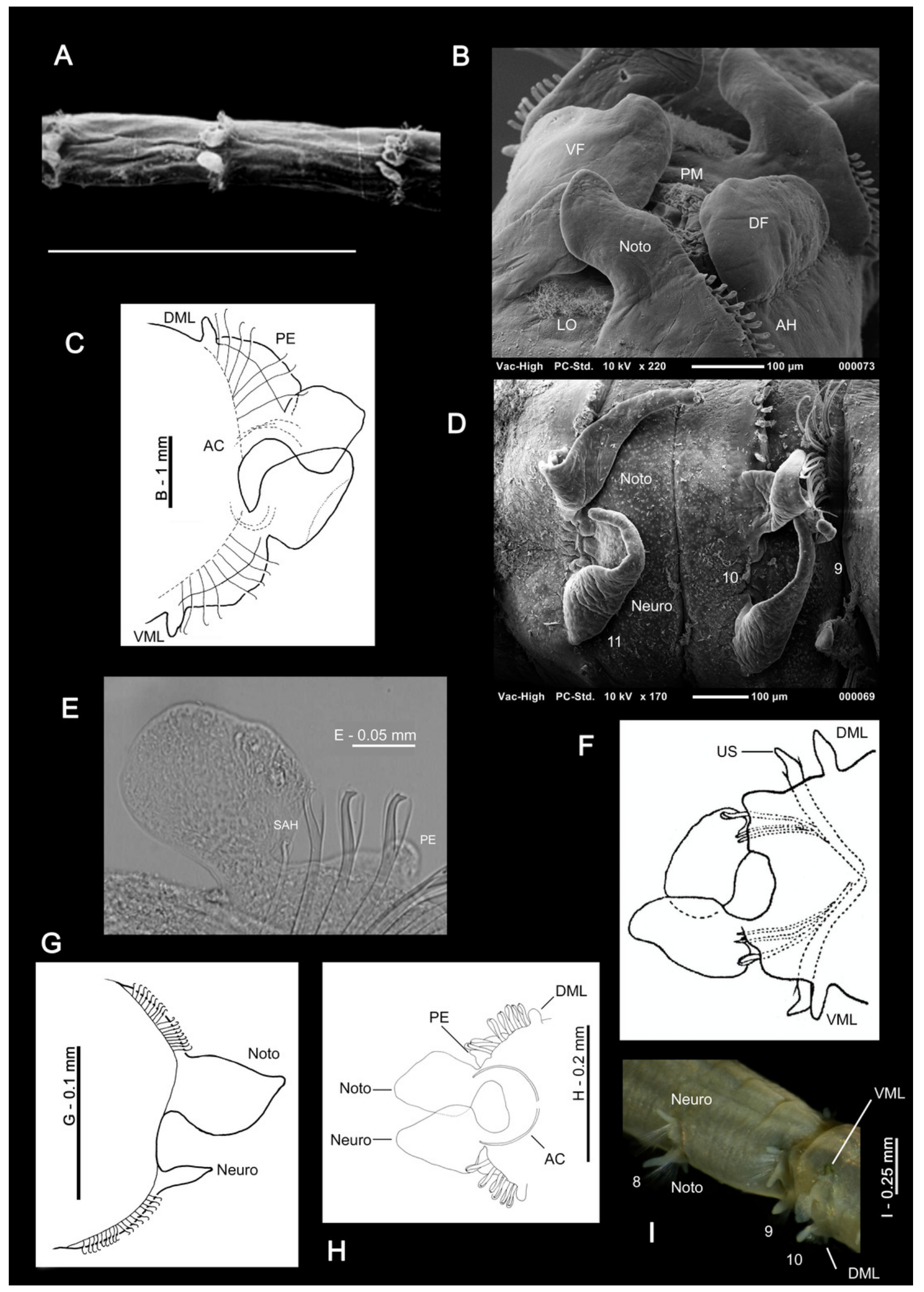

PeerJ reviewing PDF | (2021:05:61394:1:1:NEW 20 Jul 2021) 


\section{Figure 13}

Magelonid lateral abdominal pouches.

(A) schematic diagram showing a 'magelonid' with paired anteriorly open pouches in the anterior abdomen, followed by unpaired posteriorly open pouches in the mid and posterior abdomen, on alternate chaetigers; (B) schematic diagram of a magelonid with unpaired posteriorly open pouches, on alternate chaetigers; (C) schematic diagram of a magelonid with paired posteriorly open pouches, on consecutive chaetigers; (D) transverse section through the body and an anteriorly opening pouch situated between chaetigers 10 and 11 of Magelona johnstoni from Berwick-upon-Tweed (posterior half of pouch and parapodia of chaetiger 11 visible) (NMW.Z.2013.037.0010c, anterior view); (E) left-hand anteriorly opening pouch between chaetigers 10 and 11 of $M$. johnstoni from Berwick-upon-Tweed (NMW.Z.2013.037.0011b, lateral view); (F) the same from another specimen collected from the same locality, ventrolateral view (NMW.Z.2013.037.0008c); (G) posteriorly open pouch of the same specimen (ventrolateral view); $(\mathrm{H})$ posteriorly open pouches on consecutive segments of M. pacifica from Panamá (syntype, BMNH Type 1933.7.10.65/70, lateral view), pouches showing distinct medial splits. $D F=$ dorsal flap, $D M L=$ dorsal medial lobe, $L O=$ lateral organ, Neuro $=$ neuropodia, Noto $=$ notopodia, $\mathrm{PM}=$ pouch membrane, $\mathrm{PO}$ pouch $=$ posteriorly opening pouch, $\mathrm{VF}=$ ventral flap. Numbers indicate chaetiger number. 


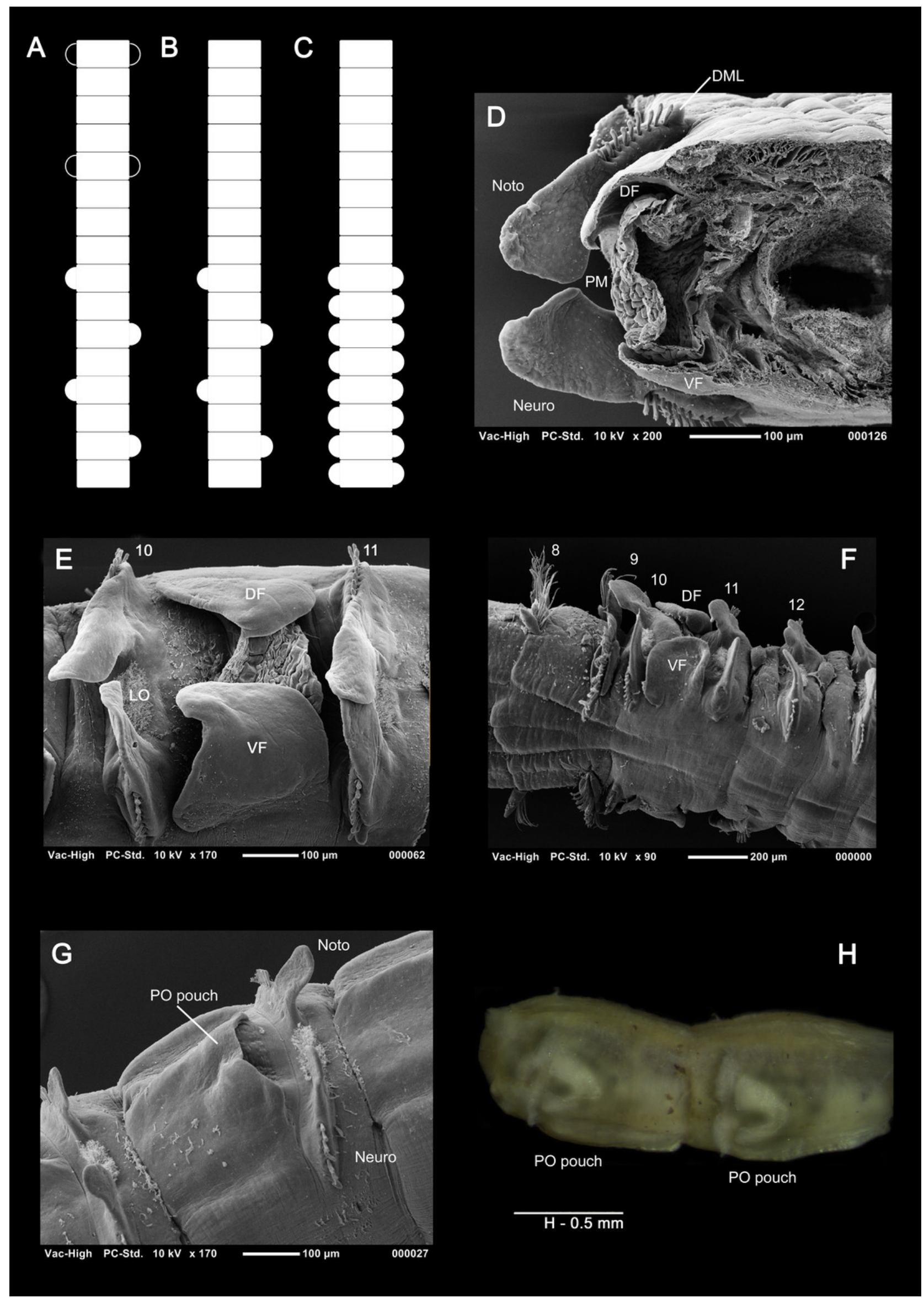

Peer) reviewing PDF | (2021:05:61394:1:1:NEW 20 Jul 2021) 


\section{Figure 14}

Magelonid abdominal hooded hooks.

(A) transverse section of the body of Magelona johnstoni from Berwick-upon-Tweed, between chaetigers 10 and 11 (posterior half of pouch and parapodia of chaetiger 11 visible) (NMW.Z.2013.037.0010c, anterior view); (B) row of hooded hooks arranged vis-à-vis of $M$. equilamellae from Ebro Delta, Catalonia; (C) bidentate hooded hooks from chaetiger 29 of $M$. minuta from the Irish Sea (NMW.Z.1991.075.1584a, lateral view); (D) bidentate hooded hook from M. papillicornis from Brazilian coast (lateral view, scale $=0.01 \mathrm{~mm}$ ); $(E)$ tridentate hooded hook from M. alleni; $(\mathrm{F}-\mathrm{H})$ quadridentate, pentadentate and hexodont hooded hooks from M. fauchaldi from Iran (paratypes, NMW.Z.2015.012.0002d-e); (I) small hooded hook adjacent to the lateral lamellae of M. sp. 3 from the Brazilian coast (from Brasil, 2003, anterior view); (J) bidentate hooded hooks of M. papillicornis from Brazilian coast, arranged vis-à-vis; (K) unidentate enlarged hook of M. sp. 3 from the Brazilian coast (from Brasil, 2003). C, E-H, hoods broken. Photos B, C, E by K. Mills. Neuro = neuropodia, Noto = notopodia, $\mathrm{SAH}=$ small abdominal hook. 


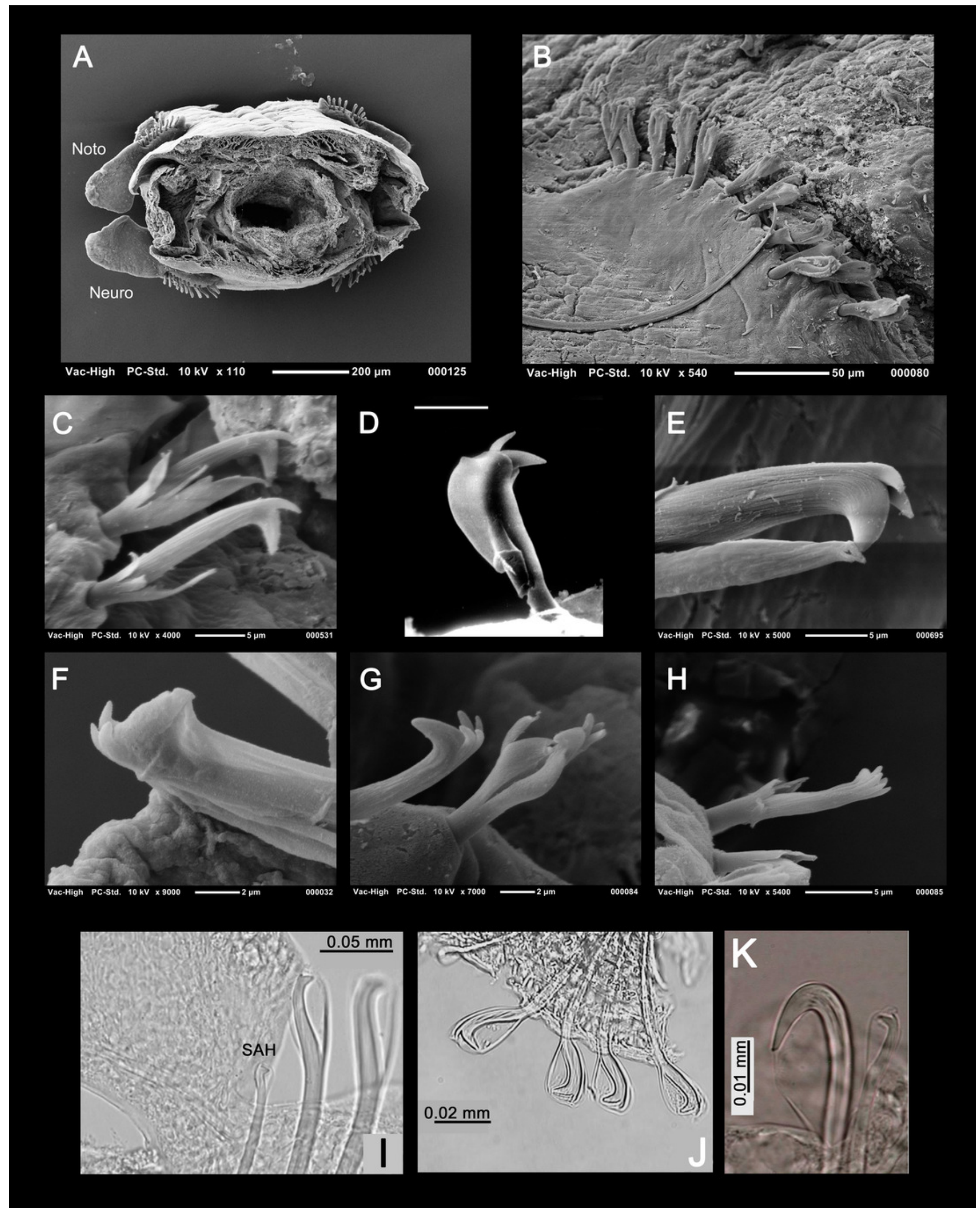




\section{Figure 15}

Magelonid pigmentation.

(A) anterior end of a live Magelona alleni (dorsal view) from Plymouth, showing thoracic pigment band on posterior thorax (photo by A.S.Y. Mackie); (B) anterior end (dorsal view) of M. fasciata from Senegal, West Africa (NMW.Z.2021.001.0009), showing distinct stripy pigmentation characteristic of the species; (C) pigment band of posterior thorax of $M$. equilamellae from Ebro Delta, Catalonia (MNCN 16.01/18576, photo by K. Mills). $\mathrm{Pp}=$ palp, $\mathrm{Pr}$ $=$ prostomium. 


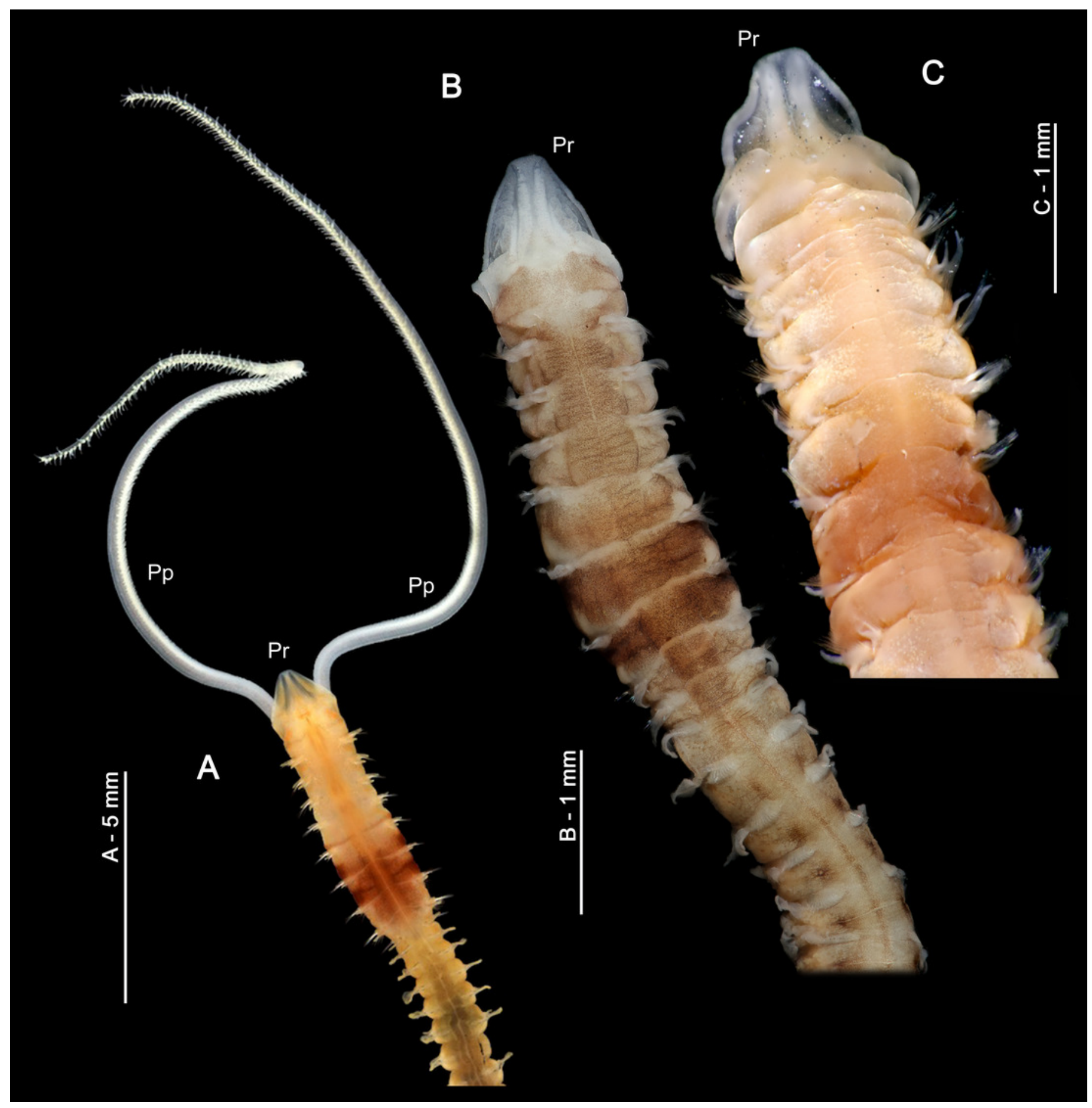




\section{Figure 16}

Magelonid pigmentation, granular bodies, tube, pygidial cirri.

(A) anterior region of Magelona minuta from the Celtic Sea (NMW.Z.2005.014.0111, dorsal view; photo by K. Mills) showing distinct transverse thoracic stripes; (B) anterior region of Magelona sp. cf. M. cincta from Iran (NMW.Z.2015.012.0004, dorsal view) showing distinct circular regions of granular bodies adjacent to the parapodia; (C) same specimen showing abdominal interparapodial patches and granular bodies along the mid-ventral line of the abdomen (ventral view); (D) granular bodies of the dorsal surface of the thoracic region of $M$. papillicornis from Brazilian coast; $(\mathrm{E})$ distinct multi-layered tube covered in sand of $M$. alleni from the Irish Sea (NMW.Z.1969.104.1094; photo by K. Mills); (F) digitiform pygidial cirri either side of the pygidium (dorsal view) from Brasil (2003); (G) posterior region of $M$. minuta from the Outer Bristol Channel (NMW.Z.2003.047.5939, ventral view; photo by K. Mills); (H) posterior region of M. alleni from Plymouth, England (paratype, BMNH 1958.5.2.1, ventrolateral view). A-C, G, H, stained with methyl green; $E$, stained with Rose Bengal. $A=$ anus, $\mathrm{Ab}=$ abdomen, $\mathrm{BO}=$ burrowing organ, $\mathrm{GB}=$ granular bodies, $\mathrm{PC}=$ pygidial cirri, $\mathrm{Pp}=$ palp, $\mathrm{Pr}=$ prostomium, $\mathrm{Th}=$ thorax. 


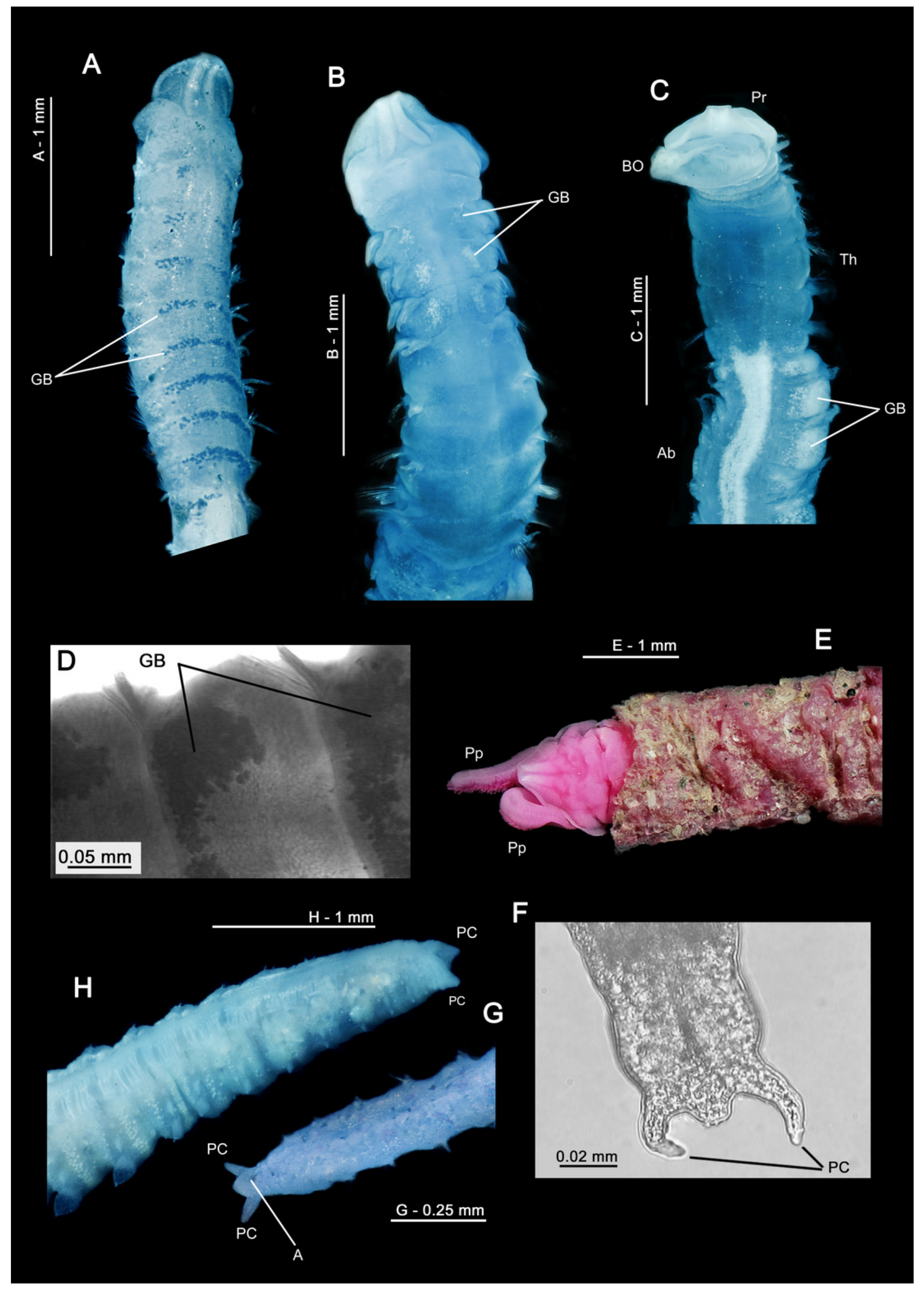

PeerJ reviewing PDF | (2021:05:61394:1:1:NEW 20 Jul 2021) 


\section{Figure 17}

Phylogenetic results. Strict consensus tree for 2,417,600 cladograms produced from data matrix in Table S1.

Note that Magelona is paraphyletic relative to Octomagelona. Letters a-u indicate clades for which some character transformation series are presented in the Results. 


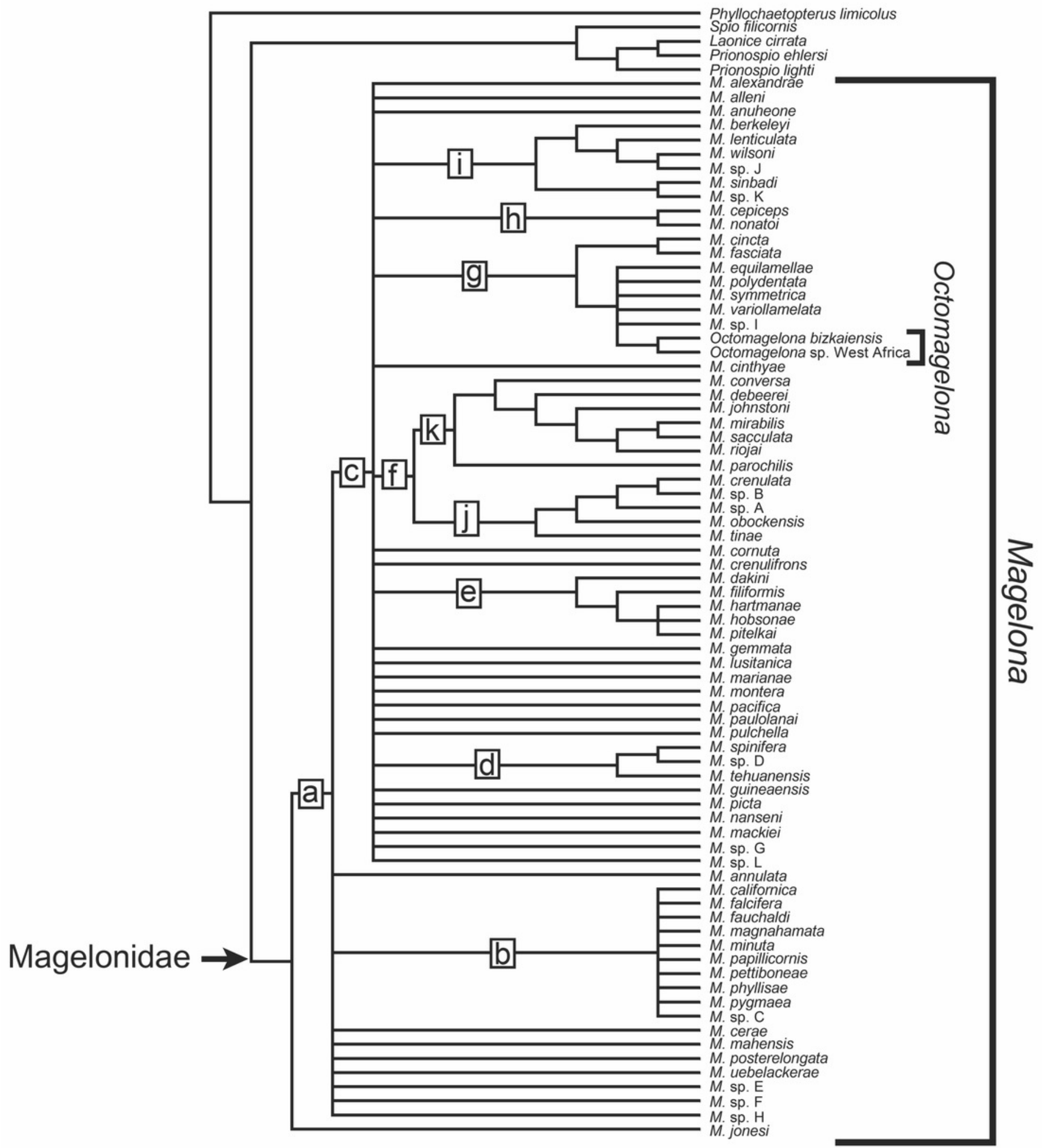




\section{Figure 18}

Phylogenetic results.

Fig 46 of the strict consensus tree for nine cladograms presented by Brasil (2003) of Magelonidae phylogenetic hypotheses. Clades referred to in that study are indicated by the Roman numerals. Reproduced as shown in Brasil (2003). 


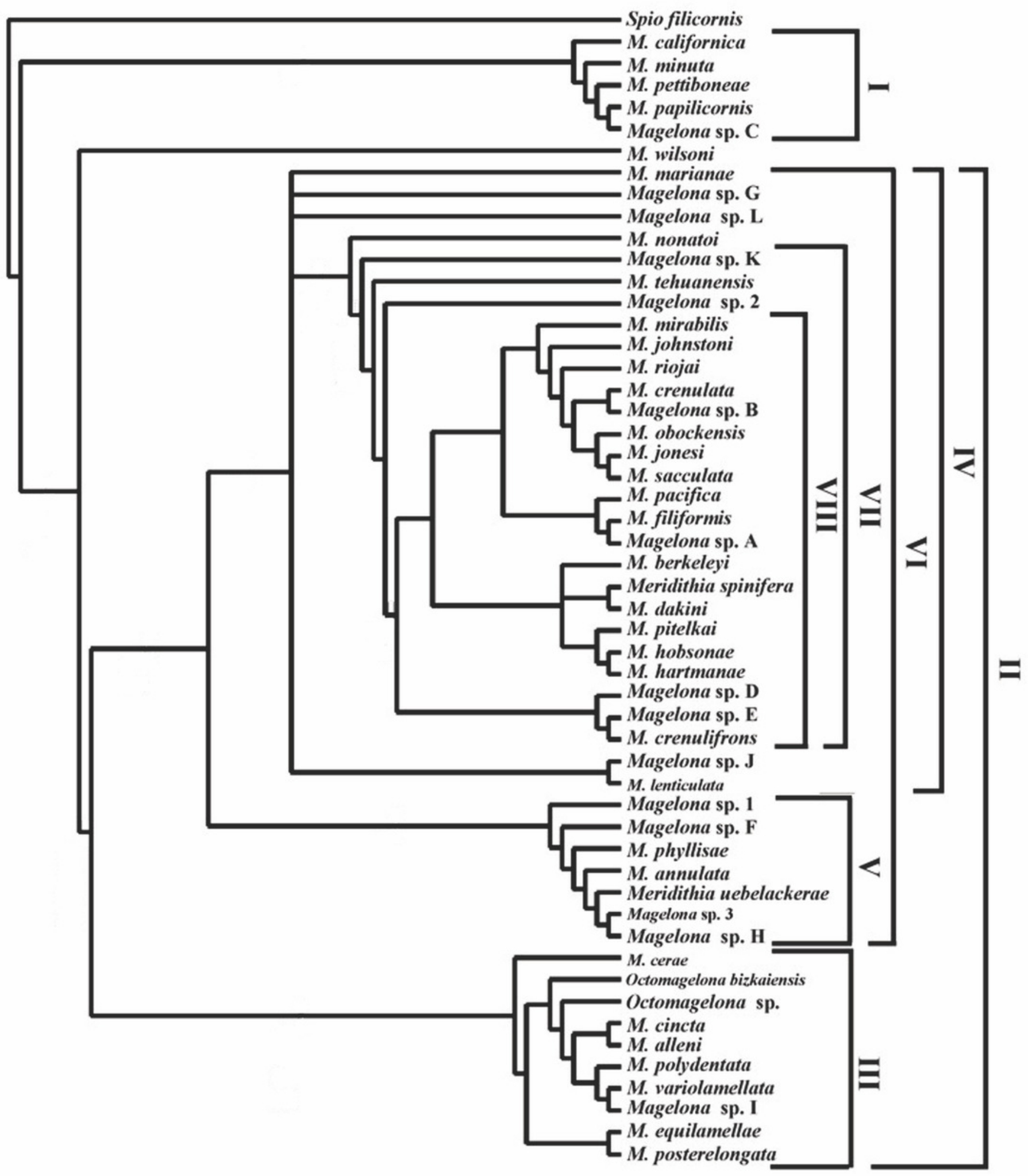

